University of California, Hastings College of the Law UC Hastings Scholarship Repository

Faculty Scholarship

2006

\title{
Rethinking Informed Consent: The Case for Shared Medical Decision-Making
}

Jaime S. King

UC Hastings College of the Law, kingja@uchastings.edu

Benjamin W. Moulton

Follow this and additional works at: http://repository.uchastings.edu/faculty_scholarship

Part of the Health Law and Policy Commons

\section{Recommended Citation}

Jaime S. King and Benjamin W. Moulton, Rethinking Informed Consent: The Case for Shared Medical Decision-Making, 32 Am. J.L. \& Med. 429 (2006).

Available at: http://repository.uchastings.edu/faculty_scholarship/324

This Article is brought to you for free and open access by UC Hastings Scholarship Repository. It has been accepted for inclusion in Faculty Scholarship by an authorized administrator of UC Hastings Scholarship Repository. For more information, please contact marcusc@uchastings.edu. 


\section{Faculty Publications \\ UC Hastings College of the Law Library}

Author: Jaime S. King

Source: $\quad$ American Journal of Law \& Medicine

Citation: $\quad 32$ Am. J.L. \& Med. 429 (2006).

Title: $\quad$ Rethinking Informed Consent: The Case for Shared Medical Decision-Making

Originally published in AMERICAN JOURNAL OF LAW \& MEDICINE. This article is reprinted with permission from AMERICAN JOURNAL OF LAW \& MEDICINE and Boston University School of Law. 


\section{Rethinking Informed Consent: The Case for Shared Medical Decision- Making $^{\dagger}$}

Jaime Staples King ${ }^{\dagger+}$ and Benjamin W. Moulton ${ }^{\dagger+\dagger}$

\section{INTRODUCTION}

In law, with rare exception such as legislative action, change is evolutionary and methodical. Unlike biomedical science where a breakthrough can quickly lead to dramatic changes in medical practice, legal precedent is more adherent and must evolve either through the legislative process or on a court by court basis in case law. Nevertheless, compelling evidence will pave the road to change within the law. Health care research conducted over the last three decades has produced a body of empirical evidence that suggests an overhaul of our current legal standards of informed consent is overdue.

This article uses health services research to examine the fundamental assumptions of our current informed consent laws and propose legal reform. Much has been written on how to bring the law to bear on medical practice in order to improve patient rights and protect physicians, but far less has been done to bring the practice of medicine to inform our legal standards. Prior legal scholarship on informed consent has made arguments regarding reform from both ethical and legal perspectives; however, only a small few have

$+\quad$ The authors would like to thank Dan Vorhaus for his excellent research and analysis in preparing Appendix A. They would also like to thank Richard Frank, Norman Daniels, Elizabeth Bartholet, and Tom McGuire for their comments and advice on previous drafts of this paper.

${ }_{t+}$ Fellow, Center for Law and Biosciences, Stanford Law School; Ph.D. Candidate in Health Policy, Harvard University; J.D., Emory University School of Law; B.A., Dartmouth College.

t+† Executive Director, American Society of Law, Medicine and Ethics; J.D., Georgetown Law Center; M.P.H., Harvard University; B.A., Harvard University. The American Journal of Law \& Medicine is co-published with the American Society of Law, Medicine and Ethics. Mr. Moulton is the Executive Director of the American Society of Law, Medicine and Ethics. Additionally, Mr. Moulton served as an advisor to the Foundation for Informed Medical Decision Making, a non-profit foundation that creates decision aids for patient education. Mr. Moulton and Mrs. Staples King, however, submitted this article for review in blind format. The editorial staff completed its review and accepted this article without knowing who the authors were. 
incorporated clinical and health services research as well as ethical and legal principles to analyze informed consent. ${ }^{1}$

Currently, the states are almost evenly split between two types of standards for informed consent - the physician-based standard, effective in 25 states, and the patient-based standard, effective in 23 states and the District of Columbia. ${ }^{2}$ Physician-based standards generally require physicians to inform a patient of the risks, benefits and alternatives to a treatment in the same manner that a "reasonably prudent practitioner" in the field would. ${ }^{3}$ On the other hand, patient-based standards hold physicians responsible for providing patients with all information on the risks, benefits and alternatives to a treatment that a "reasonable patient" would attach significance to in making a treatment decision. ${ }^{4}$ As can be seen in the cases listed in Appendix $A$, while each state may have its own variation on the language of its informed consent standard, they are quite representative of classification, and so, we will discuss the physician and patient-based standards each as a unified standard for the remainder of the paper.

Recent findings of health-services research challenge the validity of important assumptions that underlie our two informed consent standards. For instance, research performed by John Wennberg and colleagues demonstrates that around one-third of all medical decisions should depend largely on the values and preferences of the patient, rather than the norms of physician practice, as is the law under the physician-based standard. ${ }^{5}$ Patient preferences for information disclosure, risk taking, quality of life outcomes and tolerance of side effects differ greatly amongst the patient population, ${ }^{6}$ yet variations in treatment decisions often do not reflect differences in patient choice. $^{7}$ In cases where patient lifestyle, personal preferences and values are indicative of the most appropriate treatment choice, physicians are not in the best position to make treatment decisions and should not limit disclosure of alternatives. In addition, research by Deb Feldman-Stewart and colleagues

1 See, e.g., Jessica W. Berg et al., Informed Consent: Legal Theory and Clinical Practice vii-viii (2d ed. 2001); Jay Katz, The Silent World of Doctor and Patient (Johns Hopkins University Press 2002); Ken Marcus Gatter, Protecting PatientDoctor Discourse: Informed Consent and Deliberative Autonomy, 78 OR. L. REv. 941, 950 (1999); John E. Wennberg \& Philip G. Peters, Unwanted Variations in the Quality of Health Care: Can the Law Help Medicine Provide a Remedy/Remedies?, 37 Wake Forest L. REv. 925, 925-941 (2002).

2 While each state may have its own basic interpretation of each standard, they can easily be divided into the two groups based on their language and intent, with the exception of New Mexico and Minnesota, which have hybrid standards. For more information on the individual state standards please see Appendix A.

3 Tashman v. Gibbs, 556 S.E.2d 772, 777 (Va. 2002).

$4 \quad$ Canterbury v. Spence, 464 F.2d 772, 784 (D.C. Cir. 1972).

5 Center for the Evaluative Clinical Sciences, Dartmouth Medical School, Dartmouth Atlas Project Topic Brief: Preference-Sensitive Care 6 (2005), http://www.dartmouthatlas.org/topics/preference_sensitive.pdf.

6 Sidney T. Bogardus et al., Perils, Pitfalls and Possibilities in Talking about Medical Risk, 281 JAMA 1037, 1039 (1999).

7 Center for the Evaluative Clinical Sciences, Dartmouth Medical School, The Dartmouth Atlas of Health Care 199821 (1998), available at http://www.dartmouthatlas.org/atlases/98Atlas.pdf; see also John E. Wennberg, Variation in Use of Medical Services Among Regions and Selected Academic Medical Centers: Is More Better?, Commonwealth Fund ReP., Dec. 2005, at 26, available at http://www.cmwf.org/usr_doc/874_wennberg_variation_medicaresvcs.pdf. 
demonstrates that patients vary widely in their disclosure preferences and needs, ${ }^{8}$ indicating that contrary to the principles of individual autonomy and self-determination, our objective legal standards of informed consent that depend on the informational needs of a "reasonable patient" may deny many patients the amount of information they require to give an informed consent to treatment.

In the last decade, a small but distinguished group of medical and even some legal scholars have sought to address this dilemma by calling for a revision of our current methods of informed consent in favor of shared medical decision-making. ${ }^{9}$ Shared medical decision-making is a process in which the physician shares with the patient all relevant risk and benefit information on all treatment alternatives and the patient shares with the physician all relevant personal information that might make one treatment or side effect more or less tolerable than others. ${ }^{10}$ Then, both parties use this information to come to a mutual medical decision." ${ }^{11}$ Advocates of shared medical decision-making praise its improvements in patient autonomy and comprehension, its ability to reduce unwanted medical procedures and services, and its potential for increased communication and trust between physicians and patients. ${ }^{12}$ Given the current move in U.S. health policy toward increased consumer responsibility in funding medical treatments, considering whether patients receive sufficient information and decision support to enable them to meaningfully participate in their health care is more imperative than ever.

Interestingly, however, a growing number of scholars and practitioners have begun to question the practicality of shared medical decision-making in the literature, ${ }^{13}$ while the silent majority of physicians have also expressed their reluctance to change through inaction. ${ }^{14}$ Commonly heard criticisms include complaints that shared decision-making will take too much time in today's rushed medical practice, that implementation will place unbearable financial strain on the already overburdened medical system, that physicians do not have the support and resources to provide all the evidence, and that patients do not understand or want the information. ${ }^{15}$

8 Deb Feldman-Stewart et al., Practical Issues in Assisting Shared Decision-Making, 3 Health Expectations 46, 49 (2000).

$9 \quad$ See, e.g., Wennberg \& Peters, supra note 1, at 937; see also Katz, supra note 1.

1o Robert M. Kaplan, Shared Medical Decision Making: A New Tool for Preventative Medicine, 26 Am. J. Prev. Med. 81, 81 (2003).

11 Id.

12 See, e.g., Katz, supra note 1, at 121-128, 227-228.

13 See, e.g., Bogardus et al., supra note 6, at 1037-41; Geraldine M. Leydon et al., Cancer Patients' Information Needs and Information Seeking Behavior: In Depth Interview Study, 320 BRIT. MED. J. 909, 909-913 (2000); Steven H. Woolf \& Alex Krist, The Liability of Giving Patients a Choice: Shared Decision Making and Prostate Cancer, 71 Aм. FaMILY PhyS 1871, 871-72 (2005).

${ }_{14}$ See, e.g., Andrew S. Dunn et al., Physician-Patient Discussions of Controversial Cancer Screening Tests, 20 AM. J. Preventive MED. 130, 133 (2001) (finding that "a substantial number of physicians decide whether to screen patients for prostate and breast cancer without sufficiently involving patients in the decision"); Woolf \& Krist, supra note 13, at 1871 (claiming that little shared medical decision making occurs in practice despite consensus among medical organizations on the benefits of this approach).

${ }_{15}$ Steven H. Woolf, The Logic and Limits of Shared Decision Making, 166 J. URoLogY 244, 244 (2001); Woolf \& Krist, supra note 13, at 1871-72. 
This article examines the dilemma faced by physicians, judges and policymakers in establishing an appropriate standard of medical decisionmaking that enables patients to make an informed treatment decision, and argues that the states should clarify their current informed consent requirements to include shared medical decision-making as a prerequisite to a valid informed consent. Since the scope of this article is intended for a wide variety of audiences, we have included detailed backgrounds of both the current informed consent system and some of the relevant health services research. Part II provides a brief example that epitomizes the challenges associated with modern informed consent practices. Parts III and IV review the ethical and legal foundations of informed consent respectively. Part IV also gives an overview of the two current legal frameworks of informed consent. Part $\mathrm{V}$ examines the clinical evidence for treatment patterns and patient information needs that raise questions about key assumptions of the current legal standards. Part VI demonstrates how this evidence threatens the validity of our current legal standards. Part VII presents clinical evidence of the failure of the current medical system to provide sufficient information to individuals making medical decisions. Part VIII introduces shared medical decision-making as a potential solution and describes its benefits and challenges. Part IX compares the effectiveness and implications of the three different standards of informed consent, physician-based, patient-based and shared medical decision-making, across two hypothetical cases. Part X analyzes the policy implications and modifications in medical practice required to implement shared decision-making. Finally, Part XI summarizes the arguments and concludes that states should adopt the shared medical decision-making model as a prerequisite to legal informed consent.

\section{THE MERENSTEIN CASE}

In an editorial in the Journal of the American Medical Association, Dr. Daniel Merenstein relayed the facts of an unpublished trial that revealed just what was at stake in determining how much information to disclose to patients. ${ }^{16}$ Early on in his residency program in Virginia, Dr. Merenstein gave a physical exam to a highly educated patient in his mid-fifties. ${ }^{17}$ Dr. Merenstein testified at trial that during the exam, he discussed with the patient "the importance of colon cancer screening, seat belts, dental care, exercise, improved diet, and sunscreen use."18 In accordance with the practice guidelines established by the United States Preventative Services Task Force, the American College of Physicians - American Society of Internal Medicine, the American Medical Association, the American Urological Association, the American Cancer Association, and the American Association of Family Physicians he also engaged in a shared medical decision-making process of discussing all of the relevant risks and benefits regarding screening for prostate cancer via the prostate specific antigen (PSA) test with the patient. ${ }^{19}$

\footnotetext{
16 Daniel Merenstein, Winners and Losers, 291 JAMA 15, 15-16 (2004).

$17 \quad I d$. at 15.

is Id.

19 Id.; U.S. Preventive Services Task Force, Screening for Prostate Cancer:
} Recommendation and Rationale, 137 Annals. Internal. Med. 915, 915 (2002). 
The medical associations recommend shared medical decision-making for patients determining whether to have a PSA test for a number of reasons. While the PSA test can detect early-stage prostate cancer, only mixed and inconclusive evidence exists to suggest the ability of PSA screening to improve health outcomes. ${ }^{20}$ In addition, screening is associated with a number of health harms, despite the benign nature of the blood test itself. ${ }^{21}$ PSAs frequently provide false-positive results or detect prostate cancer that would never harm the patient. ${ }^{22}$ By identifying non-threatening or non-existent cancer, the PSA test often leads patients to have unnecessary surgical or radiation treatments with significant side effects, such as impotence and incontinence. For instance, while radical prostatectomy has been demonstrated to reduce mortality for men with localized prostate cancer detected from patient-reported symptoms, ${ }^{23}$ this result has not yet been found for cancer identified via PSA screening. Still, many patients with PSAdetected cancer undergo a prostatectomy. ${ }^{24}$ As a result, patients often endure substantial anxiety, unpleasant treatments and side effects to rid themselves of cancer that would never have affected their health. ${ }^{25}$ In short, the harms of PSA testing can be established, but the benefits currently cannot. Given the risks associated with having the test and the indeterminate benefit, a number of national medical associations concluded that each asymptomatic patient should determine whether he preferred to have the test upon reaching a certain age or to wait until symptoms suggested the test was appropriate. ${ }^{26}$

Dr. Merenstein testified that after learning of the high false positive rates associated with the prostate specific antigen (PSA) test, the substantial risk of side effects that may reduce his quality of life, and the low likelihood of death from prostate cancer, his patient declined the test. ${ }^{27}$ Following the visit, Dr. Merenstein never saw the man as a patient again. ${ }^{28}$

Sometime after Merenstein completed his residency program, the patient saw a physician at a different clinic. ${ }^{29}$ Without discussing the decision to screen for prostate cancer with the patient, the new physician performed a PSA test. ${ }^{30}$ Unfortunately for the patient, his PSA level was very high, which led to a subsequent diagnosis of incurable, advanced-stage prostate cancer. ${ }^{31}$

The malpractice trial began on June $23,2003{ }^{32}$ Dr. Merenstein was "nervous but confident," as he had documented discussing the risks and benefits of the PSA with the patient and noted the patient's decision to decline

\footnotetext{
$20 \quad$ U.S. Preventive Services Task Force, supra note 19, at 915.

Id.

Id.

23 Lars Holmberg et al., A Randomized Trial Comparing Radical Prostatectomy with

Watchful Waiting in Early Prostate Cancer, 347 NEw ENG. J. MED. 781, 787 (2002).

${ }_{24}$ U.S. Preventive Services Task Force. supra note 19, at 915.

25 Id.

$26 \quad$ Id. at 916.

27 Merenstein, supra note 16 , at 15.

$28 \quad I d$.

$29 \quad I d$.

so Id.

${ }^{31} \quad$ Id.

$32 \quad$ Id.
} 
after considering all of the facts. ${ }^{33}$ However, once the trial started, Dr. Merenstein's confidence began to wane.

To his surprise, Dr. Merenstein listened to the plaintiff's attorney argue that despite the fact that practice guidelines established by the American Academy of Family Physicians, the American Urological Association, and the American Cancer Society all recommended that physicians discuss the risks and benefits of PSA screening with patients, this behavior constituted malpractice in Virginia. ${ }^{34}$ In all states, to win a medical malpractice case, the plaintiff must prove that the physician violated the standard of care, which in turn resulted in the patient's injury. ${ }^{35}$ Due to the minimal risks associated with performing a PSA (a simple blood test), the plaintiff's attorney argued that the standard of care in Virginia was to order the test without discussing it with the patient. ${ }^{36}$ With four physician witnesses from the state of Virginia to support his claim, the plaintiff's attorney won his case against Merenstein's residency program, and seemingly against the use of evidence-based medicine and shared medical decision-making. ${ }^{37}$

Because the decision was an unreported jury verdict, it is impossible to know which facts the jury's decision hinged on. A finding, however, that a Virginia physician should provide a controversial test without discussing the possible risks, benefits and alternatives with his or her patient at a minimum demonstrates a great deal of tension between what is happening in some state courts and the current recommendations of medical associations and medical schools. While the case represents a worst-case scenario for both the patient and Dr. Merenstein, it raises a broad range of challenges facing physicians, patients and policymakers regarding the disclosure of medical information. How should physicians inform patients of tests or treatments with questionable efficacy? What level of disclosure coincides with their legal requirements? Should patients place blind faith in their physician's decisions or take a more active role in and responsibility for their medical care? Are patients up to the challenge of making their own medical decisions? Who should bear the responsibility when the risks accepted in a difficult decision come to fruition? Finally, how can policymakers best provide physicians and patients with clear guidelines that allow them to comprehend their rights and responsibilities? Each of these dilemmas has its roots in the ethical and legal underpinnings of informed consent.

\section{ETHICAL FOUNDATIONS OF INFORMED CONSENT}

The legal basis for informed consent arises largely from fundamental principles of medical ethics and human rights. These principles should inform and guide the goals we establish for a system of informed consent. In Beauchamp and Childress' foundational text The Principles of Bioethics, they

$33 \quad I d$.

$34 \quad I d$.

35 See generally Restatement (Second) OF ToRts $\$ 281$ (1965) (discussing elements for a cause of action for negligence); Frank J. Vandal \& Ellen Wertheimer, Torts: Cases AND Problems 179-89 (Michie 1997) (discussing the concept of the standard of care owed to others related to negligence claims).

36 Merenstein, supra note 16, at 15.

$37 \quad$ Id. at $15-16$. 
identify four main principles that should guide the practice of medicine: autonomy, beneficence, nonmalfeasance, and justice.$^{38}$ Often these ethical principles conflict with one another in the everyday practice of medicine. ${ }^{39}$ The most challenging dilemma in establishing an effective informed consent practice is balancing a physician's obligation to protect the patient's health through beneficence and the physician's obligation to respect the patient's autonomy. ${ }^{40}$

Patient autonomy is the most well known principle of medical ethics. Proponents of autonomy claim its heritage from religion, natural law and moral philosophy. ${ }^{41}$ The Puritans derived a notion of autonomy from personal religious responsibility and individual conscience, which were balanced against the individual's obligation to serve the community. ${ }^{42}$ Autonomy's roots are also found in natural law, which protects the individual's right to self-govern and the freedom to pursue one's own dictates. ${ }^{43}$ Others hold the individual autonomy discussed in bioethics to be derived from Immanuel Kant's belief that autonomy was fundamental to moral action. ${ }^{44}$ Regardless of its original roots, within the realm of bioethics, patient autonomy can be translated as the ethical principle that preserves an individual's ability to make and carry out informed decisions that arise from unbiased and thoughtful deliberation. ${ }^{45}$ Self-determination is the subset of autonomy most commonly associated with informed consent and health care, such that decisions originate freely from an autonomous agent, who understands the facts and can engage in practical reasoning to come to a decision. ${ }^{46}$ Physicians have an obligation to respect the right of patients to have sufficient knowledge regarding their medical condition and treatment choices to make an autonomous medical decision. ${ }^{47}$

Physicians also bear an obligation to act with beneficence toward their patients. $^{48}$ The principle of beneficence confers a moral obligation on physicians to act for the benefit of their patients. ${ }^{49}$ In the practice of medicine, the principle of maximizing utility, an extension of the principle of beneficence is most commonly applied. ${ }^{50}$ Rarely are physicians able to produce benefits without creating additional risks or incurring some costs. As

38 Tom L. Beauchamp \& James F. Childress, Principles of Biomedical Ethics 12 (5th ed. 2001).

39 See id. at 12, 114-115, 176, 248.

40 Id. at 176; Onora O'Neill, Autonomy and Trust in Bioethics 39 (Cambridge University Press 2002); Alfred I. Tauber, Sick Autonomy, 46 Persp. Biology \& MEd. 484, 488 (2003). See also Mark Parascandola et al., Patient Autonomy and the Challenge of Clinical Uncertainty, 12 KENNEDY INST. ETHICS J. 245, 245-247 (2002) (discussing the challenges facing physicians in the face of clinical uncertainty about a patient's health).

41 Tauber, supra note 40 , at 485 .

$42 \quad I d$.

43 Id.; see O'NeILl, supra note 40, at 29-31 (discussing naturalistic philosophy of individuality arising from "civil or social liberty").

44. Id. at 23.

45 Rebecca Kukla, Conscientious Autonomy: Displacing Decisions in Health Care, 35 Hastings Ctr. ReP. 34, 35 (2005).

$46 \quad I d$.

47 Id.

48 BEAUChaMP \& Childress, supra note 38 , at 166 .

$49 \quad I d$.

so Id. 
a result, to act with beneficence, they must act only when the benefits warrant the risks and costs associated with the procedure. ${ }^{51}$ However, beneficence must be constrained by autonomy to prevent the rights of individuals from being subjugated to the medical needs of themselves or others. ${ }^{52}$

A patient's ability to exercise self-determination often conflicts with a physician's ethical duty of beneficence. Physicians want to provide the care they believe is best for the patient, but also must acknowledge the patient's preferences. $^{53}$ This dilemma raises the extremely important question of whether the physician's primary obligation is to act for the patient's medical benefit or to promote his or her autonomous medical decision-making.

Answering this question is essential to defining the scope of the legal requirements for informed consent. Over the last few decades, it has been widely acknowledged in the literature that autonomy has been given substantial priority over the other ethical principles, including beneficence. ${ }^{54}$ The ascendance of autonomy has occurred for a number of practical and political reasons: 1) protecting autonomy is more easily aligned with existing legal principles and precedents; 2) promoting patient autonomy may relieve the physician of some responsibility and liability; 3) emphasizing patient autonomy coincides with and supports the recent shift toward consumerism in medicine; and 4) promoting autonomy appears less paternalistic than beneficence, but still permits physicians to control the flow of information. ${ }^{55}$

However, in practice, patient autonomy alone as a guiding principle proves insufficient. Patients do not want to simply be given facts by their physicians and left to make their own medical decisions. In the same way that beneficence must be constrained by autonomy, so must autonomy be constrained by beneficence. Many seek medical care to relinquish some of their autonomy and responsibility to the experts. ${ }^{56}$ Enabling a patient to exercise her autonomy does not hinder the physician's ability to provide a medical opinion. In the shared decision-making process, the patient may make an autonomous choice to participate in a full or limited way or not at all in making the final decision after receiving the relevant information. Just because patients may wish to defer to their physicians' best judgment after a discussion, however, does not mean that their autonomy was compromised, the discussion was worthless or it did not add value to the patient's overall health care. ${ }^{57}$ Instead, physician participation and beneficence enhances a patient's ability to make an autonomous choice.

Ethically, we need a standard that balances beneficence and respect for patient autonomy; that tips in favor of autonomy in equally balanced situations. Our legal standard of informed consent should strive to protect patients' ability to obtain information and either make decisions or defer decision-making to their physician. It should permit physicians to present

\footnotetext{
$51 \quad I d$.

$52 \quad$ Id. at 176.

53 Parascandola et al., supra note 40 , at 248 .

$54 \quad I d$; BeAuchamP \& Childress, supra note 38 , at 12 ; Kukla, supra note 45 , at 35 ;

O'NeILL, supra note 40 , at 34; Tauber, supra note 40 , at 485 .

${ }_{55}$ See Tauber, supra note 40 , at $485-86$.

$56 \quad I d$. at 486.

57 Alan Meisel \& Mark Kuczewski, Legal and Ethical Myths About Informed Consent, 156 ARChives INTERNAL MED. 2521, 2525.
} 
and support their medical opinions, as well as provide them with a clear understanding of what other information should be disclosed. Under such a standard, the physician should: 1) provide the patient with unbiased information on the risks and benefits of all treatment options; 2) give the patient their professional advice; 3 ) assist the patient in identifying their own values; and 4) decide with the patient which treatment choice is best. Under this standard, both patient autonomy and physician beneficence are valued and expressed in a manner that allows the patient and the physician to come to a mutual treatment decision that balances the importance of all competing factors. The next section traces the history and evolution of informed consent law.

\section{THE LEGAL FOUNDATIONS OF INFORMED CONSENT}

As the nature of the physician-patient relationship has become more complex and the clinical information available increases, the legal system must continue to adapt the informed consent doctrine to meet the needs of both physicians and patients. To determine how best to shape our informed consent laws for the future, it is important to examine how the law has evolved over time. The legal notion of consent to medical treatment was originally derived from the ethical principle of personal autonomy and its subsets: self-determination and bodily integrity. ${ }^{58}$ These principles have been established in law by state informed consent legislation and medical malpractice case law.

The legal evolution of informed consent has in many ways mirrored changes in the practice of medicine. Three times in the last century the law has adapted to meet the needs of an evolving medical system. First, courts created a cause of action under battery for patients who had been wrongfully injured by their physicians. ${ }^{59}$ Next, case law shifted from battery claims for unwanted touching to negligence claims for failure to fulfill a duty to provide the patient with sufficient information to make a personal medical decision. ${ }^{60}$ Since 1972, some state courts have elected to expand the patients' role in medical decision-making by altering the negligence standard from one based on what information a reasonably prudent physician would give (physicianbased standard) to one concerned with what information a reasonable patient would want (objective patient-based standard) ${ }^{61}$ In addition, a tiny fraction of states have gone further to base their standard on the level of information desired by the individual patient, regardless of whether others found the information pertinent to the decision (subjective patient-based standard) ${ }^{6}{ }^{6}$ Knowledge of the evolution of these three standards is essential to understanding our current informed consent laws and how to best implement change.

Gatter, supra note 1, at 946-48.

See, e.g., Mohr v. Williams, 104 N.W. 12, 14-15 (Minn. 1905).

See, e.g., Canterbury, 464 F.2d at 787; Tashman, 556 S.E.2d at 777.

Lars Noah, Informed Consent and the Elusive Dichotomy Between Standard and Experimental Therapy, 28 AM. J.L. \& MED. 361, 367 (2002).

$62 \quad I d$. at 368. 


\section{A. Battery in INFORMED CONSENT}

The legal obligation to obtain patient consent was first established in early surgical malpractice cases, in which the court ruled that the physician violated the "bodily integrity of his patient," by committing an unwanted touching. ${ }^{63}$ Battery is an intentional tort, for which an individual is liable if he intentionally causes offensive or harmful contact with another. ${ }^{64}$ For instance, in 1905, the court, in Mohr $v$. Williams, ${ }^{65}$ recognized a cause of action under battery for an individual who consented to an operation on his right ear, but the physician during surgery operated on his left ear as well. ${ }^{66}$ In making its decision, the court emphasized a patient's "right to himself" as a "free citizen's first and greatest right" and that this "right to himself" prohibited the physician from violating "the bodily integrity of his patient" without his or her knowledge and consent. ${ }^{67}$ In addition, the court highlighted the importance of the patient's decision-making process by limiting the scope of consent to only those procedures for which the physician provided information sufficient to permit the patient to accurately balance the risks and benefits in making a decision. $^{68}$ Despite this language emphasizing the patient's role, the focus in these early cases was not on self determination, but the right to bodily integrity.

In Schloendorff $v$. Society of New York Hospital, ${ }^{69}$ Judge Cardozo refined the right to patient consent by holding that the cause of action under battery relied on the violation of bodily integrity, rather than any specific harm arising from the unwanted touching. ${ }^{70}$ Under this interpretation, a surgeon could be liable for damages the moment he performed any procedure outside the scope of the consent, regardless of whether the patient received any physical injury. ${ }^{n}$

Battery, however, proved insufficient to fully capture the importance of a patient's knowledge of the risks, benefits, and alternatives of a procedure, as well as ability to use his or her own value system to decide whether to pursue a certain procedure or treatment. Medical treatment also encompassed more outpatient treatment and non-surgical procedures for which the un-consented touching requirement of battery seemed inappropriate. Over the next few decades, the courts turned their focus in patient consent cases away from battery and bodily integrity toward the value of patient autonomy.

\section{B. The Negligence Standard in Informed Consent}

The shift from battery to a negligence standard reflected judges' sentiments that a judgment of battery was inappropriate for the nature of the

$63 \quad$ Mohr, 104 N.W. at 14.

64 Restatement (SEcond) of Torts $\$ 18$ (2006). Claims for battery may also be brought in criminal proceedings as well as civil proceedings as a tort. Battery in the medical malpractice context is generally considered a tort, rather than a criminal act.

$65 M o h r, 104$ N.W. at 14.

$66 \quad I d$. at 13 .

$67 \quad I d$. at 14.

68 Id. at 15; see also Gatter, supra note 1, at 947.

69 Schloendorff v. Soc'y of N.Y. Hosp., 105 N.E. 92 (N.Y. 1914).

$70 \quad$ Id. at 93.

nId. 
offense, as physicians did not intend to harm the patient, rather they failed to provide enough information. ${ }^{72}$ In addition, judges felt a need to respond to the growing patient demand for information. ${ }^{73}$ Physician and legal scholar Jay Katz posited a number of reasons why judges preferred a negligence standard to battery: 1) battery allows for very few defenses, unlike negligence; 2) judges preferred to base the legal standard for physician behavior on actual practice rather than legal theory; 3) a negligence standard permitted judges to defer to the wisdom of the medical profession, so that physicians would only be liable for failing to disclose information that other physicians would have provided; and 4) negligence law places a bigger burden of proof on plaintiffs so as to deter frivolous claims that battery would have allowed. ${ }^{74}$ In addition, the tort of battery has a counterpart in criminal law, which could potentially leave a physician open to criminal charges for un-consented touching. ${ }^{75}$ In short, judges did not want to interfere in the ability of physicians to use their medical wisdom and expertise to make treatment decisions or subject them to criminal liability, but they did want to protect the general autonomy of patients to know and agree to procedures performed on their own bodies.

In the 1950's, courts began to acknowledge the growing number of cases that arose, not because a physician failed to receive consent to perform a certain procedure, but because the physician failed to provide the patient with sufficient information regarding the relevant risks, benefits or alternatives of the procedure to enable her to make an informed decision. ${ }^{76}$ To provide a remedy, courts began recognizing causes of action for negligence arising out of a physician's breach of a duty to provide their patient with enough information to allow them to give an "informed consent." This duty obligated physicians to "disclose and explain to the patient in language as simple as necessary the nature of the ailment, the nature of the proposed treatment, the probability of success or of alternatives, and perhaps the risks of unfortunate results and unforeseen conditions within the body." 77 Judges of the time felt no need to clarify the scope of the informed consent or the extent of patients' rights because they believed they were codifying the current practices of the medical profession. ${ }^{78}$

Over the last fifty years, individual states have increasingly required physicians to provide patients with proper information regarding the risks, benefits, and alternatives to any treatment. The specific amount and nature of information the law requires physicians to provide patients to make such determinations, however, remain largely in question. While informed consent requirements have generally shifted from an emphasis on physician preferences toward more patient autonomy and involvement, this evolution has not occurred evenly across states. ${ }^{79}$ The initial negligence standard deferred openly to the practice patterns of other physicians. Currently,

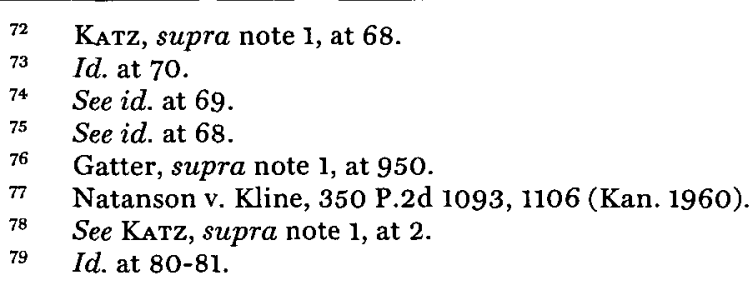


around half of the states have altered their laws to value patient autonomy over physician practice with respect to informed consent. ${ }^{80}$

\section{Physician-Based Standard}

\section{a. Foundational Cases}

In establishing the original negligence standard, now known as the "physician-based standard," judges sought to protect patient autonomy, but deferred openly to the wisdom and common practice of the members of the medical profession in a way that severely compromised their efforts. ${ }^{81}$ In 1957, the California Court of Appeals established the first negligence standard for informed consent in Salgo $v$. Leland Stanford, Jr. University ${ }^{82}$ To remedy a 55 year-old man's intermittent limping, the physicians performed an aortography procedure that was not yet the standard of care. ${ }^{83}$ Following the surgery, which had seemed free from complication, the patient awoke entirely paralyzed in both legs. ${ }^{84}$ His surgeon, Dr. Gerbode, had failed to inform the patient of any risk of paralysis. ${ }^{85}$ Judge Bray, who found the patient very sympathetic and without remedy under battery, adopted the informed consent language verbatim from the amicus brief submitted by the American College of Surgeons. ${ }^{86}$ The brief stated "a physician violates his duty to his patient and subjects himself to liability if he withholds any facts which are necessary to form the basis of an intelligent consent by the patient to the proposed treatment." ${ }^{87}$ Interestingly, this language seems to suggest that a physician's duty to inform is subjectively based upon the information important to his individual patient. Later in the opinion, however, Judge Bray diminished the impact of his prior statement by granting physicians "a certain amount of discretion" in discussing the element of risk with patients, consistent with a disclosure of the facts necessary to make an informed consent. ${ }^{88}$ In creating this exception, Justice Bray failed to clarify how and to what extent physicians could use their discretion. As a result, this exception threatens to swallow the rule.

Three years later in Natanson $v$. Kline, ${ }^{89}$ Justice Schroeder of the Kansas Supreme Court sought to promote self-determination in patients, but also to counterbalance this by granting physicians substantial leeway via the physician-based standard and the therapeutic privilege..$^{90}$ Under the physician-based standard, the court qualified the physician's disclosure duty as "limited to those disclosures which a reasonable medical practitioner would

\footnotetext{
so $\quad$ See id. at 81.

$81 \quad$ See id. at 59.

82 Salgo v. Leland Stanford Jr., Univ. Bd. of Trs., 317 P.2d 170 (Cal. Dist. Ct. App.

1957).

s3 Id. at 176 .

84 Id. at 173-74.

$85 \quad$ Id. at 173.

86 KATz, supra note 1 , at 61.

87 Id. (quoting Salgo, 317 P.2d at 176).

88 Salgo, 317 P.2d at 181.

$89 \quad$ Natanson, 350 P.2d at 1093.

90 KATZ, supra note 1 , at 70 .
} 
make under the same or similar circumstances." ${ }^{91}$ The court continued its deference by stating that "how the physician may best discharge his obligation to the patient in this difficult situation involves primarily a question of medical judgment." ${ }^{\text {29 }}$ Likewise, the therapeutic privilege permits physicians to withhold diagnosis or other information in cases where they believe disclosure might jeopardize recovery of the patient. ${ }^{93}$

The Natanson opinion established the law on medical disclosure and informed consent for the next twelve years in almost all jurisdictions that considered those issues. ${ }^{94}$ Despite its widespread adoption among the states, the opinion did little to clarify physicians' legal obligations with respect to disclosure. This kind of ambiguity has plagued the legal informed consent doctrine from the beginning, leaving physicians and patients in the dark about of the level of disclosure required.

\section{b. The Current Physician-Based Standard}

By granting physicians discretion in determining how much information to provide patients, the amount of disclosure required to meet the legal standard of care was defined in reference to the actions of other physicians. ${ }^{95}$ For a medical malpractice action, the standard of care generally requires physicians to "inform a patient of the dangers of, possible negative consequences of, and alternatives to a proposed treatment or procedure" to the same degree that a "reasonably prudent practitioner in the same field of practice or specialty in [that state]" would. ${ }^{96}$ In order to bring a claim for breach of informed consent, a patient must prove (1) that a "reasonably prudent practitioner" would have provided the additional information, (2) that the patient would not have undergone the procedure had that information been given, and (3) therefore, the physician's omissions were the proximate cause of the patient's injuries. ${ }^{97}$ Any breach of the applicable standard of care must be established by expert testimony, which would require another physician in the state to testify stating that a reasonably prudent physician would have disclosed the omitted information. ${ }^{98}$ As seen in the Merenstein case, this standard also provides that if a "reasonably prudent physician" in meeting the standard of care would not provide the patient with any information regarding the risks and benefits of the test, then a total lack of disclosure would meet the standard of care. ${ }^{99}$ This standard remains the law in 25 states. $^{100}$

\footnotetext{
$91 \quad$ Natanson, 350 P.2d at 1106.

$92 \quad$ Id. at 1106.

$93 \quad$ Id. at 1103.

$94 \quad$ KATZ, supra note 1 , at 65 .
}

95 Tashman, 556 S.E.2d at 777 (citing Dickerson v. Fatehi, 484 S.E.2d 880, 881 (1997), Rogers v. Marrow, 413 S.E.2d 344, 346 (Va, 1992), \& Raines v. Lutz, 341 S.E.2d 194, 196 (Va. 1986)).

96 Id. See Appendix A for language from the rest of the physician-based states.

$97 \quad$ See id. at $777-779$.

$98 \quad$ Id. at 777 .

99 Merenstein, supra note 1, at 15-16.

100 See infra Appendix A (listing the twenty-five physician-based states as Alabama, Arkansas, Arizona, Colorado, Delaware, Florida, Idaho, Illinois, Indiana, Kansas, Kentucky, Maine, Michigan, Missouri, Montana, Nebraska, Nevada, New Hampshire, New York, North 


\section{Patient-Based Standard}

\section{a. The Objective Patient-Based Standard - Canterbury v. Spence}

After twelve to fifteen years with only a physician-based standard, some states began to shift their informed consent standards in response to patient need. In 1972, the Appeals Court for the District of Columbia, in Canterbury $v$. Spence, ${ }^{101}$ rejected the physician-based standard in favor of a standard of care that more adequately protected patients' interests. ${ }^{102}$ As in Mohr $v$. Williams, ${ }^{103}$ the Canterbury decision focused significantly on the patient's decision-making process and the importance of having the autonomy to weigh the risks and benefits for oneself. ${ }^{104}$ The case involved a nineteen year-old boy who underwent surgery for severe back pain and experienced complications that resulted in paralysis. ${ }^{105}$ The physicians failed to warn the patient of any risk of paralysis from the procedure, and the patient sued for malpractice and failure to fully disclose the risks necessary to allow the patient to make an informed consent. ${ }^{106}$

The court began its assessment of the case from the foundation of selfdetermination. Quoting Judge Cardozo in Schloendorff, the court held that the foundation of informed consent lies in "the concept, fundamental in American jurisprudence, that 'every human being of adult years and sound mind has a right to determine what shall be done with his own body."'107 Judge Robinson argued that " $[\mathrm{t}]$ rue consent to what happens to one's self is the informed exercise of a choice, and that entails an opportunity to evaluate knowledgeably the options available and the risks attendant upon each." ${ }^{108}$ In doing so, he acknowledged the shortcomings of the physician standard that "physicians may or may not impose upon themselves." 109 By openly casting doubt upon the reality of physician consensus on acceptable disclosure practices, Judge Robinson first questioned a fundamental assumption of the physician-based standard. ${ }^{110}$ The Canterbury court replaced the physicianbased standard with one that acknowledged a larger role for patients in determining whether to proceed with medical treatment. Under the new standard, medical expertise maintained a substantial role in determining diagnosis and the available treatment options, but once those were established, physician expertise would no longer subsume objective patient preference. ${ }^{\text {II }}$ Under the new objective patient-based standard, "the test for determining whether a particular peril must be divulged is its materiality to the patient's decision: all risks potentially affecting the decision must be

Carolina, South Carolina, Tennessee, Vermont, Virginia and Wyoming). See Appendix A for a more detailed description of the laws on a state-by-state basis.

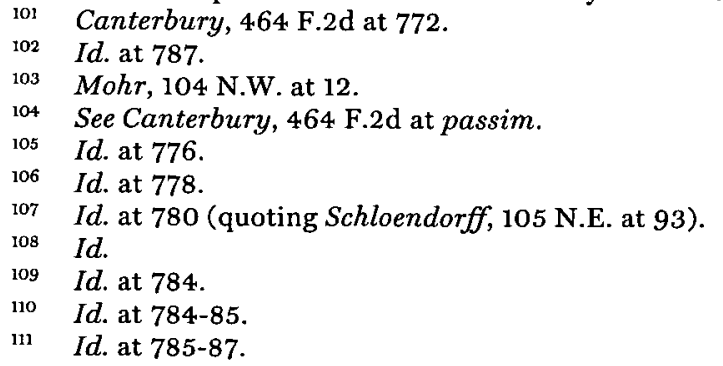


unmasked."112 Materiality was determined objectively, such that only those risks that "a reasonable person, in what the physician knows or should know to be the patient's position, would be likely to attach significance to" would constitute a "material" risk. ${ }^{113}$

While this standard makes large strides in the name of patient autonomy, it assumes that all patients value risks and benefits similarly. As a result, it is based on the needs of an objective or reasonable patient, rather than the subjective patient who will actually undergo the procedure. This objective standard protects physicians from the whims and idiosyncrasies of individual patients. While requiring some provision of information to patients, the Canterbury opinion also followed Salgo and Natanson in providing great deference to physicians' decisions when "medical judgment enters the picture" without further guidance or description as to what constituted medical judgment or what factors could be used to distinguish medical from nonmedical judgments. ${ }^{114}$ The deference to physicians when medical judgment is needed and the objective nature of the patient-based standard has significantly limited the ability of the patient-based standard to meet the informational needs of patients.

\section{b. The Subjective Patient-Based Standard - Scott v. Bradford}

In 1979, the Oklahoma Supreme Court, in Scott v. Bradford, ${ }^{115}$ went one step further than the Canterbury court in the name of patient autonomy by establishing a "subjective patient-based standard."116 Under this standard, a physician could be held negligent for failing to obtain an informed consent if the patient proved that she would not have undergone the procedure had she been told of a material risk. Whether a risk was material remained a question of fact for the jury to determine, but the court stated that a risk was material if it would "be likely to affect a patient's decision." 17 While best capturing the essence of patient autonomy, the subjective patient-based standard eliminated the protection provided to physicians by the objective standard that required them to disclose only what a "reasonable" patient would want to know. Under the subjective standard, if a material risk was not disclosed, the physician could be held negligent if the actual patient would have declined the procedure had it been revealed. ${ }^{118}$

The Oklahoma Supreme Court rejected Canterbury's objective patientbased standard because it failed to adequately protect the injured patient. ${ }^{119}$ Justice Doolin aptly noted the same error in the objective patient-based standard that continues today - that " $[\mathrm{t}] \mathrm{o}$ the extent the plaintiff, given an adequate disclosure would have declined the proposed treatment, and a reasonable person in similar circumstances would have consented, a patient's

$112 \quad$ Id. at $786-87$.

${ }^{113}$ Id. at 787 (quoting Jon R. Waltz \& Tomas W. Scheuneman, Informed Consent to

Therapy, 64 Nw. U.L. REv. 628, 639-40 (1970)).

114 See Katz, supra note 1 , at 74.

115 Scott v. Bradford, 606 P.2d 554 (Okla. 1979).

$116 \quad$ Id. at 559.

$117 \quad$ Id. at 558 .

$18 \quad$ See id. at 559.

nig See id. 
right to self-determination is irrevocably lost."120 Believing that the fulldisclosure was the only way to protect a patient's right to self-determination, ${ }^{21}$ the Oklahoma Supreme Court rejected the "reasonable man" standard in favor of a subjective patient-based standard.

Actually implementing the subjective patient-based standard, however, proved difficult in practice and seemed to leave physicians endlessly vulnerable to patient hindsight and an ever-changing disclosure standard. While Bradford has been followed in some jurisdictions, it has generally been used to establish the basic principle that physicians should provide risk information to their patients rather than to differentiate between the subjective and objective patient-based standards. ${ }^{122}$ In those cases that do invoke issues directly related to the subjective patient standard, however, courts tend to leave room for deference to physicians. ${ }^{123}$ Interestingly, the Oklahoma Supreme Court itself applied this standard with considerable deference to physician decisions just two years after Bradford in Masquat $v$. Maguire. ${ }^{124}$ In Masquat, Dr. Maguire failed to inform Mrs. Masquat of the possible alternatives to a tubal ligation or the probability of reinastismosis. ${ }^{125}$ Mrs. Masquat claimed the missing information should negate her consent, as she would not have had the procedure had she known of the risk or possible alternatives. ${ }^{126}$ In siding with Dr. Maguire's decision not to inform the patient of alternative methods of treatment, the court held that "[a]lthough various methods were available to do the ligation, the difference between them was not so significant as to vitiate consent."127 Courts that have adopted the subjective patient-based standard have had to temper the disclosure requirements to protect physicians. ${ }^{128}$

The vast majority of courts, however, have rejected the standard altogether. For instance, in 1999 the Supreme Court of Tennessee found the subjective patient standard too abstract. ${ }^{129}$ The court held that the subjective test left physicians too vulnerable to patient bitterness because all a patient needed to do was testify that had she known of the risk, she would have declined the procedure. ${ }^{130}$ In addition, the court found that the adoption of the subjective standard might preclude recovery for failure to provide informed consent if the patient died as a result of an undisclosed risk. ${ }^{131}$ As a

120 Bradford, 606 P.2d at 559 (emphasis in original).

121 See id. at 559.

122 Johnson v. Thompson, 971 F.2d 1487, 1499 (10th Cir. Okla. 1992); In re Baycol Prods. Litig., 2003 U.S. Dist. LEXIS 26846, at *22 (D. Minn. Feb. 25, 2003); Goss v. Okla. Blood Inst., 856 P.2d 998, 998 (Okla. Ct. App. 1990).

123 See, e.g., Masquat v. Maguire, 638 P.2d 1105 (Okla. 1981) (noting the lack of a causal link between unrevealed risk and injuries); Arena v. Gingrich, 733 P.2d 75, 79 (Or. Ct. App. 1987) (" $[\mathrm{T}]$ hat the test is subjective does not mean . . . that the only permissible determinants are the plaintiff's testimony and other evidence that pertains directly to the plaintiff's subjective choice").

124 See Masquat, 638 P.2d at 1107.

125 See id. at 1105.

126 See id. at 1106.

$127 \quad I d$. at 1107.

128 See id. at 1106-07; Arena, 733 P.2d at 78.

129 See Ashe v. Radiation Oncology Assocs., 9 S.W.3d 119, 122 (Tenn. 1999).

130 See id.; see also August Piper, Jr., Truce on the Battlefield: A Proposal for a Different Approach to Medical Informed Consent, J.L. MED. \& ETHICs 301, 304-05 (1994).

131 See Ashe, 9 S.W.3d at 122. 
result, the subjective patient-based standard remains largely an anomaly with only Oklahoma and Oregon maintaining anything that resembles a subjective informed consent requirement. ${ }^{32}$ The failure of the subjective patient-based standard resulted almost entirely from the inability of physicians to predict what information a patient would want and the biased nature of the post-hoc patient testimony.

A subjective-based standard, however, best reflects the ethical and legal foundations of informed consent and should represent the ultimate goal of an informed consent system. Any standard revision hoping to improve individual patient autonomy via a more subjective informed consent standard must be prepared to address the clarity of disclosure requirements and the impact of patient hindsight. Creating a hybrid of the objective and subjective patient-based standards that also guides and protects physicians through the use of shared decision-making and decision aids will arguably improve patient autonomy. ${ }^{133}$ Nevertheless, because the subjective patient-based standard is such an anomaly in practice, the remainder of this article will focus on the objective patient-based standard.

\section{c. The Current Patient-Based Standard}

The current patient-based standard (the objective standard) requires a physician to disclose any material risk. ${ }^{134}$ A risk is material if the physician believes that a reasonable person in the patient's position "would be likely to attach significance to the risk or cluster of risks in deciding whether or not to forego the proposed therapy." ${ }^{35}$ In order to win a claim for breach of informed consent, a patient must prove (1) that the physician failed to provide information on a "material risk", (2) that the patient would not have undergone the procedure had that information been given, and (3) therefore, the physician's omissions were the proximate cause of the patient's injuries. ${ }^{136}$ This standard has been adopted in 23 states and the District of Columbia. ${ }^{137}$

\section{CLINICAL EVIDENCE CHALLENGING THE ASSUMPTIONS OF THE CURRENT INFORMED CONSENT SYSTEMS}

In the last two decades, improvements in medical knowledge and clinical research in three main areas have drawn the logic of the physician and patient-based standards into question. First, contrary to the assumptions of the physician-based standard, one appropriate standard of care does not exist for most treatments. What is considered standard medical care varies

\footnotetext{
132 See Scott, 606 P.2d at 559; Macy v. Blatchford, 8 P.3d 204, 210 (Or. 2000).

133 See infra Part XI.

134 Canterbury, 464 F.2d at 786.

$135 \quad$ Id. at 787.

${ }_{136}$ See Scott, 606 P.2d at 559.

137 See infra Appendix A (listing patient-based states to include Alaska, California, Connecticut, District of Columbia, Georgia, Hawaii, Iowa, Louisiana, Maryland, Massachusetts, Mississippi, New Jersey, North Dakota, Oklahoma, Ohio, Oregon, Pennsylvania, Rhode Island, South Dakota, Texas, Utah, Washington, West Virginia and Wisconsin. The remaining two states, Minnesotta and New Mexico, have hybrid standards). See Appendix A for a more detailed description of the laws on a state-by-state basis.
} 
substantially by geographic region. ${ }^{138}$ Second, medical decision-making differs according to the types of risks, benefits and alternatives associated with a treatment choice. John Wennberg and colleagues assert that medical care can be divided into three categories based on those differences. ${ }^{139}$ In one such category, preference-sensitive care, individual patient input is paramount. ${ }^{140}$ For instance, patient preferences should guide the final treatment decision, as the treatment options have various health and quality of life tradeoffs. ${ }^{141}$ This evidence supports the move toward a patient-based standard. The third body of evidence challenges the validity of an objective patient-based standard and the notion of the "reasonable" patient. ${ }^{142}$ The data from all three areas of research vexes the assumptions of our informed consent laws. The scientific data will be presented in this section with the implications to follow in section VI.

\section{A. Physician Variation on the Standard of CARE}

The assumptions of the physician-based standard that all physicians tend to agree on a standard of care for treatment and information disclosure conflicts with evidence of wide geographic variation in treatment practices and variance between physicians on information disclosure. ${ }^{143}$ For the last three decades, John Wennberg and colleagues have performed research that demonstrates that the care provided for certain conditions varies significantly according to geographic location. ${ }^{144}$ For instance, the rate of knee replacement surgery for arthritis in Fort Meyers, Florida is 2.3 times greater than the rate of knee replacement surgery in neighboring Miami after controlling for the age, sex and race of the patient. ${ }^{145}$ This type of variation occurs all over the country for a wide range of services, such that communities may be identified by their "surgical signature." 146 As a result, in some regions patients will be much more likely to receive a specific type of procedure than in others. According to Wennberg's research, the majority of these variations do not result from variations in patient preferences for treatment or the rate of illness. ${ }^{147}$ Instead Wennberg argues that these variations reflect the tendency of physicians in certain areas to become specialists in a subset of procedures and then recommend those procedures for patients with specific

\footnotetext{
${ }_{138}$ Wennberg \& Peters, supra note 1 , at 925.

139 See id.

$140 \quad$ Id. at 934.

141 Dominick L. Frosch \& Robert M. Kaplan, Shared Decision Making in Clinical Medicine: Past Research and Future Directions, 17 AM. J. Preventive Med. 285, 287 (1999).

${ }^{142}$ See Deb Feldman-Stewart et al., The Information Required by Patients with Earlystage Prostate Cancer in Choosing Their Treatment, 87 BJU INT'L 218, 220-23 (2001).

143 See generally Center for the Evaluative Clinical Sciences, supra note 7 (concluding that health care varies with geography).

14 See, e.g., Center for the Evaluative Clinical Sciences, Dartmouth Medical School, The Quality of Medical Care in the United States: A Report on the Medicare Program, The Dartmouth Atlas of Health Care 1999 (1999), available at http://www.dartmouthatlas.org/atlases/99Atlas.pdf; John E. Wennberg \& Alan Gittelsohn, Small Area Variations in Health Care Delivery: A Population-based Health Information System Can Guide Planning and Regulatory Decision-making, 182 SCIENCE 1102 (1973).

145 Center for the Evaluative Clinical Sciences, supra note 5, at 3.

146 Id. at 11-15; Center for the Evaluative Clinical Sciences, supra note 7, at 107.

147 Center for the Evaluative Clinical Sciences, supra note 7, at 5.
} 
medical conditions; ${ }^{148}$ meanwhile, physicians in other areas recommend more conservative treatment based on medical management. ${ }^{149}$ Some surgeons focus on back surgery or knee surgery, while others concentrate on trauma or pediatric conditions. Once a surgeon has specialized and is located in a hospital, he or she is unlikely to change practice area or location. ${ }^{150}$ As a result, treatment patterns in a given area remain consistent over time. If the variations were patient or need driven, they would vary from year to year. For the most part, they do not. For instance, among the 306 hospital referral regions examined by the Dartmouth Atlas, $75 \%$ of the variation in knee replacement surgery from 2000-2001 was "explained" by the rates in the same region from 1992-1993. ${ }^{151}$ These findings indicate that physicians do not treat similar patients similarly, even in nearby cities, and that the differences in patient treatment persist over time as a result of physician culture within hospitals and cities, rather than because of variances in patient preference or effective medical care. ${ }^{152}$ Therefore, the assumption that physicians generally agree on one standard of medical care is substantially compromised.

In addition to Wennberg's findings, research by Deb Feldman-Stewart and colleagues demonstrates that physicians often differ significantly on what information they believe is relevant to treatment decisions. ${ }^{153}$ This finding raises significant questions about the validity of a "reasonably prudent physician" standard for disclosure. Feldman-Stewart et al. conducted numerous discussions with health care professionals, patients, researchers and lay people to compile a comprehensive list of issues and questions that might be important to discuss prior to making a treatment decision. ${ }^{154}$ The researchers then conducted a survey of radiation oncologists, urologists, nurses in cancer clinics and radiation therapists inquiring into how important addressing each of the questions was with various case-scenario patients. ${ }^{155}$ While the responses demonstrated general trends of consistency between the various types of health care providers regarding which questions were "essential" and "non-essential," substantial disagreement occurred within the groups regarding the importance of just under half of the questions. ${ }^{156}$ For instance, urologists agreed that 4 questions were essential to address and $\mathbf{4 1}$ questions were not essential to address, but they disagreed on the status of the remaining 33 questions. ${ }^{157}$ Likewise, radiologists agreed that 11 questions were essential, 37 questions were not essential and disagreed on the essential nature of discussing 33 questions. ${ }^{158}$ This evidence strongly suggests that the

148 Center for Evaluative Clinical Sciences, supra note 5, at 3.

149 See Center for the Evaluative Clinical Sciences, supra note 7, at 111-30 (for regions with below-average treatment rates for various procedures); see also Wennberg, supra note 7 , at 2-3 (for data on the underuse of effective care).

$150 \quad C f$. Center for the Evaluative Clinical Sciences, supra note 7 , at 38 (finding that the distribution of physician workforce in the United States did not change in any dramatic way from 1993-1996).

151 Wennberg, supra note 7 , at 8 .

$152 \quad$ Id. at 6-7.

153 Feldman-Stewart, supra note 8 , at 4.7 .

$154 \quad I d$.

155 Id.

$156 \quad I d$. at $46-4.7$.

$157 \quad I d$. at 47.

$158 \quad$ Id. 
information that would be provided by one reasonably prudent physician may substantially differ from the information provided by another reasonably prudent physician. This variance could severely compromise the ability of an individual patient to receive treatment information that is important to them or to recover for damages if the information was not provided. Both Wennberg et al. and Feldman-Stewart et al.'s research findings undermine the physician-based standard's assumptions that physicians tend to provide similar care and disclose similar information in line with a single standard of care. These issues become even more complex for certain types of medical care.

\section{Three Types of Medical Care}

John Wennberg and colleagues have also conducted research that suggests that medical care can be divided into three categories: 1) effective care; 2) preference-sensitive care; and 3) supply-sensitive care. ${ }^{159}$ These delineations are based on the amount of clinical and theoretical evidence available to support certain treatment alternatives and how the risks and benefits of certain alternatives compare to others. ${ }^{160}$ Identifying different levels of care is important because unwarranted, physician-associated variation in treatment rates have different causes and remedies, depending on the respective category of care. The existence of three types of care indicates that, even if physicians agreed on a standard of care, for some conditions there is no single standard treatment appropriate for all individuals, indicating that patient values and preferences are integral to choosing the best treatment option. This is especially pertinent for evaluating the legal standards for informed consent because if patient values are relevant to determining the best treatment option, a standard that fails to include them may hinder patient care. In addition, the role of the physician and patient may differ in medical treatment decisions for each of the three levels of care.

\section{a. Effective Care}

John Wennberg and Philip Peters have defined effective care as limited to those "services whose use is supported by well-articulated medical theories and by strong evidence of efficacy in the forms of randomized clinical trials or large cohort studies." ${ }^{161}$ This category of care is easily aligned with the legal notion of a single universal standard of medical care that all patients should want and expect from their physicians. Examples of effective care include: mammography screening for breast cancer, HgAlc and blood lipid monitoring for diabetics, and beta-blockers and ACE inhibitors following a heart attack. ${ }^{162}$ Effective care should be provided to almost all patients, as its benefits have been unequivocally proven. ${ }^{163}$ Unfortunately, most effective care services are

159 Wennberg, supra note 1 , at 925.

160 See id. at 927-32.

161 Wennberg \& Peters, supra note 9 , at 927.

162 Id.

163 John E. Wennberg, Keynote Lecture at the Instit. for Health Care Improvement Nat'l Forum: Understanding Practice Patterns: A Focus on What the Quality Movement Can Do to Reduce Unwarranted Variations (Dec. 14, 2005) (transcript available at www.dartmouthatlas.org/atlases/lecture.shtm). 
underused. ${ }^{164}$ Given knowledge of the positive impact of effective care, physicians should encourage patients to accept such treatments. Only after providing all of the relevant information and discussion should the patient be permitted to refuse effective treatment. While most patients desire effective care, the law recognizes the right of all patients to refuse medical care, regardless of whether the court feels the decision is wise or unwise. ${ }^{165}$

\section{b. Preference-Sensitive Care}

Preference-sensitive care represents around $30-35 \%$ of medical care and occurs for conditions where two or more treatment alternatives exist with differing risks and benefits or when the benefit/harm ratios are scientifically uncertain. ${ }^{166}$ In some instances, these alternatives may have approximately the same impact on survival, but have varying quality of life outcomes. ${ }^{167}$ For instance, women with localized breast cancer have an approximately equal chance of survival following a mastectomy (full removal of the breast) or a lumpectomy (a local removal of the tumor). ${ }^{168}$ Women who undergo a lumpectomy, however, will have to have radiation therapy and run a higher risk of recurrence, while women who elect the mastectomy must face the loss of a breast, potential reconstructive surgery and other disfigurement concerns. ${ }^{169}$ Wennberg termed this type of care preference-sensitive care, as treatment choices should reflect patient preferences and personal values. ${ }^{170}$

Preference-sensitive care may also encompass treatment alternatives with uncertain clinical evidence regarding their impact on survival and quality of life. For example, accepted treatment for prostate cancer consists of three options: 1) radical prostatectomy; 2) radiation; and 3) watchful waiting or conservative management. ${ }^{171}$ Recent studies show that disease-free survival rates for radical prostatectomy and radiation are slightly higher than those for watchful waiting; ${ }^{172}$ however, they are accompanied by greater instance of side effects such as bowel, erectile and urinary dysfunction. ${ }^{173}$ For patients with largely localized cancer (Gleason score 2-4), survival rates with watchful waiting do not differ from those without prostate cancer. ${ }^{174}$ In addition, patients with moderate localization (Gleason scores of 5 to 6 ) still had a

164 See Elizabeth A. McGlynn et al., The Quality of Health Care Delivered to Adults in the United States, 348 N. ENGL. J. MED., 2635, 2641-44 (2003) (indicating that on average, Americans receive about half of recommended medical care processes).

165 See Lane v. Candura, 376 N.E.2d 1232, 1233 (Mass. App. Ct. 1978).

166 See Wennberg \& Peters, supra note 9, at 925-41; see also Annette M. O'Connor et al., Modifying Unwarranted Variations in Health Care: Shared Decision Making Using Patient Decision Aids, Health AfF. (Web Exclusive) 63, 63-72 (2004); Interview by Ben Moulton with Jack E. Wennberg, Co-Founder and Senior Policy Advisor of the Foundation for Informed Medical Decision Making (2006).

${ }_{167}$ See Wennberg, supra note 164, at 9-14 (noting that doctors may treat patients with chronic hip, knee, and back conditions in more than one way).

168 Wennberg \& Peters, supra note 9, at 928.

$169 \quad I d$.

$170 \quad I d$.

i7 Center for the Evaluative Clinical Sciences, supra note 5, at 11-15.

${ }_{172}$ Wennberg \& Peters, supra note 9 , at 928.

173 Viba Bhatnagar \& Robert Kaplan, Treatment Options for Prostate Cancer: Evaluating the Evidence, 71 AM. FAM Physician 1915, 1915 (2005).

174 Id. at 1916, 1918. 
relatively small risk of dying from prostate cancer without undergoing any treatment. ${ }^{175}$ On the other hand, patients with undifferentiated cancer (Gleason scores of 7-10) had a 2-3 fold increase in the risk of dying from prostate cancer under a watchful waiting option. ${ }^{176}$ The risk of dying of prostate cancer must be weighed against the quality of life losses associated with long-term side effects of each treatment option. Radical prostatectomy is associated with a 50-90\% risk of erectile dysfunction, a $15-60 \%$ risk of urinary dysfunction and a $2-17 \%$ risk of bowl dysfunction. ${ }^{177}$ Radiation therapy bears a $30-80 \%$ risk of erectile dysfunction; $2-30 \%$ risk of urinary dysfunction, and a $0-30 \%$ risk of bowel dysfunction. ${ }^{178}$

This is a lot of information for patients to digest and qualify. In doing so, patients often weigh these risks and benefits very differently depending on their age, lifestyle and personal values. ${ }^{179}$ For patients to employ their preferences and values in making treatment decisions about care, they must have access to all relevant information about each of the treatment options.

\section{c. Supply-Sensitive Care}

Supply-sensitive care encompasses services for which the supply of resources governs their frequency of use. ${ }^{180}$ The level of spending on these services depends on the amount and extent of physician visits, hospitalizations, intensive care unit stays, referrals to specialists and the use of imaging and other diagnostic tests. ${ }^{181}$ Wennberg and colleagues found that the most significant determinant of use of these services is the capacity of the local health care system to treat additional patients. ${ }^{182}$ The Dartmouth Atlas Project has repeatedly found a positive correlation between the supply of staffed hospital beds per 1,000 residents and the hospitalization rate for medical (nonsurgical) conditions. ${ }^{183}$ Wennberg and colleagues also found that increasing the capacity of the local health care system did not increase the demand for services known to be effective at reducing morbidity and mortality or for preference-sensitive services where patient values are most important, only the demand for supply-sensitive services increased. ${ }^{184}$ Whether increased use of supply-sensitive services correlates with better patient health outcomes remains to be proven clinically; however, an initial study by Elliot Fisher suggests that regions of care with greater overall care intensity experienced

\footnotetext{
${ }_{175} \quad$ Id.

${ }^{176} \quad$ Id. at 1920.

177 Id.

$178 \quad I d$.

179 See Bogardus et al., supra note 6, at 1037-41.

180 Wennberg, supra note 164 , at 9.

181 Id.

182 Wennberg \& Peters, supra note 9, at 930 (citing Center for the Evaluative Clinical Sciences, Dartmouth Medical School, The Quality of Medical Care in the United States: A Report on the Medicare Program, The Dartmouth Atlas of Health CARE 1999 (1999), available at http://www.dartmouthatlas.org/atlases/atlas_series.shtm).

183 Wennberg, supra note 164, at 10 (citing Center for the Evalútive Clinical Sciences, Dartmouth Medical School, The Quality of Medical Care in the United States: A Report on the Medicare Program, The Dartmouth Atlas of Health Care 1999 (1999), available at http://www.dartmouthatlas.org/atlases/atlas_series.shtm).

${ }_{184}$ See $i d$.
} 
increased mortality rates. ${ }^{185}$ Overall, the provision of many supply-sensitive services wastes precious medical resources and often provides unwanted care to patients. ${ }^{186}$ Unfortunately, these uses often become part of the legal standard, as the oversupply of some services become the norms of physician behavior. As a result, strong efforts should be made to identify and minimize the overprovision of supply-sensitive care in medical practice.

Each of the three types of medical care has implications for the physicianbased standard. The consistent under-use of effective care that is theoretically and clinically proven beneficial demonstrates that even under conditions of clear obligation, physician practice patterns vary. This variance only increases for both preference-sensitive and supply-sensitive care. These geographical differences in physician practice compromise the integrity of the "reasonably prudent physician" standard, as they are not simply variances in practice tolerated by the legal standard, allowing physicians to express respected differences of opinion. These medical variances instead can set the legal standard in a practice area. Unfortunately, they often do not represent the best medical practices or patient preference, but instead are driven by external pressures on the medical system and a lack of efficient information dissemination. In addition to problems associated with geographic variance, the existence of preference-sensitive care illuminates the importance of informed choice and patient preference in medical decision-making, which is also compromised by the physician standard.

\section{Variation in Patient Preferences for Information Disclosure}

Clinical evidence also challenges the underlying premises of the patientbased standard. In addition to the variation among physicians regarding the importance of disclosing certain information, reasonable patients also differ significantly on what risks they consider "material" to their decision. ${ }^{187}$ In a survey of patients recently diagnosed with early stage prostate cancer deciding between prostatectomy, radiation, and watchful waiting, Feldman-Stewart et al. found great variation between patients regarding which questions they felt were essential to discuss with their physician. ${ }^{188}$ For this survey patients rated 93 questions on their level of importance to making a treatment decision. ${ }^{189}$ Patients agreed that 23 questions were essential to address and 12 questions were not essential to address; they disagreed, however, about the relevance of 58 of the 93 questions. $^{190}$ This study reveals that reasonable patients have substantially different informational wants and needs when making complex treatment decisions. The level of information suitable for some people is likely to be insufficient for many others. In addition, patients value different types of risks and benefits quite differently depending upon their lifestyle and

185 Id. at 11.

186 Wennberg \& Peters, supra note 1 , at 932.

187 Frosch \& Kaplan, supra note 141, at 287; see also Deb Feldman-Stewart et al., The Information Required by Patients With Early-Stage Prostate Cancer in Choosing Their Treatment, 87 BJU INT'L 218, 220-221 (2001).

188 Feldman-Stewart et al., supra note 8 , at 49 .

189 Id.

190 Id. An Index of Agreement was used to determine substantial agreement between patients and the threshold was set at $67 \%$ agreement. $I d$. 
values. The Canterbury court defined a "material risk" as one that a reasonable person in the patient's position would be likely to attach significance to. ${ }^{191}$ Reasonable people disagree, however, on what information they deem significant to the decision. This evidence suggests that a more appropriate standard of treatment information disclosure would attempt to provide patients with a broad amount of risk information, and then allow them an opportunity to ask for additional information to satisfy their subjective needs. Shared decision-making and decision aids can assist patients to attain that standard of disclosure for many individuals. Patients should no longer be beholden to the experience, opinions and preferences of their physician, as decision aids and the internet can assist them to review clinical risk and benefit information from all over the nation and determine which treatment option best comports with their personal values and lifestyle. ${ }^{192}$

In sum, identifying variations among physician behavior, treatment options, and patient preferences is important for three reasons. First, physicians do not agree on one medical standard of care and one standard of disclosure. Medical care tends to vary by physician practice patterns rather than clinically proven care in accordance with patient preference. Second, for many conditions a range of medically appropriate treatments exist, indicating that patient values and preferences are integral to choosing the best treatment option. This is especially pertinent for evaluating the legal standards for informed consent because if patient values are relevant to determining the most appropriate treatment, a standard that fails to include them may hinder patient care. Finally, wide variations in patient preferences for disclosure practices indicates that use of an objective standard based on material risks alone may not protect the ability of many individuals to obtain the information they need to make the best medical decisions possible. The following section reviews the implications of this clinical research for the current legal standards of informed consent.

\section{IMPLICATIONS OF THE CURRENT LEGAL INFORMED CONSENT STANDARDS}

As discussed above, recent developments in health services research challenge some of the most fundamental assumptions of the current legal informed consent standards. ${ }^{193}$ This section examines the questions raised by health services research regarding both the physician and patient-based standards of informed consent, as well as the impact that these standards have had on medical and legal standards of informed consent.

191 Canterbury, 464 F.2d at 787 (quoting Jon R. Waltz \& Thomas W. Scheuneman, Informed Consent to Therapy, 64 Nw. U. L. Rev. 628, 640 (1970)).

192 Frosch \& Kaplan, supra note 141, at 286.

193 See supra Part V. 


\section{A. Physician-Based Standard}

As previously discussed, the physician-based standard stands on three basic assumptions. ${ }^{194}$ First, the standard assumes that for any medical situation, there is a course of action that represents the best treatment option or options. Next, it assumes that physicians actually acknowledge and agree on the best treatment option. Finally, the physician-based standard assumes that the majority of physicians provide appropriate information on this treatment to their patient. In general, these assumptions are only supported for effective care, which is a small proportion of total care. ${ }^{195}$ For preferencesensitive and supply-sensitive care, these assumptions do not always stand on firm foundations.

Clinical evidence of regional variations in medical care demonstrates that the first two assumptions of the physician-based standard are largely unsubstantiated. ${ }^{196}$ Across geographic boundaries, physicians do not provide similar care for similar patients with similar conditions. ${ }^{197}$ Wennberg and colleagues argue that these differences do not reflect variances in patient preferences or medical necessity, but instead reflect physician practice patterns and preferences. ${ }^{198}$ In situations of preference-sensitive care or medical uncertainty, the physician may prescribe the course of treatment that best confers with his or her ability to provide care or the practice of other physicians in the area. For instance, in Elyria, $\mathrm{OH}$, researchers have found that Medicare patients are nearly four times as likely to receive angioplasty, a procedure that places a balloon catheter into a blocked artery to unclog it, as a part of their coronary care than the national average. ${ }^{199}$ While the physicians at EMH Regional Medical Center, the community hospital in Elyria, have not been accused of wrongdoing, outside experts are concerned that the high rate of angioplasty is the result of financial incentives and professional training norms in the area rather than patient preference or medical need. ${ }^{200}$ The financial incentives can be quite strong. Medicare pays EMH Regional Medical Center about $\$ 11,000$ for an angioplasty procedure that also includes the insertion of a drug coated stent to hold the artery open. ${ }^{201}$ This can amount to a great deal of money when the physicians in Elyria perform thousands of angioplasties per year, around 3,400 angioplasties in 2004. ${ }^{202}$ That rate was three times the number performed in Cleveland, just 30 miles away. ${ }^{203}$ In Cleveland, patients are more likely to receive other treatment options for blocked arteries, such as cardiac bypass surgery and a variety of heart medications to reduce blockages. ${ }^{204}$ While there is no definitive study that demonstrates one best way to treat clogged arteries, there is little doubt

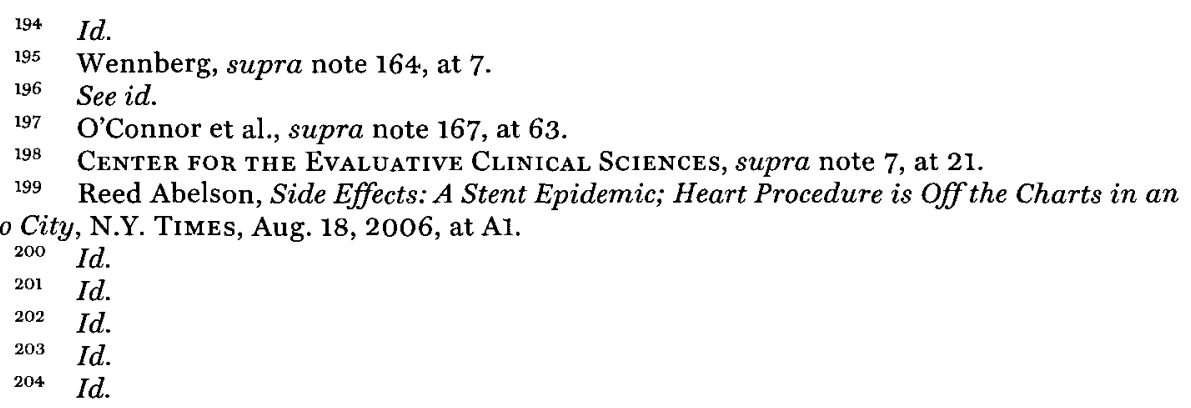


that some patients are receiving angioplasty and stents in Elyria when they could be receiving heart medications, which cost only hundreds of dollars a year. $^{205}$ The physicians in Elyria state that their patients are receiving high quality, aggressive medical care that is in line with what other cardiologists recommend. $^{206}$ The relevant question, however, is what care would their patients prefer if they had all of the facts. Some patients might prefer to try blockage reducing drugs for a while, which avoid surgery and carry much less risk, while others might be better off receiving bypass surgery, which can have better results for more serious blockages. ${ }^{207}$ Interestingly, cardiologists in Elyria do not perform bypass surgery and must refer the patient to the nearby Cleveland Clinic if a patient needs the procedure. ${ }^{208}$ As a result, it seems clear why the Elyria physicians prefer to offer angioplasty to most of their patients with arterial blockages: no clear evidence demonstrates that medication or bypass results in better outcomes, they can make significant amounts of money per angioplasty procedure, and their patients generally receive good care. The only problem is their patients, if given all the information, might prefer to have bypass or to take medication and wait, but instead they are told that the have a blockage and the doctor recommends angioplasty. Herein lies the problem.

While the law should leave room in medical care to reflect different preferences of physicians, respected minority opinions, and differing schools of thought, all of these options and their potential ramifications should be discussed in depth with patients so that they may exercise their right to make fully informed medical decisions. The law should not continue to tolerate deviations in medical practice that result from the excess capacity of the health care system, financial incentives, specialization trends in an area, or other factors external to the physician-patient relationship and the nature of the treatment options available. Unfortunately, Wennberg's data suggests that the significant geographic variations in the provision of health care around the country do not reflect variation in patient differences or medical need, but instead result from other pressures. ${ }^{209}$ As a result, the assumption of the physician-based standard that physician practice norms in an area will always result in the best care for patients is largely unfounded.

Physician variation in disclosure practices also casts substantial doubt on the notion that the majority of reasonably prudent physicians provide a similar amount of information. The research performed by Feldman-Stewart and colleagues suggests that physicians, even within the same geographic region and specialty, have not reached consensus on the content nor the quantity of information that should be disclosed. ${ }^{210}$ This indicates that the amount of information a patient will receive to make very serious and personal medical decisions will not only vary region to region, but also physician to physician.

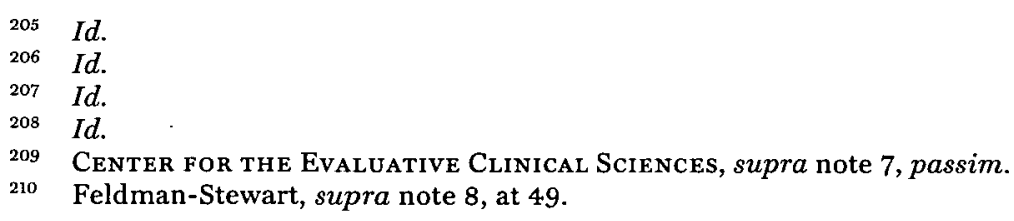


As a result, the physician-based standard has had four major impacts on the practice of medicine and informed consent procedures: (1) it grants the physician substantial autonomy in medical decisions and promotes paternalism in a time when physicians have substantial incentives to act outside of a patient's best interests; (2) it permits regional variations in what actions constitute malpractice based upon physician practice norms in an area; (3) it helps insulate physicians from malpractice suits; and (4) it hinders progress in both informed consent techniques and medical practice. ${ }^{211}$

First, by requiring only as much disclosure as a reasonably prudent physician in the same field would provide to a patient regarding a treatment, the physician-based standard keeps a significant portion of medical decisionmaking within the realm of the physician, regardless of the patient's preferences, concerns or values. The standard underscores the historic paternalism in American medicine and the legal system's continual deference to the medical practice. Unfortunately, physicians do not always provide information and make medical decisions in an unbiased manner with only their patient's interests in mind. ${ }^{212}$ In addition, they also might not be the best judge of their patient's best interests. Many managed care organizations provide financial incentives, such as bonuses from unspent funds and withholding portions of income, for physicians to control health care expenditures. $^{213}$ While many physicians today are in PPOs or POS organizations, substantial incentives still exist to limit costs and care, which might adversely affect patient care or the decision-making process. ${ }^{214}$ Alternatively, many specialists, like surgeons, are still paid on a fee for service basis, albeit a reduced fee. This payment scheme can provide incentives for physicians to advocate surgery when if given all the facts, the patient might prefer to wait in conservative management. If all of the facts are not provided to the patient in an unbiased manner, physicians retain extraordinary control over medical decision-making, in a way that can significantly compromise patient care.

This problem is even more complex in cases of preference-sensitive care. Under the physician-based standard, physicians are permitted to disclose or emphasize those options most commonly provided in the region or that confer with their medical specialties. ${ }^{215}$ However, for conditions with preferencesensitive treatment choices or those with unknown risks, the physician cannot determine the best treatment choice. The decision should be based on patient preferences and values, rather than the preferences and values of the

211 See infra notes 212-213 and accompanying text.

212 See Paul J. Feldstein, Health Policy Issues: an economic perspective on Health Reform 38-46 (Health Administration Press \& AUPHA Press 1999); Tracy E. Miller \& Carol R. Horowitz, Disclosing Doctors' Incentives: Will Consumers Understand and Value the Information?, 19 Health Affairs 149, 149-155 (2000); Richard G. Frank, Behavioral Economics and Health Economics (Nat'l Bureau of Econ. Research, Working Paper No. 10881, 2004).

213 Kate T. Christensen, Ethically Important Distinctions Among Managed Care Organizations, 23 J.L. MED. \& ETHIcs 223, 224 (1995); Eric S. Nadler et al., Does a Year Make a Difference? Changes in Physician Satisfaction and Perception in an Increasingly Capitated Environment, 107 AM. J. MED. 38, 38 (1999) (discussing capitation as financial incentive for physicians).

214 Feldstein, supra note 212, passim.

215 Center for the Evaluative Clinical Sciences, supra note 7, passim. 
physician. The treatment information that other physicians would provide in similar circumstances should not determine the standard of care for preference-sensitive care. One standard cannot accommodate the preferences of all patients in the state. ${ }^{216}$ Variations in treatment should result from variations in patient preferences, which should not conform to a geographic norm. As Wennberg and colleagues discovered, the majority of treatment variation occurs because of trends in physician practice in the area. ${ }^{217}$ This evidence of regional treatment variations refutes both the legal assumption that all physicians should abide by a single standard of care, and the legal assumption that they $d o .^{218}$ In addition, by permitting physicians to only disclose information they feel is relevant, patients often receive care that they would not have chosen had they known all of the risks and alternatives. ${ }^{219}$ In many ways, this creates the geographic variation in medical treatment choices, which can lead to alienation of the patient, reduced patient investment or compliance with the treatment choice and increased malpractice claims. ${ }^{220}$ These findings suggest that patients should be given more of a role in medical decision-making than that permitted by a standard that maintains the information and power balance firmly in the domain of the physician.

Second, these regional variations can significantly impact what constitutes malpractice in a given state that upholds the physician-based standard. Because the physician-based standard establishes the standard of care from the practice norms of physicians in the state, regional treatment trends will dictate the legal standard of care, instead of clinical effectiveness or patient preferences. For instance, physicians may offer more prostatectomies in areas where there are more patients with low to moderate Gleason scores, and as a result watchful waiting may not be considered standard of care, even though the survival rates for the two treatment alternatives are nearly equivalent. Decisions in malpractice cases will not be based upon the existence of medical error alone, but on deviation from the medical practices in the state.

Thirdly, while the physician-based standard may potentially lead to additional filing of malpractice suits by failing to include the patient in the decision-making process, the standard itself insulates physicians from being held responsible in legitimate malpractice claims. As long as physicians follow the norms of practice and mimic the disclosure actions of others, they will meet the standard of care required, regardless of the level of infringement on patient autonomy. Under the physician-based standard, doctors who act

$216 \quad I d$.

217 Wennberg \& Peters, supra note 1, at 929.

218 See John E. Wennberg \& Alan Gittelsohn, Small Area Variations in Health Care Delivery: A Population-Based Health Information System Can Guide Planning and Regulatory Decision-Making, 182 SCIENCE 1102 (1973) (finding regional variations in health care).

219 Karen R. Sepucha et al., Policy Support for Patient-Centered Care: The Need for Measurable Improvements in Decision Quality, HealTH AfFaIRs, Oct. 7 2004, http://content.healthaffairs.org/cgi/reprint/hlthaff.var.128v1.; Center FOR THE Evaluative Clinical Sciences, supra note 7 , passim.

220 Beth Huntington \& Nettie Kuhn, Communication Gaffes: A Root Cause of Malpractice Claims, 16 Baylor U. Med. Center Proc. 157,157-160 (2003) (attributing these problems to lack in physician communication); Charles Vincent et al., Why Do People Sue Doctors? A Study of Patients and Relatives Taking Legal Action, 343 THE LANCET 1609,1609 (1994) (discussing reasons patients take legal actions against doctors). 
irresponsibly in unison with others will be legally protected, while those who deviate from the norm to improve patient care or disclosure may be held liable.

Furthermore, the physician-based standard promotes unity among physicians that can hinder a patient's evidentiary base. To succeed in a medical malpractice case as a patient under the physician-based standard, you must provide testimony from other physicians stating that your physician failed to disclose the level of information that a reasonably prudent physician would. Finding a physician to testify against another is often not an easy task, except in cases of clearly egregious omissions. ${ }^{221}$ The physician-based standard promotes solidarity among physicians and uniformity in their actions in such a manner that may stifle a patient's ability to bring a successful claim for failing to disclose sufficient information to enable the patient to make an informed consent. ${ }^{22}$

Finally, by obligating physicians to follow in the patterns of those around them, the legal system has substantially limited the ability of the practice of medicine to evolve. From a treatment standpoint, physicians attempting new methods of care act outside of the standard of care and can be held liable for malpractice. $^{223}$ Only when enough physicians have taken a chance on a treatment to produce a shift in general practice will it be legally safe for all physicians to use the treatment. ${ }^{24}$ Likewise, as the Merenstein case demonstrated, evolution to meet patient disclosure needs has proved just as challenging as treatment evolution under the physician-based standard. ${ }^{225}$ Despite abiding by the recommendations of the American Cancer Society, the American Academy of Family Physicians, the American Urological Association, and the U.S. Preventative Services Task Force and providing his patient with accurate clinical factual information to aid him in a decision, Dr. Merenstein's actions were held outside the standard of care for Virginia because a majority of physicians in the area had decided not to follow the guidelines and provide patients with all relevant information on PSA testing. ${ }^{226}$ The stifling of innovation and creativity in medical care is perhaps the best reason for revising the legal standard for informed consent in all physician-based states.

The physician-based standard reflects a view of the medical system from an earlier time where society deferred to the decisions of physicians, paternalism was expected and patient concerns and goals were secondary. ${ }^{227}$ Two major changes in the medical system now bring the appropriateness of those views under scrutiny. Clinical effectiveness trials and evidence-based medicine provide access to risk and benefit information that increases the ability for the patient to express their autonomous choice. Secondly, managed care, capitation and physician incentives to reduce the use of care all raise substantial questions about a physician's ability to be unbiased in disclosing

221 Piper, supra note 130, at 302.

$222 \quad I d$

${ }^{223}$ Joseph P. Graskemper, The Standard of Care in Dentistry: Where Did It Come From? How Has It Evolved?, 135 J. AM. Dental Ass'n 1449, 1453-54 (2004).

224 Id.

225 See Merenstein, supra note 16 , at 15-16.

$226 \quad I d$

227 Frosch \& Kaplan, supra note 141, at 286. 
information on certain kinds of care. ${ }^{228}$ We have now entered a time where additional patient involvement in medical decision-making should not only be mandatory to ensure patient autonomy and counterbalance outside influences and biases of physicians, but also to potentially improve patient satisfaction and health outcomes through increased patient investment in the treatment choice. $^{229}$

\section{B. Patient-Based Standard}

Clinical evidence also demonstrates that current efforts by courts to improve patient involvement have not gone far enough. ${ }^{230}$ Touted as a victory for patients' rights, the Canterbury opinion represents more of a judicial compromise of competing interests than a bastion for individual autonomy. ${ }^{231}$ As mentioned above, the patient-based standard is based on the objective standard of what information a "reasonable" patient would want to know. ${ }^{232}$ Judge Robinson wanted to protect a patient's right to all relevant information regarding medical treatment, while at the same time protecting physicians from malpractice liability for unwittingly failing to inform a patient of a seemingly insignificant or extremely unlikely risk. ${ }^{233}$ Otherwise, physicians could bear limitless liability and the Sisyphean task of staying on top of all medical knowledge. ${ }^{234}$ Unfortunately, by creating an objective standard, the Canterbury opinion limited an individual's ability to receive the medical information relevant to his or her specific needs. ${ }^{235}$

Health services research provides evidence that the "reasonable patient" assumption of the patient-based standard is flawed on two different levels. Primarily, patients regularly disagree on what risks are "material" to a treatment decision, as they rate adverse outcomes differently. ${ }^{236}$ In decisions where the treatment options have closely related risks and benefits, people often judge the same set of facts very differently based on their different utilities for certain health states and levels of risk aversion. ${ }^{23}$ This is especially true for quality of life outcomes such as reduced mobility, incontinence, impotence, reduced function of a body part, or significant discomfort. $^{238}$ Patients often weigh the value of these "side effects" of treatment very differently when comparing treatment alternatives. ${ }^{239}$

Secondly, since great variation exists in patient preferences for risk taking behaviors and for different qualities of life, a physician's ability to determine what would be a "material risk" to any individual is greatly compromised.

228 Nadler et al., supra note 214 , at 38.

229 Edward Guadagnoli \& Patricia Ward, Patient Participation in Decision-Making, 47

Soc. SCI. \& MED. 329, 332 (1998).

230 See supra pp. 446-4,48.

231 Id.

$232 I d$.

233 Id.

234 Canterbury, 464 F.2d at 788.

235 See supra pp. 446-448.

${ }^{236}$ Bogardus et al., supra note 6, at 1039.

237 Id.; Woolf, supra note 15, at 244.

238 Frosch \& Kaplan, supra note 141, at 287.

239 Id. 
Unfortunately, physicians tend to poorly predict patient preferences. ${ }^{240}$ For instance, Teno and colleagues surveyed 2,636 patients with life threatening illnesses and their physicians regarding the patient's preferences for life saving cardiopulmonary resuscitation. ${ }^{241}$ The study found that in over onethird of pairings the physician incorrectly assumed the patient's preferences in these life and death situations. ${ }^{242}$ When the decisions are more complex and involve quality of life concerns, the ability of a physician to predict what will be a material risk to a patient will only decline. ${ }^{243}$ In addition, the study also revealed that reasonable patients' preferences also varied widely for cardiopulmonary resuscitation. ${ }^{244}$ While the patient-based standard increases the emphasis on patient autonomy, its failure to acknowledge that equally "reasonable" people can value alternative treatment risks and outcomes differently enough to make some risks material to some individuals and not others suggests that significant improvements in the name of patient autonomy can be made in the legal standard for informed consent. ${ }^{245}$

The materiality requirement of the patient-based standard also leaves physicians vulnerable by failing to acknowledge that people have very different levels of risk aversion and that every medical treatment presents a "nearly infinite array of ever-more remote possibilities for harm." ${ }^{246}$ Risks associated with medical treatment alternatives exist on a continuum, both in probability and in harm. Therefore, the idea that all physicians and patients draw the same bright lines distinguishing those "material" risks from "immaterial" risks is misleading. As acknowledged by August Piper, "[b]ecause the risks exist only in shades of gray, the courts have been unable to state expressly what a 'small' risk is - that is, to indicate how small a risk must be before it is considered so minute that it does not require disclosure."${ }^{247}$ The courts force physicians to use their intuition with respect to determining which risks are material, but then punish them when their intuition proves incorrect. ${ }^{248}$ As a result, the materiality requirement also leaves physicians vulnerable to malpractice claims for failure to provide an informed consent. ${ }^{249}$ While the patient-based standard made some strides in the name of patient autonomy, it did not go far enough and in doing so increased physician vulnerability.

\section{The Status of the Current Informed Consent Systems}

Our current informed consent laws stand on a foundation of false assumptions. The physician-based standard, based on the assumption that all physicians provide a universal standard of acceptable treatment, divides

240 Joan Teno et al., Preferences for Cardiopulmonary Resuscitation: Physician-Patient Agreement and Hospital Resource Use, 10 J. Gen. Internal Med. 179, 180 (1995); Woolf, supra note 15 , at 244 .

241 Teno et al., supra note 240 , at 180 .

242 Id. at 179.

243 Id. at 184; Frosch \& Kaplan, supra note 141, at 287.

24.4 Teno et al., supra note 240 , at 182-83.

245 Frosch \& Kaplan, supra note 141, at 287; see supra pp. 2, 6 .

246 Piper, supra note 130 , at 303.

247 Id.

$248 \quad I d$

249 See id. 
patients and physicians, preserves paternalism and greatly hinders improvements in treatment and communication. Likewise, the patient-based standard relies on the belief that reasonable people all value the same health outcomes and lifestyle choices in exactly the same manner and continues to place control over what information is disseminated largely within the physician's power. Neither standard provides physicians with a clear explanation of their legal disclosure obligations, nor do they provide patients with a valid understanding of what information they have a legal right to possess. $^{250}$

Interestingly, the trend in legal regulation of medical decision-making has not consistently moved toward increased patient autonomy. Since Canterbury, a number of state courts, including Virginia, Georgia and Maine, have reaffirmed their choice of the physician-based standard. ${ }^{251}$ This reaffirmation of the physician-based standard and the continued 25-24 split amongst the states suggests considerable disagreement regarding the benefits of each standard, ${ }^{252}$ which could perhaps serve as additional evidence that the time for the individual states to consider a different and more widely acceptable standard is upon us.

In many ways, the law of informed consent has not yet achieved its most fundamental goals. As Jay Katz so eloquently stated it:

The law of informed consent is substantially mythic and fairy tale-like as far as advancing patients' rights to selfdecisionmaking is concerned. It conveys in its dicta about such rights a fairy tale-like optimism about human capacities for "intelligent" choice and for being respectful of other persons' choices; yet in its implementation of dicta, it conveys a mythic pessimism of human capacities to be choice-makers. The resulting tensions have had a significant impact on the law of informed consent which only has made a bow toward a commitment to patient's self-determination, perhaps an attempt to resolve these tensions by a belief that is "less important that this commitment be total than that we believe it to be there. ${ }^{253}$

During the last two decades, states have begun to make revisions to their informed consent laws on an ad hoc basis. ${ }^{254}$ Fourteen state legislatures passed laws mandating that physicians inform breast cancer patients of the risks and benefits associated with both mastectomy and lumpectomy. ${ }^{255}$ Six of these states were patient-based, and eight were physician-based, indicating

250 Bogardus et al., supra note 6 (discussing how doctors should approach informing patients of medical risks and the confusion surrounding their duty).

${ }_{251}$ Katz, supra note 1, at 80 (citing McMullen v. Vaughn, 227 S.E.2d 40 (Ga. 1976);

Woolley v. Henderson, 418 A.2d 1123 (Me. 1980); Bly v. Rhodes 222 S.E.2d 783 (Va. 1976)).

${ }^{252}$ Id. at 80-82.

253 Jay Katz, Informed Consent - A Fairy-Tale?: Law's Vision, 39 U. PITT. L. Rev. 137, 174. (1977).

254 See Office of Program and Policy Information, Division of Cancer Prevention and Control, Centers for Disease Control and Prevention, State Lazos Relating to Breast Cancer: Legislative Summary, January 1949 to May 2000 (2000) 3, available at http://www.cdc.gov/cancer/breast/pdf/BCLaws.pdf.

255 Id. 
the need for reform under both standards. ${ }^{256}$ Despite existing laws requiring physicians to provide patients with information on alternatives to the same extent that a "reasonably prudent physician" would or a "reasonable patient" would want, lawmakers felt that the current informed consent doctrines were insufficient to ensure that patients received information on two effective and well known forms of cancer care with equal survival rates. ${ }^{257}$ The need to create new laws to reinforce old standards is alarming. It suggests that substantial numbers of women were not receiving the appropriate information under either standard for a very clear-cut case of preferencesensitive care, where the patient's preferences mattered most in selecting a treatment. Continuing to remedy the deficiencies of the current standards on an ad hoc basis endangers both patients and physicians and should not be the road of choice.

In addition to the theoretical flaws associated with the current legal standards for informed consent, recent surveys of patient opinion and satisfaction demonstrate that many patients are dissatisfied with the quantity and quality of information they receive from physicians to assist them with treatment decisions. ${ }^{258}$ These studies reveal that patient needs are not being met by the current legal system and that fundamental changes should be made in order to successfully meet the ethical goals and obligations associated with medical decision-making. ${ }^{259}$

\section{VII.CLINICAL EVIDENCE ON THE CURRENT EFFECTIVENESS OF INFORMED CONSENT}

In recent years, researchers have performed a number of studies to evaluate the ability of the current informed consent practices to adequately inform patients' treatment decisions. ${ }^{260}$ These studies demonstrate that across medical specialties and geographic areas, current informed consent practices are falling well short of their goal. ${ }^{261}$ In fact, failure to provide sufficient information about the patient's condition and the available treatment options is the most common source of patient dissatisfaction. ${ }^{262}$

In 1997, Braddock et al. audiotaped close to five hundred physicianpatient encounters in outpatient settings in the Portland, OR area and analyzed them across six criteria of informed consent: 1) description of the

${ }^{256}$ See id. The patient-based states are California, Louisiana, Maryland, Minnesota, Pennsylvania and Texas. The physician-based states are Florida, Kansas, Kentucky, Maine, Michigan, Montana, New York and Virginia.

257 See id.

258 See Angela Coulter, Editorial, Patient Information and Shared Decision-Making in Cancer Care, 89 Brit. J. CANCer S15, S15 (Supp. 12003 ).

259 See id. at S15-S16; Angela Coulter \& Paul D. Cleary, Patients' Experiences with Hospital Care in Five Countries, 20 Health Affairs 244, 247-48 (2001); Richard Grol et al., Patients in Europe Evaluate General Practice Care: An International Comparison, 50 BRIT. J. Gen. Prac. 882, 884-86 (2000).

${ }_{260}$ See Coulter, supra note 260, at S15; Coulter \& Cleary, supra note 259, at 247-48; Grol et al., supra note 259 , at 884 .

${ }^{26 \mathrm{I}}$ See Coulter, supra note 260 , at S15; Coulter \& Cleary, supra note 259, at 247-48; Grol et al., supra note 259 , at 884 .

262 See Coulter, supra note 260, at S15; Coulter \& Cleary, supra note 259, at 247-48; Grol et al., supra note 259 , at 884 . 
nature of the condition, 2) discussion of alternatives, 3 ) discussion of the risks and benefits, 4) discussion of the uncertainties, 5) assessment of the patient's understanding, and 6) elicitation of the patient's preference. ${ }^{263}$ Overall, conversations leading to a medical decision met on average fewer than two of the above criteria (mean 1.23, median 1.0) ${ }^{264}$ Most commonly physicians discussed the nature of the condition ( $83 \%$ ), while risks and benefits and the extent of patient understanding were included much less frequently $(9 \%$ and $2 \%$, respectively). ${ }^{265}$ The amount of disclosure did increase for more significant decisions, like in-office procedures, changes in medication dosage and prescribing a new medication, such that physicians included some discussion of the risks and benefits up to $22 \%$ of the time for those decisions. ${ }^{266}$ However, discussing risks and benefits even $22 \%$ of the time falls extraordinarily short of the legal requirements and patient needs.

Braddock et al. posited two main reasons for physician failure to meet the informed consent requirements. ${ }^{267}$ Primarily, physicians felt that the procedures were so routine as to not warrant the discussion. ${ }^{268}$ As the study occurred in an outpatient setting, this perception might explain the low levels of disclosure for a number of procedures, but not for more invasive in-office procedures and prescription changes. Secondly, physicians claim that they do not have the time to have extensive discussions with patients about every medical decision. ${ }^{269}$ Interestingly, Braddock et al. pointed out that no study has been done to determine how much time increasing disclosure would add. ${ }^{270}$ Such a study would be extremely beneficial in assessing the cost effectiveness of implementing shared decision-making.

The remainder of this article focuses on the potential for shared medical decision-making to remedy the problems that exist within our current informed consent system by providing guidance to physicians on how much and what kind of information to disclose to patients. A number of legal and medical scholars have advocated that physicians and patients should go through the process of shared medical decision-making in making nearly all treatment decisions. ${ }^{27}$ The procedural and structural changes that must be made within the medical system to implement shared medical decisionmaking in routine practice, however, have created a great debate amongst scholars regarding the practicality of imposing it as a legal requirement. ${ }^{272}$ The next section analyzes both the benefits and risks of modifying the legal

263 Clarence H. Braddock et al., How Doctors and Patients Discuss Routine Clinical Decisions, 12 J. Gen. Internal Med. 339, 340 (1997).

$264 \quad I d$. at 339 .

$265 I d$.

$266 \quad I d$. at 342 .

$267 I d$. at 34.4

$268 I d$.

$269 I d$.

$270 \quad I d$.

27 Katz, supra note 1 , at xiii-xxi. Wennberg \& Peters, supra note 1, at 937; see also Angela Coulter, Editorial, Shared Decision-making: The Debate Continues, 8 Health Expectations 95-96 (2005).

${ }^{272}$ See Steven H. Woolf et al., Promoting Informed Choice: Transforming Health Care to Dispense Knowledge for Decision Making, 143 Annals Internal Med. 293, 293 (2005) (discussing the procedural and structural changes necessary to implement and difficulties in implementing shared decision-making in routine practice). 
disclosure standard to require patients and physicians to engage in shared medical decision-making.

\section{SHARED MEDICAL DECISION-MAKING}

The most recent species to arise in the evolution of informed consent is shared medical decision-making. While shared medical decision-making could be considered one appropriate form of patient-based consent, it goes two steps further by incorporating evidence-based medicine and by requiring both the patient and the physician to contribute information and participate in the decision-making process. ${ }^{273}$ The goal of shared decision-making is to strike a compromise between the preservation of individual autonomy afforded by the subjective patient-based standard and the practicality of the objective patient-based standard. ${ }^{274}$ As under the subjective patient-based standard, physicians or decision counselors engaging in shared decisionmaking would remain responsible for answering all of the patient's questions and addressing their concerns regarding the procedure. ${ }^{275}$ Unlike the subjective-based standard, however, physicians will have access to a more clearly defined and in some cases standardized set of information that should be initially disclosed. ${ }^{276}$ Under shared decision-making, physicians and decision counselors should assist patients to identify their personal values relevant to the treatment decision. ${ }^{277}$ The objective patient-based standard sought to protect physicians by only making them responsible for conveying "material" information on treatments that a "reasonable" patient would want. ${ }^{278}$ Unfortunately, as demonstrated in prior sections, ${ }^{279}$ neither physicians nor patients seem to agree on what information is material to making an informed decision and often treatment decisions are made that the patient would not desire if he or she had received additional information. ${ }^{280}$ In an effort to provide patients with sufficient information, enable them to have their personal questions addressed, and prevent physicians from being endlessly vulnerable to lawsuits, we propose modifying the current patientbased standard to incorporate shared decision-making as a prerequisite to the

273 See Cathy Charles et al., Shared Decision-making in the Medical Encounter: What Does It Mean? (Or it Takes at Least Two to Tango), 44. Soc. ScI. \& MED. 681, 687 (1997).

${ }^{274}$ See generally Simon N. Whitney et al., A Typology of Shared Decision Making, Informed Consent, and Simple Consent, 140 AnNals InTERNAL Med. 54 (2004) (distinguishing shared decision-making from the traditional legal doctrine of informed consent).

275 See Scott, 606 P.2d at 557.

${ }^{276}$ See Charles, supra note 273 , at 684 (suggesting that the requirements of share decision-making include interventions that not only provide patients with information, but also with a way of thinking about treatment decision-making that helps patients focus on key issues and evaluate relevant options).

277 Id. at 687.

278 See supra Part IV.B.2.a.

279 See supra Parts V.A, V.A.3.

280 Center for the Evaluative Clinical Sciences, supra note 7 , at 170-177; Feldman-Stewart, supra note 8, at 46-54. 
provision of an informed consent for medical care, excepting emergency care and minimally invasive, highly effective care. ${ }^{281}$

Our proposal alters the current patient-based standard in two ways. First, it significantly reduces the guesswork required of physicians. The required disclosure will be broadened to include any information that could be relevant, rather than material, to a reasonable patient making the decision. Information is relevant if $1 \%$ of the patient population would want to know of a specific risk, alternative or potential outcome in making the decision. The relevancy standard expands the amount of required disclosure substantially and improves patients' abilities to receive necessary information, but in doing so creates some substantial practical problems.

On its own, this standard would impose an extremely burdensome requirement on physicians to gather, synthesize and remain up-to-date on both medical and health services information for complex decisions. In these situations, decision aids and other guidelines for disclosure prove indispensable. Over the last decade, use of decision aids has grown substantially to help patients make medical decisions. ${ }^{282}$ Decision aids, such as the ones created by The Foundation for Informed Medical DecisionMaking (FIMDM) in collaboration with Health Dialog, collect and analyze the latest clinical evidence regarding the risks and benefits of different treatment options and then present the information in a manner patients can understand. ${ }^{283}$ These aids are created and reviewed by clinical researchers, practicing physicians, health services researchers and biostatisticians on a semiannual basis to ensure both the accuracy and integrity of the information conveyed. ${ }^{284}$ The decision aids provide information on the pros and cons of each option in an unbiased manner. ${ }^{285}$ In addition, the aids often offer explanations for why in some cases there is a lack of evidence to support one treatment over another. ${ }^{286}$ Patient video decision aids often include interviews and testimonies from both patients and physicians regarding both good and bad experiences in an attempt to provide the full range of possible outcomes. ${ }^{287}$ Once patients have received this information and had time to digest it, their communication with their physician proves significantly more fruitful. $^{288}$ Another method of assisting patient decision-making is through

${ }^{281}$ One possible way of identifying minimally invasive, highly effective care is through the United States Preventative Services Task Force, which has created a system of evaluating medical treatments for invasiveness and effectiveness. See U.S. Preventative Services Task Force (USPSTF), http://www.ahrq.gov/clinic/uspstfix.htm (last visited May 1, 2006).

${ }_{282}$ Cathy Charles et al., Treatment Decision Aids: Conceptual Issues and Future Directions, 8 Health Expectations 114, 114 (2005).

283 Foundation for Informed Medical Decision-Making, Decision Support and Shared Decision-Making, http://www.fimdm.org/decision_sdms.php (last visited August 30, 2006); see also Health Dialog, www.healthdialog.com (last visited August 30, 2006).

${ }^{284} I d$. For more information on how decision aids are created, see Foundation for Informed Medical Decision-Making, Decision Aids and Shared Decision-Making, Program Development and Updates, Foundation Procedures for Development of Decision Aids, www.fimdm.org/decision_sdms.php (last visited August 30, 2006).

285 Foundation for Informed Medical Decision-Making, supra note 283.

$286 I d$.

$287 \quad I d$

288 Annette O'Connor et al., Decision Aids for Patients Facing Health Treatment or Screening Decisions: Systemic Review, 319 BMJ 731, 732-733 (1999). 
the decision coach. ${ }^{289}$ These individuals prepare patients to have a meaningful conversation with the physician by assisting them to weigh the relative risks and values of each treatment option for themselves. ${ }^{290}$ Decision coaches and videos both use strategic communication tactics to improve patient understanding and avoid patient bias. For instance, disclosing risk information in both qualitative and quantitative terms can prove very helpful for patients who may relate better to one form of information. ${ }^{291}$ Another widely effective method for assisting patients with risk information is to associate treatment risks with risks in every day life, such as having a car accident, catching the flu, or stubbing one's toe. ${ }^{292}$ Decision aids are used to not only clarify decisions for patients, but also to help them identify their own values and perceptions of different outcomes.

Decision aids are currently being integrated into the health care system through a number of different avenues. Dartmouth-Hitchcock Medical Center, for example, has created its own Center for Shared Decision-Making which offers patients free access to a decision coach, a library of decision aids covering a wide range of conditions, as well as health care decision guides which can assist a patient in working through their preferences and values regarding a treatment decision. ${ }^{293}$ The Ottawa Health Research Institute (OHRI) has created a vast inventory of decision aids that allows both physicians and patients to search for a condition and locate an appropriate decision aid. ${ }^{294}$ The OHRI database provides information on who developed the decision aid, when it was created, where it can be found, and how reliable the information is based upon the CREDIBLE criteria for decision aid evaluation developed by OHRI. ${ }^{295}$ Companies like Health Dialog also provide services to employers and insurance companies that assist their employees and insureds to use shared decision-making and decision aids in making medical decisions. ${ }^{296}$ Health Dialog has experienced a great amount of success by offering its decision aid videos, information and counseling services to large corporations and insurance companies. ${ }^{297}$ It has also become one of the fastest growing private companies in the country, covering about 16 million individuals. ${ }^{298}$ Shared decision-making and the use of decision aids to make medical decisions are becoming much more widely used as both the

289 Woolf et al., supra note 272, at 296.

$290 \quad I d$.

291 See Bogardus et al., supra note 6, at 1039-40.

292 See id. at 141.

293 Dartmouth Hitchcock Medical Center, Center for Shared Decision-Making, http://www.dhmc.org/webpage.cfm?site_id=2\&org_id=108\&gsec_id=0\&sec_id=0\&item_id=2 486 (last visited Aug. 30, 2006).

294. Ottawa Health Research Institute, A-Z Inventory of Decision Aids, http://decisionaid.ohri.ca/AZinvent.php (last visited Aug. 30, 2006).

${ }_{295} I d$. We will discuss the importance of evaluating decision aids through methods like the CREDIBLE criteria in later in this section.
296 See Health Dialog, Collaborative
Care, www.healthdialog.com/hd/Core/CollaborativeCare/CCToolsResources.htm (last visited August 30, 2006).

297 See Health Dialog Awards, http://www.healthdialog.com/hd/Ancillary/Aboutus/awards.htm (last visited Oct. 11, 2006) (listing awards Health Dialog's communications materials have received).
298 See
Health
Dialog
History,

http://www.healthdialog.com/hd/Ancillary/Aboutus/history.htm (last visited Oct. 11, 2006). 
news of improved patient decision-making and satisfaction spreads, as well as the resources needed for broader implementation become more available.

Unfortunately, decision aids are not available for every major medical decision. The creation of good decision aids is expensive and time consuming. ${ }^{299}$ FIMDIM generally begins by running a number of focus groups with a broad spectrum of both patients and physicians to determine not only the pros and cons of certain types of care, but the full range of opinions, perspectives and experiences. ${ }^{300}$ Discussions with providers also add a context to what type of information patients will be receiving from their physicians, as well as what pressures exist for doctors in making the relevant decisions. ${ }^{301}$ Next, a medical editor, usually a general practitioner who has done research in the area, will work with a team of researchers to produce an evidence document which summarizes all of the clinical information that patients have expressed an interest in knowing. ${ }^{302}$ Finally, the decision aid must be produced, usually in the form of a patient video with volunteer testimony, and then critically evaluated by medical editors, patient representatives, clinical advisors, etc. ${ }^{303}$ All of this takes about 6-9 months and costs around $\$ 150,000$ to $\$ 200,000 .^{304}$

While a number of organizations are working on creating new decision aids and expanding the available resources, decision aids, while preferable, are not essential to the practical ability to engage in shared decision-making. Other resources exist to provide synthesized, up-to-date information to physicians in a quick and easy manner. For instance, The Cochrane Collaboration has created an immense database that systematically reviews clinical evidence, synthesizes it and provides summaries to physicians. ${ }^{305}$ The Cochrane summaries and others like them allow physicians to provide patients with accurate clinical information on different treatment options as well as the strengths and weaknesses of the evidence. ${ }^{306}$ Physicians can then engage patients in shared decision-making by discussing with the patient the benefits and risks of each treatment option for their particular lifestyle and values. Just discussing what knowledge the doctor has with the patient, giving the patient time to process the info, think of questions, discuss their concern and decide their role will greatly improve our informed consent system.

On the other hand, decision aids have the potential to be biased or potentially misleading. To ensure an unbiased and informed disclosure, the information provided in decision aids should be approved by credentialed, neutral bodies made up of lay people, physicians and researchers who are trained to make such decisions, not individual physicians. Requiring decision aids to be credentialed assists physicians in two ways: 1) if they use the

\footnotetext{
299 Interview with Jack E. Wennberg, supra note 167.

$300 \quad$ See Foundation for Informed Medical Decision-Making, supra note 283.

301 See id.

${ }_{302}$ See id.

303 See id.

304 Interview by Ben Moulton with Floyd J. Fowler Jr., President of the Foundation for Informed Medical Decision Making (2006).

305 The Cochrane Collaboration, Library Introduction,

http://www.cochrane.org/reviews/clibintro.htm (last visited October 14, 2006).
306 Id.
} 
decision aid, they know that it has been judged fair and unbiased by a neutral body and will inform their patients; and 2) even if they decide not to use the aid with patients, physicians can use the aids as references for determining their own disclosure practices. By creating a credentialing body to certify that these decision tools present the relevant potential risks and benefits of treatment in an explicit and neutral manner, physicians can have easy access to the initial set of information that they should provide to their patients. ${ }^{307}$

After the patient has received the decision tool or the relevant information from their physician, they should engage in a process of shared decisionmaking, in which the physician or decision coach assists the patient in identifying their own personal values associated with the relevant risks and benefits. $^{308}$ This process can help patients to personalize the information and appreciate the scientific uncertainty associated with their treatment options. The physician and patient consider together how each option coincides with the patient's preferences for risk taking and health outcomes and hopefully results in a mutual decision on treatment. ${ }^{309}$ During this discussion, patients have the opportunity to raise individual concerns or questions not previously addressed. Physicians should also provide patients with additional information if their values or questions suggest that it would be pertinent to the individual patient's decision. At the end of the discussion, the patient will sign an informed consent that acknowledges that he or she has engaged in shared decision-making with the physician and that all of his or her questions have been answered sufficiently to permit the patient to agree to the specific treatment decision. While this approach to informed consent has not yet been fully recognized by the courts, shared decision-making is gaining momentum within the medical community as the most effective way to make treatment decisions that involve significant tradeoffs, such as elective surgery vs. conservative management. ${ }^{310}$

In evaluating shared medical decision-making in comparison to our current methods of obtaining informed consent, it is important to establish the overarching goals of medical decision-making and an informed consent system. This brings us back to the question regarding whether a physician has a stronger ethical obligation to respect patient autonomy or act with beneficence. What happens when these goals conflict with one another? Most importantly, should we establish a legal system that favors patient autonomy over patient health?

According to Anglo-American legal tradition, freedom is based upon the notion of autonomous self-determination. ${ }^{311}$ The Supreme Court, in Cruzan, ${ }^{312}$ affirmed the right of an individual to refuse life-saving treatment, and even more recently in Gonzales v. Oregon, ${ }^{313}$ upheld the state of Oregon's

\footnotetext{
307 See Frosch \& Kaplan, supra note 141, at 291.

308 See O'Connor et al., supra note 167 , at 64 .

309 See id.

310 Frosch, supra note 141, at 287; Pamela J. McCabe \& Penny Kalpin, Bold Voices in Progressive Care Using Shared Decision Making to Implement Evidence-Based Practice in Progressive Care, 25 Critical Care Nurse 76, 76 (2005); O'Connor et al., supra note 141, at

See Natanson, 350 P.2d at 1104 .

Cruzan v. Dir., Mo. Dept. of Health, 497 U.S. 261, 278 (1990).

Gonzales v. Oregon, 126 S. Ct. 904 (2006).
} 63-64. 
right to permit an individual to decide to take medication in an effort to accelerate his or her own death. ${ }^{314}$ These decisions clearly establish the primacy in the law of an individual's autonomy over her health and the ability of a competent individual to make medical decisions that may not be in her best medical interest. With this outer boundary in mind, we must consider how much discretion physicians should have in determining what information to provide patients, even when the provision of information might dissuade the patient from pursuing medical treatment the physician feels is necessary. From a legal standpoint, if the patient is mentally competent, the physician should discuss with him or her all of the relevant information, the risks and benefits, and the physician's medical opinion. Physicians should not refuse to disclose relevant information in an effort to ensure that a patient makes the "correct" medical choice. As the research demonstrates, physicians are not very good at deciding what treatments patients would choose if they had all of the information, ${ }^{315}$ and the law should not pass an individual's autonomy and bodily integrity over to physicians to make decisions that will not only impact the individual's medical status, but their quality of life as well. ${ }^{316}$ Even in patient-based states, disclosure is based on what the physician thinks a reasonable person in that situation would want to know. ${ }^{317}$ In the face of substantial evidence suggesting that patients would decide differently than the physician if given all of the information and that patients do not feel that their informational needs are being met, the time for the law to provide unquestioned deference to the choices of physicians is now over.

Establishing a medical disclosure standard that remedies the failures of the current standards, preserves patient autonomy, improves communication between physician and patient, and works well in everyday practice will not be easy. While shared medical decision-making is a promising candidate to obtain these goals, implementing it as a prerequisite to a legal informed consent will be fraught with challenges. The following sections discuss the benefits and detriments of incorporating shared medical decision-making into the legal informed consent framework.

\section{A. Benefits of Shared Medical Decision-Making}

Shared medical decision-making offers substantial benefits to both patients and physicians in negotiating treatment decisions. First and foremost, shared medical decision-making improves patient autonomy. This aids patients in two ways: 1) it satisfies their desire for more information and inclusion, and 2) it improves their overall wellbeing. ${ }^{318}$ Mazur and Hickam found that $78.5 \%$ of patients wanted to share authority with the physician or have a majority of the decision-making power in medical decisions. ${ }^{319}$

\footnotetext{
$314 \quad I d$. at 904.
}

315 Teno et al., supra note 240, at 183-84.

316 See id. at 184-85.

317 Canterbury, 464 F.2d at 787 (citing Jon R. Waltz \& Thomas W. Scheuneman, Informed Consent to Therapy, 64 Nw.U. L. REv. 628, 639-40 (1970)).

318 Guadagnoli \& Ward, supra note 229 , at 332 (1998).

319 Dennis J. Mazur \& David H. Hickam, Patients' Preferences for Risk Disclosure and Role in Decision Making for Invasive Medical Procedures, 12 J. Gen. Internal Med. 114, 116 (1997). 
Levinson et al. supported this by finding that $96 \%$ of patients preferred to be offered choices, asked their opinions, and included in the decision-making process. ${ }^{320}$ Patients, however, feel strongly that the physician's opinion should remain an integral part of the treatment decision process. ${ }^{321}$ Under shared decision-making, patients will be able to receive the information they desire, have an opportunity to ask questions and determine how much they would like to participate in making the final decision. Once fully informed and having discussed the issue with physicians, patients may defer entirely to their physician, collaborate with him or her, or make the final decision alone. In addition, patient preferences for involvement and treatment choices may change over time, which further supports shared decision-making's process approach that maintains an open discussion between the patient and the physician throughout the all phases of treatment. Therefore, shared medical decision-making would accommodate both patients' continued need for information and inclusion, as well as their varied desires for participation in making the final decision.

Clinical evidence suggests involving the patient in the process may also improve overall physical and mental health. ${ }^{322}$ Even minimal amounts of involvement, such as providing patients with information on their condition and the alternative treatment options, have led to improved outcomes in a few studies. ${ }^{323}$ Numerous studies have shown that increased patient involvement and participation leads to improved psychological and well-being outcomes. ${ }^{324}$ For instance, Brody et al. found that patients who exhibited a more active role in their health care experienced less discomfort $(\mathrm{p}=.04)$; greater reduction of symptoms $(p=.008)$; more improvement in general medical conditions $(p=.04)$; a greater sense of control $(p=.04)$; less concern with the illness $(p=.04)$; and a greater sense of satisfaction with the physician $(p=.02)$ than more passive patients one week after the visit. ${ }^{325}$ In a study of early stage

320 Wendy Levinson et al., Not All Patients Want to Participate in Decision Making: $\boldsymbol{A}$ National Study of Public Preferences, 20 J. Gen. INTE RNAL MED. 531, 532 (2005).

321 James L. Bernat \& Lynn M. Peterson, Patient-Centered Informed Consent in Surgical Practice, 141 Archives of SuRgery 86, 87 (2006); Dennis J. Mazur et al., The Role of Doctor's Opinion in Shared Decision Making: What Does Shared Decision Making Really Mean When Considering Invasive Medical Procedures?, 8 Health EXPECTations 97, 102 (2005).

322 David S. Brody et al., Patient Perception of Involvement in Medical Care: Relationship to Illness Attitudes and Outcomes, 4 J. Gen. Internal Med. 506, 510 (1989); Angela Coulter, Assembling the Evidence: Patient-Focused Outcomes Research, II HEALTH LIB R. REv. 263, 264 (1994); Levinson, supra note 320, at 531.

${ }^{323}$ Guadagnoli \& Ward, supra note 229, at 332; Sherrie H. Kaplan et al., Assessing the Effects of Physician-Patient Interactions on the Outcomes of Chronic Disease, 27 MED. CARE S110, S118-19 (Supp. 1989).

324 See David S. Brody et al., supra note 322, at 510; David S. Brody et al., The Relationship Between Patients' Satisfaction With Their Physicians and Perceptions About Interventions They Desired and Received, 27 MED. CARE 1027, 1032-33 (1989); B.J. Evans et al., A Communications Skills Programme for Increasing Patient Satisfaction with General Practice Consultations, 6 o Brit. J. Med. Psychol. 373, 373-378 (1987); L.J. Fallowfield et al., Psychological Outcomes of Different Treatment Policies in Women with Early Breast Cancer Outside A Clinical Trial, 301 BRIT. MED. J. 575, 577-79 (1990); Guadagnoli, supra note 318, at 333-335 (citing J. Ashcroft et al., Mastectomy vs. Breast Conservation: Psychological Effects of Patient Choice of Treatment, in Psychological Issues in Malignant Disease 55-71 (M. Watson \& S. Creer eds. 1986)).

${ }_{325}$ Brody et al., supra note 322 , at 510 . The ' $\mathrm{p}$ ' value associated with each result indicates the level of statistical significance. Typically, statistically significant results must 
breast cancer patients by Morris and Royle, patients who were not given a choice of surgery experienced greater depression and anxiety before the surgery $(p<.05)$, as well as two months after the surgery $(p<.05) .^{326}$ Interestingly, four months after surgery no significant difference existed between patients given a choice and those that were not. ${ }^{327}$ Pre-operative education has also been associated with improved recovery time and reduced patient anxiety. ${ }^{328}$ While the long term effects of choice and involvement in treatment decisions may be limited, reducing substantial anxiety and depression prior to and in the months after surgery remains an important and worthy goal.

In addition, a handful of studies have connected increased patient involvement with improved treatment outcomes. ${ }^{329}$ For instance, Shulman rated ninety-nine hypertensive patients based on their active involvement in the treatment process. ${ }^{330}$ Those patients with a greater active-patient orientation were more likely to have their blood pressure under control and to comply with the treatment regimens than those who scored lower on the scale. $^{331}$ This most likely occurred because the patient felt more invested in the treatment choice and was more informed about why certain elements of the treatment were necessary. Kaplan, Greenfield and Ware also found that patients who had less control in conversations with their physician, were less involved in the medical decision, and expressed less opinions and emotion with their physicians experienced poorer control of diabetes and hypertension than their counterparts. ${ }^{332}$ Also, breast cancer patients that expressed greater control in conversations with their physicians and revealed more information to their physician tended to experience less symptoms during chemotherapy $(p<.05){ }^{333}$ In contrast, breast cancer patients experienced more symptoms during chemotherapy when the physician had more control, provided the patient more information than the patient provided back, and experienced a negative affect. ${ }^{334}$ This finding may indicate that the opportunity for the patient to share personal information and goals is integral to obtaining health benefits from the increased discussion in shared decision-making. Being able to discuss and select a treatment choice that is more likely to reflect ones' own

have a $95 \%$ or higher probability that the results in the given data did not occur by chance. A 'p' value of .05 signifies that there is a $95 \%$ probability that the finding of these results did not occur by chance. Generally, in order to have statistical signicance, 'p' must be less than or equal to .05 .

${ }_{326}$ J. Morris \& G. Royle, Choice of Surgery for Early Breast Cancer: Pre and Postoperative Levels of Clinical Anxiety and Depression in Patients and Their Husbands, 74 BrIT. J. SURGERY 1017, 1018 (1987).

$327 \quad I d$.

328 Gail C. Webber, Patient Education: A Reviete of the Issues, 28 MED. CARE 1089, 1099 (1990).

${ }^{329}$ Kaplan, supra note 323, at S119-120; P. Mendonca \& S. Brehm, Effects of Choice on Behavioral Treatment of Overweight Children, 1 J. Soc. Clinical Psychol. 343, 343-358 (1983); Beryl A. Schulman, Active Patient Orientation and Outcomes in Hypertensive Treatment, 17 MEd. CARE 267, 270 (1979).

330 Shulman, supra note 329, at 269-270.

331 Id. at 271-72.

332 Kaplan, supra note 323 , at $\mathrm{S} 120$.

${ }_{333}$ Id .

334 Id. 
values or fit into one's lifestyle makes treatment completion more probable. ${ }^{335}$ While other studies have seen no effect from increased patient involvement, the majority of research finds an association between increased patient involvement in decision-making and improved psychological and minor health outcomes. ${ }^{336}$ As Angela Coulter acknowledged over a decade ago, most medical procedures are not performed to save an individual's life, but to improve their quality of life. ${ }^{337}$ Therefore, if the goal is to make their day-today life better, it makes no sense to ignore patient preferences about treatment choices. ${ }^{338}$

It also makes little sense to ignore patients' preferences about their role in decision-making. Nancy Keating and colleagues found that while many patients want to be given information and be involved in the decision, patient preferences for the role they play in treatment decisions vary widely. ${ }^{339}$ Of the 1,081 patients surveyed, $97 \%$ preferred to be provided with substantial information on their treatment choices. ${ }^{340}$ A majority of all patients (64\%) preferred a collaborative role, in which the physician discusses the alternatives with the patient and then the two of them decide which treatment choice is best. $^{341}$ This collaborative model represents the traditional shared decisionmaking model. ${ }^{342}$ However, both patients who prefer to be provided with information including the physician's recommendations and then decide whether to agree (9\%), and patients who prefer to receive all relevant information and make the decision on their own (24\%) could be accommodated by the shared decision-making model proposed in this paper (97\% in all). ${ }^{343}$ Patients should be offered all information and then granted the opportunity to determine how much they want to participate in making the decision. Keating et al. found that patients whose actual role in decisionmaking matched their preferred role were "more likely to be very satisfied with their choice of therapy compared to those patients who received a more active or a less active role in decision-making than they desired." 344 of all patients stating their actual role was more active than desired, $79 \%$ preferred a collaborative decision-making process and were forced to make the decision on their own without physician assistance. ${ }^{345}$ Shared decision-making would greatly improve the treatment decision-making process in these cases by offering physician input, without hindering the ability of other patients who prefer to make the decision all on their own. In addition, only $3 \%$ preferred to have the physician make the decision with little input from the patient. ${ }^{346}$ For such individuals, they have the option to refuse to review the information or to

335 Guadagnoli \& Ward, supra note 229, at 332.

336 Id.; Kaplan, supra note 323, at S118-19.

337 Coulter, supra note 322 , at 265.

$338 \quad I d$. at 268.

339 Nancy L. Keating et al., Treatment Decision Making in Early-Stage Breast Cancer: Should Surgeons Match Patients' Desired Level of Involvement?, 20 J. ChINICAL ONCology 1473,1473 (2002).

$340 \quad I d$. at 1476

341 Id. at 1475 .

342 Id. at 1476 .

343 Id. at 1475-76.

$344 \quad I d$. at 1476 .

345 Id.

346 Id. 
review the information and leave the final decision up to the physician. Their autonomy is not compromised by a shared decision-making standard as they can still leave the decision up to the physician. This result is largely different from the current situation, which protects the autonomy of the small percentage of individuals who do not want additional information, but not those who do. As a result, establishing open communication between physician and patient via shared decision-making to allow the patient to disclose their preferences for their role in decision-making can greatly improve the physician-patient relationship and treatment decision-making for many patients without compromising the decision-making preferences of others.

Physicians also stand to benefit from engaging in a shared medical decision-making process with their patients. Shared medical decision-making provides physicians with more insight into their patients' lives and their ability to tolerate the negative effects of certain treatment options. This information will improve a physician's capacity to advise his or her patient on treatment choices. Additionally, such conversations will strengthen the bonds between patient and physician, assist with mutual understanding and potentially reduce feelings of responsibility and blame if complications occur. Finally, if physicians have engaged in a thorough process of shared medical decision-making with the patient and documented it, the medicolegal liability should be greatly reduced because of improved communication with the patient and a better understanding of their goals. ${ }^{347}$ Physicians James Bernat and Lynn Peterson probably said it best when they described shared medical decision-making as the "best blending of physician expertise and patient choice." ${ }^{\text {348 }}$ In other words, performed correctly, shared medical decisionmaking establishes the balance between patient autonomy and beneficence.

In some cases, the potential benefits of shared medical decision-making could extend to the entire U.S. health care system. As noted by researchers from the Dartmouth Center for Evaluative Clinical Sciences, "[c]hanging the practice of medicine so that treatment choices reflect patient preferences has the potential to radically change the consumption and quality of health care." ${ }^{349}$ According to their research, the amount of care provided in a shared medical decision-making environment might be substantially less than under the current system. ${ }^{350}$ Although managed care has eliminated a substantial amount of unnecessary care from the health care system, the modern system still pays some general practitioners and specialists by procedure. ${ }^{351}$ In cases of preference-sensitive care, where a number of acceptable treatment options exist, instead of assisting the patient to come to the best decision for their lifestyle and preferences, physicians often advise patients to have a procedure rather than conservatively manage the condition even when both courses of action have the same long term prognosis in order to make additional money and guard against malpractice liability. Shared medical decision-making

347 Huntington \& Kuhn, supra note 220, at 160; Vincent et al., supra note 220, at 1613; Woolf et al., supra note 272 , at 298 .

348 Bernat \& Peterson, supra note 321, at 87.

349 Center for the Evaluative Clinical Sciences, supra note 5 , at 5.

$350 \quad I d$.

351 Feldstein, supra note 212, at 115-19. 
reduces the demand for certain forms of preference-sensitive care, such as prostatectomies by up to $40 \%$, because when given the option, some patients prefer to decline or wait to receive care. ${ }^{352}$ This could not only result in a reduction in costs, but also a reduction in complications from unnecessary procedures. While these trends should be researched in more depth to determine the long term cost effectiveness of shared decision-making to reduce spending money on unwanted care, current data suggests that the U.S. may be able to reduce medical services and expenditures by simply listening to patient preferences and providing them only with beneficial care they desire.

\section{Challenges and Risks of Shared Medical Decision-Making}

Despite these potential benefits, a number of physicians have recently spoken out against the practicalities of implementing shared medical decision-making in medical practice, and especially as a legal requirement. ${ }^{353}$ The criticisms of shared medical decision-making can be divided into three categories: 1) time, expense and resources; 2) communication challenges; and 3) patient needs and expectations. ${ }^{354}$ Each provides a distinct hurdle that the medical system would have to surmount in order to implement shared medical decision-making effectively. However, overcoming these obstacles would greatly improve medical decision-making for both patients and providers.

\section{a. Time, Expense and Resources}

First and foremost, critics claim that implementing shared decisionmaking in a meaningful way requires overcoming immense hurdles only surmountable by investing enormous amounts of time and money. Many physicians have also argued that shared medical decision-making will require substantial changes in their practice that are unsustainable in the current medical environment. ${ }^{355}$ Time pressure, financial incentives, resource constraints and concerns over physician autonomy all threaten the ability of shared medical decision-making to provide a practical solution to the current failings of our informed consent system. However, the magnitude of these limitations may be reduced over time through innovative solutions.

\section{i. The Current Patient-Based Standard}

In today's medical practice, time is of the essence. Physicians argue that they do not have time to examine every possible angle of a medical decision with every patient. ${ }^{356}$ Time pressures have increased for physicians in the last two decades, as managed care has financially incentivized seeing more patients in less time. Undoubtedly, shared decision-making will require more

352 Center for the Evaluative Clinical Sciences, supra note 144, at 226.

353 Maria J. Silveira \& Chris Feudtner, Letter to the Editor, Shared Medical DecisionMaking, 293 JAMA 1058, 1058 (2005); Woolf et al., supra note 272, at 295; Woolf \& Krist, supra note 13 , at 1871 .

354 Woolf et al., supra note 74, at 294-95.

355 See Woolf \& Krist, supra note 13, at 1871-72.

356 Braddock et al., supra note 263, at 339-345; Woolf et al., supra note 272 , at 295 ; Woolf \& Krist, supra note 13, at 1871. 
physician time initially. Physicians, assistants and decision coaches must be trained to learn shared decision-making protocols and procedures. However, decision aids and other decision management tools can greatly reduce the time the physician would need to dedicate to shared medical decision-making. For instance, a physician could send a patient home with a video or informational pamphlet to review with his or her family and then schedule a discussion for another day. This would enable the patient to absorb the material and consider his/her concerns and questions prior to meeting with the physician, so that the discussion is more efficient and fruitful. For more complex decisions, physicians may recommend that patients see a decision coach in order to sort through their relevant preferences, values and goals. Both of these strategies will reduce the amount of time the physician spends gathering information and providing it to the patient, while also enabling the shared decision-making discussion to be more in depth and productive. While there will certainly be a substantial initial time investment required in order to train physicians to properly engage in shared decision-making and implement a system that incorporates the distribution of decision aids and other information, this investment would pay off over time by reducing the overall time needed to engage in shared decision-making. FIMDM is currently conducting research on the time, expense and practical issues associated with integrating shared decision-making into medical practice. ${ }^{357}$ This and other research on implementation strategies will prove invaluable to assessing the resources required to properly implement a shared decisionmaking system.

\section{ii. Financial Incentives}

Similar to time pressures, the current financial incentives for physicians generally work against the practice of shared medical decision-making. Physicians are not reimbursed for additional time spent with each patient discussing the decision. ${ }^{358}$ In addition, Wennberg has shown that a consistent practice of shared medical decision-making may lead to a reduction in medical services as many patients would forego care if they had all of the facts. ${ }^{359}$ Woolf and colleagues point out that less treatment will provide less financial reward for physicians, again reducing the incentive for their support of shared medical decision-making. ${ }^{360}$

However, participating in shared medical decision-making may produce hidden financial incentives for physicians in the form of reduced malpractice claims and managed care organization incentives for performing shared medical decision-making. In a recent review of studies reviewing why patients sue physicians, Huntington and Kuhn found that "overwhelmingly, the dominant theme in these studies' findings was a breakdown in the patientphysician relationship, most often manifested as unsatisfactory patient-

357 Foundation for Informed Medical Decision Making, Research Agenda, http://www.fimdm.org/research_agenda.php (last visited October 18, 2006).

${ }_{358}$ Woolf \& Krist, supra note 13, at 1871.

359 Center for the Evaluative Clinical Sciences, supra note 144, at 226-27.

360 See Woolf et al., supra note 347 , at 295; see also David Blumenthal, Decisions, Decisions: Why the Quality of Medical Decisions Matters, Health AfF. (Web exclusive) VAR 124, VAR 126-127 (2004). 
physician communication," led to the decision to file suit. ${ }^{361}$ Not all patients who are injured sue their physician, and not all patients who sue were negligently injured. In fact, of the 94 patients who did sue, $41.4 \%$ responded that the physician could have done something after their injury to prevent them from taking legal action, while $60 \%$ stated that some form of communication after the incident could have prevented the suit. ${ }^{362}$ Common complaints from patients who sued their physician for malpractice included that the physician would not listen, would not talk openly, attempted to mislead them, or did not warn them of long term complications. ${ }^{363}$ Shared decision-making could address many of these communication difficulties between physician and patient and potentially lead to a reduction in medical malpractice claims.

In addition, managed care organizations may find that it is in their best interest to provide financial incentives to reward physicians for engaging in shared decision-making with patients. Clinical data shows that in general when patients are provided substantial information and engage in shared decision-making the amount of care used declines. ${ }^{364}$ Incentivizing physician participation in shared decision-making could save managed care companies more money than encouraging them to rush through more patients in less time, inspiring patient dissatisfaction, confusion, and potentially additional expenses in unwanted care.

\section{iii. Resource Constraints}

Resource constraints also limit the ability of shared medical decisionmaking to be easily implemented into every physician practice. Creating, credentialing and disseminating current decision aids for all medical procedures with alternative treatment options presents an expensive, time consuming, labor-intensive task. However, a number of organizations worldwide, such as The Cochrane Collaboration, Health Dialog and The Ottawa Health Research Institute, have begun creating these decision aids and have already accumulated a large library of resources. ${ }^{365}$ More work in this area is certainly required, but successful methods for constructing the decision aids and credentialing them are already in progress.

The expense of incorporating the process of shared decision-making into all non-emergency medical decisions, excepting those that involve minimally invasive and highly effective treatments, is likely to be substantial. Although the exact economic costs are unknown at this point, the increase in physician time spent with patients and/or the added salaries of decision coaches will prove expensive endeavors for the medical system. However, these costs may be offset by reductions elsewhere in the system. For instance, improved

361 Huntington \& Kuhn, supra note 220, at 157.

362 Vincent et al., supra note 220 , at 1612 (finding the breakdown of those for whom some form of communication would have prevented a lawsuit to be as follows: explanation and apology $37 \%$; admission of negligence $14 \%$; listened and not treated as neurotic $5 \%$; and honesty $4 \%$ ).

363 Huntington \& Kuhn, supra note 220, at 157.

364 Center for the Evaluative Clinical Sciences, supra note 5, at 6.

${ }_{365}$ The Cochrane Collaboration, http://www.cochrane.org (last visited Oct. 18, 2006); Health Dialog, http://www.healthdialog.com/hd (last visited Oct. 18, 2006); The Ottawa Health Research Institute, http://decisionaid.ohri.ca/index.html (last visited Oct. 18, 2006). 
communication and patient satisfaction that are widely associated with shared decision-making could reduce frivolous malpractice claims. Secondly, the reduction of expenses in providing unwanted care and treating the side effects or iatrogenic harms resulting from such unwanted care will help offset additional spending on shared decision-making. Finally, patients receiving treatment for chronic conditions who engage in shared decision-making are more likely to maintain their treatment regimen, thereby reducing future health care costs. While the overall cost effectiveness of shared decisionmaking has not yet been proven, critics' claims that it will raise health care expenditures significantly are equally unproven. ${ }^{366}$ Cost effectiveness research should be done to determine the broad financial implications of shared decision-making.

In fact, spending health care resources to create, credential and disseminate decision tools may represent a very good investment. Doing so will improve physician's ability to provide excellent care. Creating a decision aid requires a careful analysis of available medical research and the merit of certain procedures. As a result of this synthesis, physicians will have improved access to knowledge of what advances have been made, how certain treatments compare to one another and what risks are associated with certain treatment choices, thereby allowing them to better advise their patients. Providing unbiased, synthesized information to physicians also saves substantial time and money in physician research and/or provision of ineffective or under-effective treatments.

A non-financial criticism is that access to quality research that evaluates the effectiveness of every treatment is not currently available in the medical literature. ${ }^{367}$ Physicians often do not have easy access to all published medical information in their offices. However, neither of these current deficiencies should prevent shared medical decision-making from occurring in the present. Both will improve significantly over time. In order to engage in shared medical decision-making, physicians must provide patients with access to the best information available on the various risks and benefits of all treatment options; however, this does not require them to provide patients with information that does not yet exist. By standardizing the information given and avoiding each individual physician from having to research the literature for each patient, decision aids can provide a significant benefit by gathering and synthesizing the latest information from the literature for physicians and patients. If a decision aid is not available, physicians should provide patients with a broad range of initial information and engage him or her in a detailed discussion regarding the treatment and alternatives until the patient has asked all of his or her questions and feels satisfied that they have come to an informed and well thought out decision.

In addition, many physicians are able to access nearly all medical literature via Internet databases. Medical knowledge, even within one specialty, has far surpassed the ability of an individual to maintain and update all of the relevant knowledge, such that knowing where to look for

366 Michael J. Barry, Health Decision Aids to Facilitate Shared Decision Making in Office Practice, 136 ANNALS INTE RNAL MED. 127, 133 (2002) (noting that the cost effectiveness of shared decision making has not been studied).

367 Coulter, supra note 322, at 263; Feldman-Stewart et al., supra note 8 , at 52. 
information and how to analyze it will prove far more important than the treatments and solutions learned in medical school. Access to medical information for physicians and patients should evolve together. As patients demand more information for medical decision-making, physicians should seek services that provide that information quickly and easily. Both the Internet and decision aids can and will greatly reduce the burden placed on physicians in keeping track of the ever-expanding medical literature. ${ }^{368}$

iv. Limiting Physician Autonomy

Finally, requiring physicians to provide information on all treatment options may also require them to change their preferred methods of practice. According to Steven Woolf and colleagues, few clinicians can quote accurate statistics from memory or eliminate their personal biases in a manner required to provide an objective presentation of the options. ${ }^{369}$ Physicians are creatures of habit making them often slow to implement change into their practice, even if that change would improve quality of care and patient health. ${ }^{370}$ For instance, their pharmaceutical choices are often very consistent because they tend to use easily available information from medical school or from pharmaceutical representatives to make prescription choices. ${ }^{371}$ Likewise, physicians also vary significantly on what information and risks they feel are important in making treatment decisions, which often leads them to make very different choices. ${ }^{372}$ While physicians are more than entitled to their medical preferences and expert opinions on which treatment choices prove most effective, they should offer patients an explanation for their opinions accompanied with the relevant information. Shared medical decision-making will help keep physicians from getting stuck in outdated treatment patterns. In addition, the fact that physicians cannot quote extensive statistics from rote memorization or that they tend to prefer the same treatment choices are insufficient reasons to fail to implement shared medical decision-making. As mentioned above, the Internet and decision aids can assist physicians to access risk information quickly and easily without resorting solely to memorization.

\section{b. Communication Challenges}

Physicians frequently cite communication difficulties as a reason why shared medical decision-making, which sounds beneficial in theory, would not prove worthwhile in practice. $^{373}$ Primarily, providing patients with probabilities and risk information in a way that they can comprehend and internalize is extremely challenging, especially for physicians who are not

368 Woolf et al., supra note 272, at 295; see also Center for Information Therapy, http://www.informationtherapy.org (last visited March 29, 2006).

369 Woolf et al., supra note 272 , at 295.

370 Frank, supra note 212, at 8; see also Inst. of Med., Crossing The Quality Chasm: A New Health System for the Twenty-First Century 32 (National Academies Press 2001).

371 Frank, supra note 212, at 8.

372 Feldman-Stewart et al., supra note 8, at 47-49.

373 Bogardus et al., supra note 6, at 1037; Woolf et al., supra note 272, at 295. 
formally trained to do so ${ }^{374}$ Patients frequently interpret risk information in a biased manner. ${ }^{375}$ For instance, patients often experience an availability bias, where they overestimate their risk of contracting a condition that receives substantial media coverage, such as breast cancer. ${ }^{376}$ Other common biases include: 1) compression bias, which results in patients overestimating small risks and underestimating large ones; 2) small numbers bias, where patients misinterpret their individual risk based on a small number of known cases (my two friends both had complications after their hysterectomies, so I probably will too); and 3) miscalibration bias, in which patients tend to be overly confident about the extent or accuracy of their knowledge. ${ }^{377}$ In addition to the biases in interpretation, probabilities and percentages are often misunderstood by lay individuals, such that misunderstanding the information may compound the misinterpretations caused by the biases. To make things worse, the stress and pressure often associated with serious medical decisions can further impair the cognitive functioning of patients and their family members. ${ }^{378}$ Given these tendencies physicians often have trouble providing patients accurate risk information in a way that they do not succumb to certain biases or misjudgments that may confound their decisionmaking capabilities.

While without assistance many patients may misconstrue certain risks or probabilities, a trained decision counselor or decision aid can greatly assist individuals to avoid falling into cognitive traps. ${ }^{379}$ Evidence of this phenomenon has been demonstrated by the success of genetic counselors to assist individuals to comprehend their risks of contracting or passing on certain hereditary disorders. ${ }^{380}$ The major problem with the current system is that many physicians are either not trained in communication skills needed to effectively assist in patient decisions or do not have access to the resources needed to assist patients to understand the information well enough to make an informed choice. ${ }^{381}$ Many physicians do not have the time or the resources to undergo communication skills training. However, specialized decision counselors or patient videos could assist patients to understand their risks, while minimizing the physician time and expense spent in the process.

A second communication challenge associated with shared medical decision-making involves diminishing trust between patient and physician. According to Jay Katz, physicians are reluctant to share all information with

374 Bogardus et al., supra note 6, at 1037-1041.

${ }_{375}$ See Baruch Fischoff, Risk Perception and Communication Unplugged: Trenty Years of Progress, 15 Risk ANalysis 137, 1937-45 (1995); Baruch Fischoff et al., Risk Perception and Communication, 14 Ann. Rev. Pub. Health 183, 186-190 (1993).

${ }^{376}$ Bogardus et al., supra note 6, at 1040; Amos Tversky \& Daniel Kahneman, Availability: A Heuristic For Judging Frequency And Probability, 5 Cognitive Psychol. 207, 207-32 (1973).

377 Bogardus et al., supra note 6, at 1040; Frank, supra note 212, at 14-20.

${ }_{378}$ Feldman-Stewart et al., supra note 8 , at 47.

379 O'Connor et al., supra note 288, at 733; Woolf et al., supra note 272, at 295-298.

380 Michael J. Green et al., Effect of a Computer-Based Decision Aid on Knowledge, Perceptions, and Intentions about Genetic Testing for Breast Cancer Susceptibility, 292 JAMA 442, 445-449 (2004); A.G.W. Hunter et al., A Randomized Trial Comparing Alternative Approaches To Prenatal Diagnosis Counseling In Advanced Maternal Age Patients, 67 Clinical Genetics 303,303 (2005).

${ }^{381}$ Woolf et al., supra note 272. 
patients because they believe that admitting uncertainties and gaps in medical knowledge may compromise the trust and faith a patient has in his or her physician. ${ }^{382}$ In today's medical environment, where most physicians often profess more certainty or confidence to patients than they actually possess, this belief may be justified. ${ }^{383}$ Some patients encountering a provider who professed a lot of uncertainty and left many decisions open-ended might be put off by that approach and lose faith in the physician's abilities. ${ }^{384}$ However, a system that requires blind faith from patients and half-truths by physicians is unsustainable and unethical. The best way to preserve the lasting trust of patients is to admit the lack of certainty in the medical profession as a whole and promote a mutual relationship between physicians and patients in a joint effort to make the best medical decision possible.

\section{c. Patient Needs and Expectations}

Physicians also claim that many patients do not want to know all of the risk information or contribute substantially in the decision-making. ${ }^{385}$ While research demonstrates that the vast majority of patients do want to be offered choices and discuss their opinions with their physicians, around half of patients prefer to rely on the physician to make the final decision. ${ }^{386}$ Patients also vary substantially in their preferences for control over decision-making and they often want to participate in different ways. ${ }^{387}$ As a result of these findings, some physicians have argued against recommending shared medical decision-making for all patients and especially against including it in the legal duty of obtaining informed consent. ${ }^{388}$

Variation in patient decision-making preferences does not negate the need for shared medical decision-making. On the contrary, it substantiates it. Participating in a process of shared medical decision-making does not require a patient to make the final decision nor invalidate their ability to defer to their physician's judgment. It does require the physician to offer the patient all of the relevant information and to discuss their opinions with them. If at the end of that process, the patient has thought through the options and prefers to abdicate their final choice to the physician, that option is a perfect reflection of their informed autonomous choice. All that shared medical decisionmaking requires is that the patient listens to the information and discuss their opinions. After that, patients may decide to allow the physician to make the decision, to collaborate with the physician, or to make the decision on their own. If we permit physicians to bypass this process, patients who might feel reluctant to ask questions or actively gather information may not realize their true preferences prior to the decision being made. As noted above, physicians frequently misjudge patient preferences when they fail to provide them with

\footnotetext{
382 KATZ, supra note 1 , at 168-75.

383 Coulter, supra note 322 , at 264 .

384 KATZ, supra note 1, at 204-05.

385 Levinson et al., supra note 320, at 533; Geraldine M. Leydon et al., Cancer Patients Information Needs and Information Seeking Behaviour: In Depth Interview Study, 320 BMJ 909, 911, 913 (2000).

Levinson et al., supra note 385 , at 532 .

$387 \quad I d$.

388 Id. at 531-35; Woolf \& Krist, supra note 13, at 1872.
} 
sufficient information and opportunity to express their own opinions. ${ }^{389}$ Permitting this to continue in an effort not to inconvenience physicians would be in error.

Although some practical concerns exist and adjustments must be made in order to implement shared medical decision-making as a prerequisite to a legal informed consent, all of the adjustments will improve medical care, patient comprehension and investment in their treatment and push the practice of medicine away from outdated procedures. The most important challenge raised against shared decision-making is its overall implementation and maintenance costs. However, the results of a cost effectiveness study should not be conclusive about the merits of shared decision-making; any overall costs should be weighed against the substantial benefits afforded to patients, physicians and the health care system in general by shared decisionmaking.

\section{IMPLEMENTING SDM AS A LEGAL PREREQUISITE FOR INFORMED CONSENT}

Shared medical decision-making will also improve the legal aspects of informed consent for both patients and physicians. We envision states incorporating shared medical decision-making into their informed consent requirements via legislation or case law. Under such a system, a patient must have participated with his or her physician in shared medical decision-making in order to provide a valid informed consent. Physicians may satisfy this requirement in two ways: 1) use of a credentialed decision-tool or decision coach; or 2) by providing the patient with all risk, benefit and outcome information on all treatment alternatives that $1 \%$ of the patient population finds relevant. ${ }^{390}$ If information is not available to the physician on what information $1 \%$ of the population finds relevant, as is likely for many treatments, the physician should use the $1 \%$ standard as a guideline to determine initial disclosure and then engage the patient in shared decisionmaking. Any of these steps should be followed by a detailed discussion with the patient of their options and their preferences for treatment choices and participation in the final decision. The choice the physician makes between a decision aid and personally informing the patient should determine which party bears the burden of proof in a claim for failure to provide an informed consent. If the physician has provided the patient with access to a credentialed decision tool or a decision coach, then the patient will bear the burden of proving that the information was insufficient or that the discussion between the patient and physician was so inadequate as to negate consent. Alternatively, if the physician elects to engage in shared decision-making unassisted, she will bear the burden of proving that she informed the patient to the same degree that the credentialed decision-tool or coach would have and engaged the patient in a discussion of the risks, benefits and alternatives to each treatment in a manner sufficient to enable them to make an autonomous decision about decision. Again, this provision does not require the patient to make the decision, only to decide, after presented with all of the

\footnotetext{
389 Teno et al., supra note 24,0, at 183-84.

390 See infra Part X.
} 
relevant facts, whether they would prefer to make the decision alone, collaborate with the physician, or have the physician make the final decision. As a result, physicians will have more guidance regarding what information should be provided and have been provided with a process for helping patients make an informed treatment decision, patients will have the ability to be more informed about their medical care and make treatment decisions that coincide with their personal values and preferences, and physicians should experience less liability by discussing and documenting treatment decisions in depth with their patients. The following two hypothetical scenarios demonstrate how shared medical decision-making could improve the legal informed consent doctrine for both patients and physicians.

\section{A. Case 1: The Small, But Serious Risk}

Ms. Smith came to see her ophthalmologist due to rapid deterioration in her left eye following an accident. She was 35 years old and in otherwise excellent health. Her vision in that eye had been steadily more occluded over the last two years and was approaching total blindness. Her right eye maintained perfect vision. Dr. Rogers examined the patient's eye and determined that without surgery she would be entirely blind in her left eye within 6 months. Dr. Rogers discussed the fact that the surgery proved effective around $50 \%$ of the time as well as the risks associated with anesthesia and surgery recovery in general. No other treatment alternatives were appropriate. Ms. Smith elected to have the surgery, which unfortunately proved unsuccessful.

On the day after the surgery, Ms. Smith began experiencing reduced vision in her right eye. Within a week, Ms. Smith was blind in both eyes. Upon returning, Dr. Rogers explained to her that she was experiencing an extremely rare condition known as sympathetic opthalmia, when the healthy eye reduced its function to the level of a damaged eye after trauma. The general risk of sympathetic opthalmia is around 3 in 10,000 following surgery similar to Ms. Smith's and most physicians in Dr. Rogers' state do not reveal the risk to patients because they feel it will needlessly scare them or deter them from receiving necessary surgery. ${ }^{391}$ Ms. Smith sued Dr. Rogers saying that if she had known that there was any risk of total blindness she would have declined the surgery.

\section{Physician-Based Standard}

Under the physician-based standard, Dr. Rogers will most likely be held not liable for failure of informed consent. The slight risk of sympathetic opthalmia accompanied with the testimony of other ophthalmologists in the area that disclosing the risk is not standard practice should be sufficient to relieve Dr. Rogers from liability. If other physicians do not disclose for similar reasons, Dr. Rogers should have no trouble finding ample support from the medical community in the form of expert witnesses, as the physician-based standard promotes unity of opinion among providers. In fact, according to

391 Dara J. Kilmartin et al., Commentary: Sympathetic Ophthalmia Risk Following Vitrectomy: Should We Counsel Patients? , 84 BRIT. J. Opthalmology, 448, 448-49 (2000). 
the Merenstein precedent, ${ }^{392}$ Dr. Rogers could have been held liable if she informed Ms. Smith of the risk of sympathetic opthalmia and Ms. Smith declined the surgery resulting in blindness in one eye since it was standard practice not to warn of the risk.

The physician-based standard stymies progress in treatment and disclosure by forcing physicians to conduct their practice in the same manner as other physicians in their state. This legal standard of care often compromises patient autonomy, and treatment decision-making. The physician-based standard handicaps physicians' ability to trust their patients with information and patients' ability to participate meaningfully in treatment choices. The standard provides no remedy for patients like Ms. Smith who were denied important information that would have been determinative in their treatment decisions, and suffered serious consequences as a result. Not only does it provide no remedy for wronged patients, but it also demands that physicians perpetuate the lack of disclosure. The physician based standard is inappropriate as a legal requirement for medical decision-making and should not be upheld in any state. Unchecked deferral to the medical profession is no longer warranted now that research is more easily accessible to demonstrate the effectiveness and merit of their treatment choices.

\section{Patient-Based Standard}

Under the patient-based standard, Dr. Rogers will most likely be held negligent for failure to provide the patient with all the information a reasonable patient would desire, but this result is not certain. The argument that a reasonable patient would want to know that a surgery to correct blindness in one eye carried a risk of total blindness regardless of how miniscule is likely to prove persuasive. However, it is possible that a jury could conclude that a "reasonable patient" would not want to be burdened by knowing every extremely rare, but possible risk associated with a treatment. Under this standard, the importance of the risk to Ms. Smith is unaccounted for. Her ability to recover depends entirely on whether the jury finds that a reasonable person would want to know of a 3 in 10,0000 risk.

Ironically, in addition to meeting this objective standard, Ms. Smith must also prove that she subjectively would have decided to decline the surgery had she been warned of the risk. Therefore, physicians' decisions must only meet an objective standard of agreeing with the "reasonable patient," while patients must prove that their desire for information is both subjectively and objectively warranted. Patients who have been denied information often have an uphill battle to prove that the physician should have provided them the information in cases of extremely rare risks. In this case, the patient-based standard is likely to impose liability on the physician for failure to provide information on such a serious risk, no matter how unlikely. However, cases with less severe risks are much more difficult for patients to prove that the risk would cause a reasonable person to decline to have the procedure. In this way, the patient standard leaves patients vulnerable to the risk preferences of others in order to determine whether they can recover for undisclosed harms from a treatment.

392 See supra notes $36-37$ and accompanying text. 
The patient-based standard also leaves physicians quite vulnerable in cases of rare risks. Determining how much information to provide a patient about potential risks currently involves a striking a delicate balance for many physicians. Often physicians are reluctant to inform patients of extremely rare risks because the patient may decline to have a procedure that the physician feels is important. ${ }^{393}$ On the other hand, failing to provide information about "material" risks could result in legal liability if such a risk occurs. The patient-based standard offers physicians too little instruction on what risks are "material" especially for risks with infrequent occurrence and those with moderately severe harms. Neither the physician-based standard nor the patient-based standard "explain precisely how a physician should decide what a reasonable person would want to be told." 394 Furthermore, research demonstrates that physicians vary significantly in what information they feel is important to convey to patients, thereby creating even more variation among the standard. ${ }^{395}$

The patient-based standard provides an improvement over the physicianbased standard in protecting patient autonomy and bodily integrity. However, it fails to provide clear guidance to physicians on what information they are required to provide to patients and neglects entirely the existence of variation between patients regarding values and risk aversion. As a result, the standard leaves both patients and physicians vulnerable in cases where the risks are moderate or unlikely as the standard is subject to numerous interpretations of a "material" risk.

\section{Shared Medical Decision-Making}

Under a shared medical decision-making standard, Dr. Rogers should be held negligent for failing to disclose the risk of total blindness from sympathetic opthalmia. Given the risk of total blindness from an operation to eliminate blindness in one eye, it is very likely that more than one percent of patients would find that information relevant to deciding whether or not to undergo the procedure. Therefore, information on the risk of sympathetic opthalmia would almost definitely be included in a credentialed decision tool or in the standard disclosure requirements. If for some reason it was not, Ms. Smith also would have had an opportunity to discuss the procedure in depth with her physician and ask questions relevant to her fear of total blindness. As a result, Ms. Smith would have told Dr. Rogers that she preferred to be blind in one eye rather than take any risk of total blindness. Ms. Smith's preference is not likely to be shared by all patients, but certainly some will feel the same way. Others will prefer to accept a 3 in 10,000 risk of total blindness to restore sight to their left eye. Only by being informed of all of the relevant risks, even if very small, can a patient reveal their preferences to their provider in order to make the best decision. Throughout the process of shared medical decision-making, physicians should express their opinions when asked and try to mitigate patients' irrational fears. However, if a patient has a strong preference against taking a certain risk, they should not be forced by the

393 Alan Meisel \& Mark Kuczewski, Legal and Ethical Myths About Informed Consent, 156 Archives Internal Med., 2521, 2525 (1996).

394 Bogardus et al., supra note 6 , at 1039.

395 Feldman-Stewart et al., supra note 8 , at 49. 
physician to take it, or worse, not be told about it, simply because the physician feels the patient will not make the right choice if informed.

\section{B. Case 2: A Preference-Sensitive Alternative}

Mr. Kensie is a 65 year-old man who just received a diagnosis of early stage prostate cancer following a PSA Gleason score of 4 and local biopsy. Mr. Kensie's oncologist, Dr. Thomas, explained the treatment options available to Mr. Kensie: watchful waiting, radiation therapy or radical prostatectomy. Greatly alarmed with his new diagnosis, Mr. Kensie asked about the relevant life expectancy and side effects associated with each treatment. Dr. Thomas informed him that a radical prostatectomy would remove Mr. Kensie's entire prostate providing him with a good disease-free survival rate of between 73$83 \%$ after five years. ${ }^{396}$ Radiation therapy would be used to shrink or eliminate the cancer and could also provide Mr. Kensie with a good disease free survival rate comparable with that of prostatectomy. Dr. Thomas revealed that each of these active treatments bears a substantial risk of erectile dysfunction and urinary dysfunction. On the other hand, watchful waiting conferred a higher risk of metastasis and a slightly higher risk of death from the cancer, but did not carry the risks of erectile and urinary dysfunction associated with radiation or radical prostatectomy.

Following some discussion of the other risks associated with each treatment such as general anesthesia for the prostatectomy and illness associated with radiation treatment, Dr. Thomas said that his advice for Mr. Kensie would be to have the radiation treatment. When Mr. Kensie asked again how the prostatectomy side effects compared with those associated with radiation therapy, Dr. Thomas replied that radiation therapy had a lower risk of erectile dysfunction than radical prostatectomy. Mr. Kensie nodded and agreed to the radiation.

Following the treatment, Mr. Kensie recovered well and was disease-free. However, he suffered from severe bowel dysfunction that severely compromised his quality of life. Six months after the surgery, Mr. Kensie read an article describing the increased risk of bowel dysfunction associated with radiation treatment rather than radical prostatectomy or watchful waiting. Feeling that the quality of his life had been dramatically reduced by the treatment, he sued Dr. Thomas for failure to inform him of the risk of bowel dysfunction.

\section{Physician-Based Standard}

Under the physician-based standard, again the success of Mr. Kensie's claim depends entirely on the state in which he lives and the practices of the physicians within. According to the Dartmouth Atlas of Healthcare, the care a patient receives will depend highly on their location, the capacity of the health care system in their area and the practice preferences of the physicians in their area, rather than on the preferences of the individual patients being

396 Vibha Bhatnagar \& Robert M. Kaplan, Treatment Options for Prostate Cancer: Evaluating the Evidence, 71 AM. FaM. Physician, 1915, 1918 (2005). 
treated. ${ }^{397}$ The information sufficient to fulfill a patient's right to make an informed consent should only vary by region or state in accordance with differences in the legal disclosure requirements as contemplated by the state legislature or the courts. Variances in the legal standard of disclosure should not occur in states with highly similar or identical informed consent standards as a result of differences in physician practice patterns and the capacity of the health care system. In areas where physicians do not warn their patients about all of the quality of life risks associated with treatments for prostate cancer, Mr. Kensie's claim will be unlikely to succeed. Physicians vary significantly on what information they believe is important to provide their patients regarding prostate cancer treatments. ${ }^{398}$ As a result, in some areas the norm will be for physicians to provide information on bowel dysfunction, but not in others. Likewise, if Dr. Thomas had provided Mr. Kensie with all of the risks of radiation and prostatectomy and his cancer later metastasized under the watchful waiting option, Dr. Thomas could have been liable for presenting watchful waiting in some states. On the other hand, in the many areas that promote disclosure of all quality of life risks to patients, Mr. Kensie would have a viable claim for negligence against Dr. Thomas.

The legal system should no longer allow by such inconsistencies in medical practice to determine the autonomy rights of patients. Nor should inconsistencies in physician practice confound an individual physician from providing his patient with all relevant information in hopes of finding the best treatment solution for the individual. Information exists that can enable physicians and patients to better tailor treatment choices to patient goals and values, while at the same time eliminating much of the disclosure guess work for physicians. It is time for a change.

\section{Patient-Based Standard}

Under the patient-based standard, this case is a toss up as well. One could argue that a reasonable patient would want to know about all major quality of life issues associated with a certain treatment and any additional risks from one alternative to another. However, data from a recent survey suggests that patients are in substantial disagreement on their need to know information related to risks of bowel dysfunction, along with 30 other questions related to prostate cancer treatment. ${ }^{399}$ Feldman-Stewart et al. found that $\sim 40 \%$ of patients with early stage prostate cancer felt information related to the effect on bowel function was necessary to make the treatment decision, $\sim \mathbf{5 8 \%}$ felt such information was unnecessary, and $\sim 2 \%$ remained uncertain. Such a discrepancy existed for over half of the questions deemed possibly relevant to prostate cancer treatment decisions by focus groups and surveys of oncologists, urologists and patients. ${ }^{400}$ Studies like these greatly diminish the credibility of the "reasonable patient" standard. Patients have extremely different values, levels of risk aversion and preferences for different quality of life impacts. ${ }^{401}$ Feldman-Stewart et al. demonstrated that a "core"

\footnotetext{
397 Center for the Evaluative Clinical Sciences, supra note 7 , at 18.

398 Feldman-Stewart et al., supra note 8, at 48-49.

399 Feldman-Stewart et al., supra note 142, at 221.

$400 \quad I d$

401 See id. at 222.
} 
set of questions exist that a majority of patients find necessary, but that for a substantial portion of the relevant issues reasonable patients disagree about what should be disclosed. As a result, the outcome of this case will depend on the ability of either side to convince the jury that the information is necessary or not. The patient-based standard, especially in cases of preference-sensitive care can result in extremely arbitrary decisions that have little to do with protecting the autonomy or bodily integrity of the patient.

\section{Shared Medical Decision-Making}

Under shared decision-making, the substantial percentage of individuals who found risk of bowel dysfunction relevant would require its disclosure under the standard. Likewise, the physician should have discussed the risk of bowel dysfunction with the patient, especially in response to the patient's concern about the differences in risks between radiation therapy and radical prostatectomy. Primarily, shared decision-making clarifies the legal requirements for physicians. They should provide the patient with relevant information on the mortality and quality of life risks and benefits of all treatment alternatives. Then they should discuss the treatment options with the patient and provide any additional information relevant to his or her specific needs. In comparison to the physician-based standard, the physician would know to reveal all quality of life variances between different treatments and the practice of other physicians would not need to guide her conduct. In comparison to the patient-based standard, physicians will not have to guess at what a "reasonable" patient would want to know, as patients would receive a substantial base of information and then be given the opportunity to ask for additional information, especially for treatment options where reasonable patients differ substantially on what information is necessary and unnecessary.

Shared medical decision-making has the potential to make vast improvements within to the current legal doctrines of informed consent. However, in order to do so, significant policy and practice obstacles must be addressed in order to make shared medical decision-making a feasible possibility agreeable to physicians, patients, and law-makers.

\section{IMPLEMENTING SHARED MEDICAL DECISION-MAKING - POLICY IMPLICATIONS}

In order solve some of the problems with current legal standards and adequately implement shared medical decision-making, four major adjustments within the current system must be made: 1) establishing an autonomous partnership between patients and physicians; 2) clearly defining the disclosure requirements; 3) ensuring the integrity of decision tools or aids; and 4) improving the quality and quantity of outcome studies of treatments on survival rates and quality of life factors. These are goals that we must achieve as we move toward a standard of shared decision-making. 


\section{A. Patients as Autonomous Partners}

Primarily, physicians need to view patients as autonomous partners in medical decision-making. With the increasing role of consumerism in today's health care markets, patients are being asked to take a more active role in financing their health care. For the majority of Americans who are insured, the shift toward health savings accounts and consumer responsibility demands that patients have more of a role in medical decisions, as their choices will impact both their health and their financial wellbeing. Just as managed care forced physicians to be more cognizant of the choices they were making in medical care, consumerism will force patients to acknowledge both the health and financial consequences of certain treatment decisions. These changes make the protection of patient autonomy more important than ever before.

In order for any change to occur within the medical system, physicians and patients must relinquish their paternalistic roles in favor of a partnership, in which each party brings a significant expertise and through mutual participation the most effective medical treatment can be selected. Physicians should freely give their medical opinion regarding the best treatment options, as they are the medical experts. Likewise, patients should provide information on the treatment choices that best suit their lifestyle and personal values. Only through shared discussion of both the medical and personal elements of the decision can the best overall decision be made.

\section{B. Clear Standard of Disclosure}

In order to provide patients with a fair description of the risks and benefits of other treatment options, physicians must know what they are obligated to disclose. A consistent complaint within the medical profession is that they do not know how much and what kind of information they are required to provide patients regarding treatment decisions. ${ }^{402}$ While engaging in a process of shared medical decision-making will do much to elicit relevant information from patients and physicians, a clear standard of information required to be offered should be established so that physicians and patients know what they should expect. We propose a standard that requires physicians to provide all relevant information, defined as that information which $1 \%$ of the patient population would want to know in order to make the treatment decision. This level of disclosure provides a wide range of information to patients, while also setting a clear disclosure expectation that informs physicians of their responsibilities. However, while the standard is comprehensible, we acknowledge that data on what information $1 \%$ of the population finds necessary to make the decision is currently unavailable for most medical decisions. This information could be obtained through broad focus groups and studies similar to those performed by Feldman-Stewart and colleagues to assess the relevance of certain information to patients and lay individuals. $^{403}$ These focus groups and studies must engage a diverse spectrum of the patient population including individuals from all races, age

402 Bernat \& Peterson, supra note 321, at 88; Meisel \& Kuczewski, supra note 393.

403 Feldman-Stewart et al., supra note 142, at 218-223. 
groups, socio-economic groups, and geographic regions. Focus groups of this kind have also been successfully used by FIMDM and Health Dialog in order to determine what information to include in their decision aids. ${ }^{404}$ While these studies are being performed, the $1 \%$ relevancy standard should serve as a guideline to demonstrate the wide spectrum of information that should be provided to patients regarding their treatment. Physicians should give patients not only all or almost all information regarding the risks and benefits of various treatments, but should ensure that the patient has had all of their questions satisfactorily answered prior to making a final decision. The goal of shared decision-making is for the patient and physician to feel that they fully understand the nature of the procedure, the risks and benefits, as well as the individual values and preferences that influence the treatment decision, such that both are willing to sign a statement of agreement on their full understanding and the treatment choice. This can be done regardless of whether the standard of disclosure has been statistically defined for that treatment decision. However, performing research to accurately determine the $1 \%$ standard of relevancy remains an important goal for to establish clear disclosure standards for physicians.

\section{Credentialing}

The process of incorporating shared medical decision-making in to the legal informed consent framework almost certainly will require the use of decision aids in clinical practice. However, decision aids are only useful if they provide up-to-date information, assist the patient in values clarification and provide guidance in deliberation in the decision making process. ${ }^{405}$

In order to assure their effectiveness and unbiased content, patient decision aids should be credentialed by an independent entity. Credentialing could be accomplished in the same manner that legal and medical commentators have argued for federal certification of clinical practice guidelines. ${ }^{406}$ The model proposed by Rosoff for voluntary certification is instructive to the effort needed here. In arguing that the time has come for clinical practice guidelines to be used in courts as evidence of the standard of care, Rosoff proposed that AHRQ take the responsibility of certificating, updating and promoting the use of clinical practice guidelines. Once approved, the certified guideline could be accepted as setting the standard for litigation in malpractice claims or for resolving coverage disputes about medical appropriateness. A similar process can be used to certify decision aids and incorporate them into clinical practice. The National Committee for Quality Assurance (NCQA), which already evaluates health plans on a range of quality assurance measures and provides them with accreditation ratings that are then made available to the public, has the experience and reputation

404 Foundation for Informed Medical Decision-Making, www.fimdm.org (last visited Aug. 30, 2006); Health Dialog, www.healthdialog.com (last visited Aug. 30, 2006).

405 Wennberg, supra note 164, at 15.

406 See, e.g., Arnold J. Rosoff, Evidence-Based Medicine and the Law: The Courts Confront Clinical Practice Guidelines, 26 J. Health Pol. PoL'Y \& L. 327 (2001). 
to run the kind of national accreditation process needed to certify decision aids and would be an excellent candidate. ${ }^{407}$

However, since NCQA is a national agency, federalism concerns arise. These could be addressed by permitting states to endorse the use of credentialed decision aids through legislative action or case law on an individual basis. We do not anticipate that all states will adopt shared decision-making or strongly encourage the use of credentialed decision-aids in a unified or rapid manner, nor do we expect a national mandate on the issue, but we believe that state adoption of these policies are important goals for the future of American health care.

Incorporating shared medical decision-making into clinical practice via decision aids will benefit both physicians and patients. The clinical evidence of the efficacy of decision aids is compelling. Clinical trials show that "compared to a control group, patients who use decision aids are better informed about the benefits, risks and clinical uncertainties associated with treatment options available to them."408 In addition, patients who have engaged in shared decision-making and used decision aids make "better" decisions that more clearly reflect the patients' values. ${ }^{409}$ Finally, the majority of the clinical trials revealed a net reduction in demand for more invasive surgical options, after patients had undergone shared decision-making and the used a decision aid to assist them in selecting a treatment option. ${ }^{410}$

Credentialing of decision aids could occur on three levels: 1) the level of the instrument, such as a decision tool; 2) the individual level, such as a decision coach or provider; and 3) the institutional level, such as managed care organization as hospitals. Each decision tool should receive a certification that it provides an unbiased account of up-to-date, clinically proven information, as well as patient testimony. Decision tools must be supplemented regularly and be accompanied by methods for disseminating new information quickly and easily to the physicians and institutions that use them. Individuals should receive credentials for being trained in shared decision-making and decision analysis techniques. Finally, institutions may receive credentials for promoting shared decision-making by providing decision coaches and counselors, offering the use of decision tools, and maintaining a certain percentage of providers trained in shared decisionmaking. Credentialing decision tools, providers and institutions allows patients to identify those physicians and institutions that offer shared decision-making and feel assured that they have received the best available information. Likewise, physicians can ensure that they are doing all they can to inform their patients in a fair and unbiased manner, as well as, helping to shield themselves from potential liability.

The Ottawa Health Research Institute has developed criteria for assessing patient decision aids that may provide guidance to developing a credentialing system within the U.S. Their CREDIBLE criteria is part of the Cochrane Systemic Review of Patient Decision Aids, which was created by an

${ }_{407}$ See National Committee for Quality Assurance, NCQA Report Cards, http://hprc.ncqa.org/menu.asp (last visited August 30, 2006).

4.08 Wennberg, supra note 7 , at 15.

409 Id.

$410 \quad I d$. 
international group of researchers to assess the impact of decision aids on medical decision-making and the resultant health outcomes. ${ }^{411}$ The acronym describes the process by which the decision should be judged in order for it to be certified. The decision aid must demonstrate that it is: competently developed; recently updated; evidence-based; that conflicts of interest have been disclosed; that it provides a balanced presentation of treatment options benefits and harms; and that the decision aid is efficacious at improving decision making through a rigorous evaluation process. ${ }^{412}$

A rigorous accreditation process, such as the Cochrane Systemic Review, is necessary to protect the interests of physicians and patients. While many creators of decision aids have spent significant time and resources developing their instruments and techniques, these efforts have largely been ad hoc and may differ substantially from one another. In addition, these aids may be biased toward or against treatments. These biases carry extreme significance. A consistent claim of shared medical decision-making is that it will reduce the overall amount of health care provided by eliminating a significant percentage of unwanted care. ${ }^{413}$ This reduction in care could provide substantial savings for insurance companies and physicians paid via capitation by allowing them to retain money paid upfront for care. Patients may also see savings in the form of reduced premiums. As a result, decision aids that provide greater monetary savings may provide a substantial competitive economic advantage, thereby incentivizing the company making the aid to inappropriately bias the product against receiving the most expensive treatments. If decision-making aids are sold commercially, the importance of having an independent and unbiased entity either creating and defining the content or certifying the unbiased content of the products cannot be overstated. Existing entities that oversee the quality of U.S. medical care, such as AHRQ and NCQA, could serve as credentialing bodies. Specialty associations, leading scholars and practitioners, and medical schools could all play a role in establishing and updating the content of the decision aids. A website could be created to update and supplement the information provided on the videotapes and in pamphlets.

\section{Research on Survivability and Quality of Life Outcomes}

Finally, research must be conducted to fill in the information gaps in medical knowledge regarding the survivability and quality of life outcomes for different treatment options. ${ }^{414}$ As late as the early 1990s, some scholars estimated that only 15-20\% of medical interventions had been evaluated and proven effective. ${ }^{415}$ In addition to the lack of outcomes research, which has increased in the last decade, but still has light-years to come, substantial

411 See Annette M. O'Connor et al., Decision Aids for People Facing Health Treatment or Screening Decisions, I Cochrane Database Systematic Revs. 1 (2003), available at http://decisionaid.ohri.ca/docs/Cochrane_Review.pdf (evaluating over two hundred decision aids using the CREDIBLE criteria).

Ottawa Health Research Institute, CREDIBLE Criteria, http://decisionaid.ohri.ca/cred.html (last visited Mar. 15, 2006).

413 Center for the Evaluative Clinical Sciences, supta note 5, at 6.

${ }_{414}$ Coulter, supra note 322, at 268 ; Feldman-Stewart et al. supra note 8 , at 53.

415 Coulter, supra note 322, at 263-64. 
efforts must be made to synthesize valuable information and provide it to physicians in a fast, usable and reliable manner, such as a decision aid. As Feldman-Stewart and colleagues argue, in order to have a coherent view of the potential risks and benefits of a treatment, we must have a method of assimilating research from a broad range of studies and disciplines. ${ }^{416}$ In addition to survival and quality of life outcomes research, studies must be conducted to determine physician and patient preferences for information disclosure and the effectiveness of different disclosure techniques. A consistent flow of information on which to base treatment decisions is needed to supplement decision tools and aids, and to be able to give patients the up to date information relevant to their treatment choices.

Each of these four adjustments is critical to implementing shared medical decision-making in an optimal fashion. They should be considered part of the current evolution of medical care that uses the research tools and information capabilities of our current society to improve the practice of medicine for both the patient and the physician. The legal system must also evolve in step with this change in medical care.

\section{CONCLUSION}

Empirical clinical research demonstrates that our current legal concepts of informed consent are at odds with not only modern medical practice, but also individual autonomy rights. As a result, legal scholars should rethink current informed consent laws. Ironically, after placing autonomy at the center of informed consent, we have created a legal framework that fails to promote the personal values of individual patients. In order to protect selfdetermination, we must establish a system that enables patients to have access to the information pertinent to their personal values and beliefs in order to make an informed decision. On the other hand, promoting patient autonomy does not mean that physician expertise should be ignored or disregarded. Patients and physicians should communicate with one another regarding treatment options in order to mutually define the best solution. Our current legal standards in many ways preclude or inhibit such a discussion.

A substantial overhaul of the current informed consent system is needed to balance the patient autonomy with physician expertise and beneficence. Rather than pitting patients and physicians against one another, requiring patients to have blind faith in their physicians, or requiring physicians to only provide statistical information but not their professional opinion, an informed consent standard that encourages open communication, shares input and responsibility between physician and patient, and reestablishes the physicianpatient relationship should be instituted. Shared decision-making can accomplish these goals.

However, the complexity and arduousness of this proposal should not be underestimated. The creation and credentialing of the decision aids required to supply the American health care system is a gargantuan task. To do so will not only take a major commitment from the federal government and the health care researchers to provide funding and information, but also from

$416 \quad$ Feldman-Stewart et al. supra note 8, at 52. 
providers, patients, state and local governments, and voters to support implementation of shared decision-making. Despite the bureaucratic headaches, however, the enormous expenditure of financial and human resources, and the need for state-by-state adoption, we believe that in the long run the benefits of shared decision-making and the use of evidence-based decision aids far outweigh the costs. Such a system would provide patients and physicians with: clarity of the information required for disclosure; ease with which to retrieve it, update it and supplement it; and the resources necessary to inform patients of the' relevant options without significantly draining physician resources. Patients would experience more autonomy in their medical decisions and more opportunity to consider their own value systems in their treatment options. Physicians will no longer have to guess regarding their legal liability and they can generally improve the health outcomes of their patients by enabling them to be more invested in the treatment choice.

Undoubtedly, implementation will be challenging. Bringing about substantial change in the medical or legal system always is. But these goals are not impossible, they simply require determination to improve medical practice and the way the law addresses it. While incorporation of a shared decision-making requirement into informed consent laws must occur on a state level, there is a role for the federal government to incentivize the adoption of shared decision-making requirements, to provide a uniform, independent credentialing body for decision aids, and to promote and fund both the clinical outcomes research and patient and physician preferences research needed to create decision aids. We view the creation, synthesis and easy access to medical outcomes research from all over the world to be the next great step in improving medical care. Not only will this information improve physicians' ability to offer the best care to their patients, but partnering this information with a shared decision-making approach to making treatment decisions will dramatically improve the ability of patients to receive treatments that best coincide with their lives. A change of this kind is long overdue and is necessary to realign the legal and medical conceptions of informed consent so that patients, physicians and courts can attain a mutual understanding of legal informed consent obligations, and so the ethical and legal goals of informed consent may be achieved in modern medical practice. 


\section{APPENDIX A \\ STATE INFORMED CONSENT LAWS}

\begin{tabular}{|c|c|c|c|c|c|}
\hline State & Classification & $\begin{array}{l}\text { Statutory } \\
\text { Authority }\end{array}$ & Key Case & $\begin{array}{l}\text { Other Pertinent/ } \\
\text { Recent Case Law }\end{array}$ & Explanatory Notes \\
\hline & $-i$ & 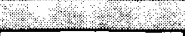 & 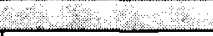 & Q & \\
\hline $\mathrm{AL}$ & $\begin{array}{l}\text { Physician- } \\
\text { Based }\end{array}$ & \begin{tabular}{|l|} 
ALA. CODE \\
$\$ 6-5-484$ \\
$(2005)$ \\
(Degree of \\
Care Owed to \\
Patient). \\
\end{tabular} & $\begin{array}{l}\text { Fain v. Smith, } \\
479 \text { So. } 2 d 1150 \\
\text { (Ala. 1985). }\end{array}$ & $\begin{array}{l}\text { Wells v. Storey, } \\
792 \text { So. } 2 \mathrm{~d} 1034 \\
\text { (Ala. 1999). }\end{array}$ & \\
\hline AK & $\begin{array}{l}\text { Patient- } \\
\text { Based }\end{array}$ & $\begin{array}{l}\text { ALASKA STAT. } \\
\text { \$09.55.556 } \\
(2004) \\
\text { (Informed } \\
\text { Consent). } \\
\end{array}$ & $\begin{array}{l}\text { Korman v. } \\
\text { Mallin, } \\
858 \text { P.2d 1145 } \\
\text { (Alaska 1993). }\end{array}$ & $\begin{array}{l}\text { Marsingill v. } \\
\text { O'Malley, } \\
\text { 128 P.3d 151 } \\
\text { (Alaska 2006). }\end{array}$ & \\
\hline $\mathrm{AZ}$ & $\begin{array}{l}\text { Physician- } \\
\text { Based }\end{array}$ & $\begin{array}{l}\text { ARIZ. REV. } \\
\text { STAT. ANN. } \\
\$ 12-563 \\
(2006) \\
\text { (Necessary } \\
\text { Elements of } \\
\text { Proof). } \\
\end{array}$ & $\begin{array}{l}\text { Riedisser v. } \\
\text { Nelson, } \\
534 \text { P.2d 1052 } \\
\text { (Ariz. 1975). }\end{array}$ & $\begin{array}{l}\text { Potter v. Wisner, } \\
823 \text { P.2d } 1339 \\
\text { (Ariz. Ct. App. } \\
\text { 1991). }\end{array}$ & \\
\hline AR & $\begin{array}{l}\text { Physician- } \\
\text { Based }\end{array}$ & $\begin{array}{l}\text { ARK. CODE } \\
\text { ANN. } \\
\text { \$16-114-206 } \\
\text { (2006) } \\
\text { (Plaintiff's } \\
\text { Burden of } \\
\text { Proof). } \\
\end{array}$ & $\begin{array}{l}\text { Fuller v. Starnes, } \\
597 \text { S.W.2d } 88 \\
\text { (Ark. 1980). }\end{array}$ & $\begin{array}{l}\text { Aronson v. } \\
\text { Harriman, } \\
\text { 901 S.W.2d } 832 \\
\text { (Ark. 1995). }\end{array}$ & \\
\hline CA & $\begin{array}{l}\text { Patient- } \\
\text { Based }\end{array}$ & None & \begin{tabular}{|l|} 
Cobbs v. Grant, \\
502 P.2d 1 \\
(Cal. 1972). \\
\end{tabular} & $\begin{array}{l}\text { Arato v. Avedon, } \\
858 \text { P.2d 598 } \\
\text { (Cal. 1993). } \\
\end{array}$ & \\
\hline $\mathrm{CO}$ & $\begin{array}{l}\text { Physician- } \\
\text { Based }\end{array}$ & None & $\begin{array}{l}\text { Bloskas v. } \\
\text { Murray, } \\
646 \text { P.2d } 907 \\
\text { (Colo. 1982). }\end{array}$ & $\begin{array}{l}\text { Melville v. } \\
\text { Southward, } \\
791 \text { P.2d 383 } \\
\text { (Colo. 1990); } \\
\text { Lininger v. } \\
\text { Eisenbaum, } \\
\text { 764 P.2d 1202 } \\
\text { (Colo. 1988). }\end{array}$ & $\begin{array}{l}\text { Colorado also allows } \\
\text { claims for negligent } \\
\text { misrepresentation. See } \\
\text { Bloaskas v. Murray. For } \\
\text { example, even if a } \\
\text { physician complies with } \\
\text { the professional standard } \\
\text { of disclosure, but } \\
\text { provides false } \\
\text { information that is } \\
\text { extrinsic to the duty to } \\
\text { warn, he or she may still } \\
\text { be liable if the patient } \\
\text { detrimentally relies on } \\
\text { that information. }\end{array}$ \\
\hline CT & $\begin{array}{l}\text { Patient- } \\
\text { Based }\end{array}$ & None & $\begin{array}{l}\text { Logan v. } \\
\text { Greenwich Hosp. } \\
\text { Ass'n, } \\
465 \text { A.2d 294 } \\
\text { (Conn. 1983). }\end{array}$ & $\begin{array}{l}\text { Godwin v. } \\
\text { Danbury Eye } \\
\text { Physicians and } \\
\text { Surgeons, } \\
757 \text { A.2d 516 } \\
\text { (Conn. 2000). }\end{array}$ & \\
\hline $\mathrm{DE}$ & $\begin{array}{l}\text { Patient- } \\
\text { Based }\end{array}$ & \begin{tabular}{|l|} 
DEL. CODE \\
ANN. tit. 18, \\
$\$ 6852(2004)$ \\
(Informed \\
Consent). \\
\end{tabular} & $\begin{array}{l}\text { Robinson v. } \\
\text { Mroz, } \\
\text { 433 A.2d } 1051 \\
\text { (Del. 1981). }\end{array}$ & $\begin{array}{l}\text { Good v. Bautista, } \\
\text { No. 84C-MR-46, } \\
\text { 1987 WL 761786 } \\
\text { (Del. Super. Ct. } \\
\text { June 30, 1987). }\end{array}$ & \\
\hline
\end{tabular}




\begin{tabular}{|c|c|c|c|c|c|}
\hline State & Classification & $\begin{array}{l}\text { Statutory } \\
\text { Authority }\end{array}$ & Key Case & \begin{tabular}{|l|} 
Other Pertinent/ \\
Recent Case Law
\end{tabular} & Explanatory Notes \\
\hline 4 & \multicolumn{5}{|c|}{ [Cable Continued] } \\
\hline DC & $\begin{array}{l}\text { Patient- } \\
\text { Based }\end{array}$ & None & $\begin{array}{l}\text { Crain v. Allisoin, } \\
\text { 443 A.2d } 558 \\
\text { (D.C. 1982). }\end{array}$ & \begin{tabular}{|l|} 
Anderson v. Jones, \\
606 A.2d 185 \\
(D.C. 1992). \\
\end{tabular} & \\
\hline FL & $\begin{array}{l}\text { Physician- } \\
\text { Based }\end{array}$ & $\begin{array}{l}\text { FLA. STAT. } \\
\text { \$766.103 } \\
(2006) \\
\text { (Florida } \\
\text { Medical } \\
\text { Consent } \\
\text { Law). }\end{array}$ & $\begin{array}{l}\text { Gassman v. } \\
\text { United States, } \\
\text { 589 F. Supp. } \\
\text { 1534 (D. Fla. } \\
\text { 1984). }\end{array}$ & \begin{tabular}{|l} 
Jackson v. United \\
States, \\
No. 3:04-CV-444- \\
J-32HTS, 2006 \\
WL 229514 \\
(D. Fla. 2006).
\end{tabular} & $\begin{array}{l}\text { Florida and Kentucky } \\
\text { both have informed } \\
\text { consent statutes that } \\
\text { require that disclosure } \\
\text { be, in the first } \\
\text { instance, in } \\
\text { accordance with an } \\
\text { accepted standard of } \\
\text { medical practice. The } \\
\text { information disclosed } \\
\text { must also be sufficient } \\
\text { to provide a } \\
\text { reasonable individual } \\
\text { with a generally } \\
\text { understanding of the } \\
\text { information disclosed. } \\
\text { Though this is a } \\
\text { somewhat weakened } \\
\text { version of the pure } \\
\text { physician-based } \\
\text { standard, it } \\
\text { nonetheless qualifies } \\
\text { as a physician-based } \\
\text { standard. }\end{array}$ \\
\hline GA & $\begin{array}{l}\text { Patient- } \\
\text { Based }\end{array}$ & $\begin{array}{l}\text { GA. CoDE } \\
\text { ANN. } \\
\$ 31-9-6.1 \\
(2006) \\
\text { (Consent to } \\
\text { Certain } \\
\text { Surgical or } \\
\text { Diagnostic } \\
\text { Procedures; } \\
\text { Disclosure of } \\
\text { Information } \\
\text { to Person } \\
\text { from Whom } \\
\text { Consent is } \\
\text { Required). }\end{array}$ & $\begin{array}{l}\text { Ketchup v. } \\
\text { Howard, } \\
\text { 543 S.E.2d } 371 \\
\text { (Ga. Ct. App. } \\
\text { 200o). }\end{array}$ & $\begin{array}{l}\text { Albany Urology } \\
\text { Clinic, P.C. v. } \\
\text { Cleveland, } \\
\text { 528 S.E.2d } 777 \\
\text { (Ga. 2000). }\end{array}$ & $\begin{array}{l}\text { This is an unsettled } \\
\text { area of Georgia law. } \\
\text { The informed consent } \\
\text { statute only requires } \\
\text { consent for certain } \\
\text { procedures. Whether } \\
\text { and to what extent } \\
\text { there is a broader } \\
\text { common law } \\
\text { informed consent } \\
\text { requirement remains } \\
\text { in question. The } \\
\text { court in Ketchup } \\
\text { seems to have } \\
\text { answered in the } \\
\text { affirmative, but this } \\
\text { finding has not been } \\
\text { affirmed by the } \\
\text { Georgia Supreme } \\
\text { Court. Nevertheless, } \\
\text { to the extent that an } \\
\text { informed consent } \\
\text { requirements exists in } \\
\text { Georgia, it is patient- } \\
\text { based. }\end{array}$ \\
\hline
\end{tabular}




\begin{tabular}{|c|c|c|c|c|c|}
\hline State & Classification & $\begin{array}{l}\text { Statutory } \\
\text { Authority }\end{array}$ & Key Case & $\begin{array}{l}\text { Other Pertinent/ } \\
\text { Recent Case Law }\end{array}$ & Explanatory Notes \\
\hline (2) & 26ris & 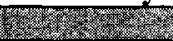 & (27) & wor 1 w & (3) \\
\hline HI & $\begin{array}{l}\text { Patient- } \\
\text { Based }\end{array}$ & $\begin{array}{l}\text { HAW REV. } \\
\text { STAT. } \\
\$ 671-3 \\
\text { (2005) } \\
\text { (Informed } \\
\text { Consent). }\end{array}$ & $\begin{array}{l}\text { Carr v. Strode, } \\
\text { 904 P.2d 489 } \\
\text { (Haw. 1995). }\end{array}$ & $\begin{array}{l}\text { Barcai v. Betwee, } \\
50 \text { P.3d } 946 \\
\text { (Haw. 2002). }\end{array}$ & $\begin{array}{l}\text { Hawaii has a } \\
\text { controlling statute for } \\
\text { informed consent that } \\
\text { has not, in violation of } \\
\text { the Hawaii } \\
\text { Legislature's } \\
\text { instructions, been } \\
\text { fully expounded upon } \\
\text { by the board of } \\
\text { medical examiners. As } \\
\text { a result, Hawaii's } \\
\text { courts have adopted } \\
\text { the common law } \\
\text { patient-based } \\
\text { standard of informed } \\
\text { consent to aid in the } \\
\text { interpretation and } \\
\text { application of the } \\
\text { informed consent } \\
\text { statute. }\end{array}$ \\
\hline ID & $\begin{array}{l}\text { Physician- } \\
\text { Based }\end{array}$ & $\begin{array}{l}\text { IDAHO CODE } \\
\text { ANN. } \\
\$ 39-4505 \\
\text { (2006) } \\
\text { (Sufficiency } \\
\text { of Consent). }\end{array}$ & $\begin{array}{l}\text { Sherwood v. } \\
\text { Carter, } \\
805 \text { P.2d } 452 \\
\text { (Idaho 1991). }\end{array}$ & $\begin{array}{l}\text { Anderson v. } \\
\text { Hollingsworth, } \\
\text { 41 P.3d 228 } \\
\text { (Idaho 2001). }\end{array}$ & \\
\hline IL & $\begin{array}{l}\text { Physician- } \\
\text { Based }\end{array}$ & None & $\begin{array}{l}\text { Ramos v. Pyati, } \\
\text { 534 N.E.2d } 472 \\
\text { (Ill. App. Ct. } \\
\text { 1989). }\end{array}$ & $\begin{array}{l}\text { Welton v. } \\
\text { Ambrose, } \\
\text { 814 N.E.2d } 970 \\
\text { (Ill. App. Ct. } \\
\text { 2004). }\end{array}$ & \\
\hline IN & $\begin{array}{c}\text { Physician- } \\
\text { Based }\end{array}$ & None & $\begin{array}{l}\text { Culbertson v. } \\
\text { Mernitz, } \\
602 \text { N.E.2d } 98 \\
\text { (Ind. 1992). }\end{array}$ & $\begin{array}{l}\text { Bowman v. } \\
\text { Beghin, } \\
713 \text { N.E.2d } 913 \\
\text { (Ind. Ct. App. } \\
\text { 1999). }\end{array}$ & \\
\hline IA & $\begin{array}{l}\text { Patient- } \\
\text { Based }\end{array}$ & None & $\begin{array}{l}\text { Pauscher v. } \\
\text { Iowa Methodist } \\
\text { Med. Ctr., } \\
\text { 408 N.W.2d } 355 \\
\text { (Iowa 1987). }\end{array}$ & $\begin{array}{l}\text { Kennis v. Mercy } \\
\text { Hosp. Med. Ctr., } \\
491 \text { N.W.2d 161 } \\
\text { (Iowa 1992). }\end{array}$ & \\
\hline KS & $\begin{array}{l}\text { Physician- } \\
\text { Based }\end{array}$ & None & $\begin{array}{l}\text { Natanson v. } \\
\text { Kline, } \\
\text { 350 P.2d 1093 } \\
\text { (Kan. 1960). }\end{array}$ & $\begin{array}{l}\text { Wecker v. Amend, } \\
918 \text { P.2d } 658 \\
\text { (Kan. Ct. App. } \\
\text { 1996). }\end{array}$ & \\
\hline
\end{tabular}




\begin{tabular}{|c|c|c|c|c|c|}
\hline State & Classification & $\begin{array}{l}\text { Statutory } \\
\text { Authority }\end{array}$ & Key Case & \begin{tabular}{|l|} 
Other Pertinent/ \\
Recent Case Law
\end{tabular} & Explanatory Notes \\
\hline 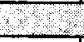 & 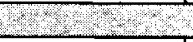 & 140? & \multicolumn{3}{|c|}{ Trable cowtinued } \\
\hline KY & $\begin{array}{l}\text { Physician- } \\
\text { Based }\end{array}$ & $\begin{array}{l}\text { KY. REV. } \\
\text { STAT. ANN. } \\
\text { \$304.40- } \\
320(2005) \\
\text { (Informed } \\
\text { Consent; } \\
\text { When } \\
\text { Deemed } \\
\text { Given). }\end{array}$ & $\begin{array}{l}\text { Holton v. } \\
\text { Pfingst, } \\
\text { 534 S.W.2d } 786 \\
\text { (Ky. 1976). }\end{array}$ & $\begin{array}{l}\text { Vitale v. Henchey, } \\
\text { 24 S.W.3d } 651 \\
\text { (Ky. 2000); } \\
\text { Keel v. St. } \\
\text { Elizabeth Medical } \\
\text { Center, } \\
\text { 842 S.W.2d } 860 \\
\text { (Ky. 1992). }\end{array}$ & $\begin{array}{l}\text { Florida and Kentucky } \\
\text { both have informed } \\
\text { consent statutes that } \\
\text { require that disclosure } \\
\text { be, in the first } \\
\text { instance, in } \\
\text { accordance with an } \\
\text { accepted standard of } \\
\text { medical practice. The } \\
\text { information disclosed } \\
\text { must also be sufficient } \\
\text { to provide a } \\
\text { reasonable individual } \\
\text { with a generally } \\
\text { understanding of the } \\
\text { information disclosed. } \\
\text { Though this is a } \\
\text { somewhat weakened } \\
\text { version of the pure } \\
\text { physician-based } \\
\text { standard, it still } \\
\text { qualifies as a } \\
\text { physician-based } \\
\text { standard nonetheless. }\end{array}$ \\
\hline LA & $\begin{array}{l}\text { Patient- } \\
\text { Based }\end{array}$ & $\begin{array}{l}\text { LA. REv. } \\
\text { STAT. ANN. } \\
\text { \$40:1299.40 } \\
\text { (2006) } \\
\text { (Consent to } \\
\text { Medical } \\
\text { Treatment; } \\
\text { Exception; } \\
\text { Louisiana } \\
\text { Medical } \\
\text { Disclosure } \\
\text { Panel; } \\
\text { Availability } \\
\text { of Lists to } \\
\text { Establish } \\
\text { Necessity } \\
\text { and Degree). }\end{array}$ & $\begin{array}{l}\text { Hondroulis v. } \\
\text { Schuhmacher, } \\
553 \text { So.2d } 398 \\
\text { (La. 1988). }\end{array}$ & $\begin{array}{l}\text { Brandt v. Engle, } \\
\text { 2000-3416 (La. } \\
6 / 29 / 01) ; 791 \\
\text { So.2d 614. }\end{array}$ & $\begin{array}{l}\text { While the Louisiana } \\
\text { informed consent } \\
\text { standard is } \\
\text { appropriately } \\
\text { categorized as } \\
\text { patient-based, it is a } \\
\text { two-pronged } \\
\text { standard. The first } \\
\text { prong requires } \\
\text { evaluation of the risk } \\
\text { in question for } \\
\text { materiality, which } \\
\text { usually will require } \\
\text { some expert } \\
\text { testimony. The second } \\
\text { prong then considers } \\
\text { all material risks from } \\
\text { the point of view of a } \\
\text { reasonable patient, } \\
\text { and asks whether or } \\
\text { not they are } \\
\text { significant. }\end{array}$ \\
\hline $\mathrm{ME}$ & $\begin{array}{l}\text { Physician- } \\
\text { Based }\end{array}$ & None & $\begin{array}{l}\text { Ouellette v. } \\
\text { Mehalic, } \\
\text { 534 A.2d 1331 } \\
\text { (Me. 1988). } \\
\end{array}$ & \begin{tabular}{|l|} 
Dubois v. United \\
States, \\
324 F. Supp. 2d \\
143 (D. Me. 2004). \\
\end{tabular} & \\
\hline MD & $\begin{array}{l}\text { Physician- } \\
\text { Based }\end{array}$ & None & $\begin{array}{l}\text { Sard v. Hardy, } \\
\text { 379 A.2d 104 } \\
\text { (Md. 1977). }\end{array}$ & $\begin{array}{l}\text { Dingle v. Belin, } \\
749 \text { A.2d } 157 \\
\text { (Md. Ct. Spec. } \\
\text { App. 2000); } \\
\text { Faya v. Almaraz, } \\
\text { 620 A.2d } 327 \\
\text { (Md. Ct. Spec. } \\
\text { App. 1993). }\end{array}$ & \\
\hline
\end{tabular}




\begin{tabular}{|c|c|c|c|c|c|}
\hline State & Classification & $\begin{array}{l}\text { Statutory } \\
\text { Authority }\end{array}$ & Key Case & $\begin{array}{l}\text { Other Pertinent/ } \\
\text { Recent Case Law }\end{array}$ & Explanatory Notes \\
\hline \multicolumn{6}{|c|}{ [Table Continued] } \\
\hline MA & $\begin{array}{c}\text { Patient- } \\
\text { Based }\end{array}$ & None & $\begin{array}{l}\text { Harnish v. } \\
\text { Children's Hosp. } \\
\text { Med. Ctr., } \\
\text { 439 N.E.2d 240 } \\
\text { (Mass. 1982). }\end{array}$ & $\begin{array}{l}\text { McMahon v. } \\
\text { Finlayson, } \\
632 \text { N.E.2d } 410 \\
\text { (Mass. App. Ct. } \\
\text { 1994). }\end{array}$ & \\
\hline MI & $\begin{array}{l}\text { Physician- } \\
\text { Based }\end{array}$ & None & $\begin{array}{l}\text { Rice v. } \\
\text { Jaskolski, } \\
\text { 313 N.W.2d } 893 \\
\text { (Mich. 1981). }\end{array}$ & None & \\
\hline $\mathrm{MN}$ & Hybrid & None & \begin{tabular}{|l|} 
Kinikin v. \\
Heupel, \\
305 N.W.2d 589 \\
(Minn. 1981).
\end{tabular} & $\begin{array}{l}\text { K.A.C. v. Benson, } \\
\text { 527 N.W.2d 553 } \\
\text { (Minn. 1995); } \\
\text { Brown v. Park } \\
\text { Nicollet Clinic } \\
\text { Healthsys., No. } \\
\text { C0-00-1525, } \\
\text { 2001 WL 506722 } \\
\text { (Minn. Ct. App. } \\
\text { May 15, 2001). }\end{array}$ & $\begin{array}{l}\text { The Minnesota } \\
\text { standard incorporates } \\
\text { all possibilities. It } \\
\text { first requires } \\
\text { physicians to disclose } \\
\text { information to the } \\
\text { same degree that a } \\
\text { skilled practitioner in } \\
\text { the same field would. } \\
\text { If, however, the } \\
\text { physician knows a } \\
\text { patient may want } \\
\text { more information, the } \\
\text { physician has a duty } \\
\text { to provide that as } \\
\text { well. To the extent } \\
\text { that the physician did } \\
\text { not provide } \\
\text { information the } \\
\text { patient wanted, the } \\
\text { jury should consider } \\
\text { what a reasonable } \\
\text { patient would have } \\
\text { found significant. }\end{array}$ \\
\hline MS & $\begin{array}{l}\text { Patient- } \\
\text { Based }\end{array}$ & None & $\begin{array}{l}\text { Hudson v. } \\
\text { Parvin, } \\
582 \text { So. 2d } 403 \\
\text { (Miss. 1991). }\end{array}$ & $\begin{array}{l}\text { Blailock v. Hubbs, } \\
919 \text { So. 2d } 126 \\
\text { (Miss. 2005); } \\
\text { but see } \\
\text { Whittington v. } \\
\text { Mason, } \\
\text { 905 So. 2d 1261 } \\
\text { (Miss. 2005). }\end{array}$ & $\begin{array}{l}\text { Although Blailock } v \text {. } \\
\text { Hudson has been } \\
\text { called into question } \\
\text { by Whittington } v \text {. } \\
\text { Mason, the decision } \\
\text { still appears to be } \\
\text { good law in } \\
\text { Mississippi. }\end{array}$ \\
\hline MO & $\begin{array}{l}\text { Physician- } \\
\text { Based }\end{array}$ & None & $\begin{array}{l}\text { Aiken v. Clary, } \\
\text { 396 S.W.2d } 668 \\
\text { (Mo. 1965). }\end{array}$ & $\begin{array}{l}\text { Wilkerson v. Mid- } \\
\text { America } \\
\text { Cardiology, } \\
908 \text { S.W.2d } 691 \\
\text { (Mo. Ct. App. } \\
\text { 1995). }\end{array}$ & \\
\hline MT & $\begin{array}{c}\text { Physician- } \\
\text { Based }\end{array}$ & None & $\begin{array}{l}\text { Llera v. Wisner, } \\
557 \text { P.2d } 805 \\
\text { (Mont. 1976). }\end{array}$ & $\begin{array}{l}\text { Hill v. Squibb \& } \\
\text { Sons, E. R., } \\
592 \text { P.2d 1383 } \\
\text { (Mont. 1979). }\end{array}$ & \\
\hline $\mathrm{NE}$ & $\begin{array}{c}\text { Physician- } \\
\text { Based }\end{array}$ & $\begin{array}{l}\text { Neb. Rev. } \\
\text { STAT. } \\
\text { \$44-2816 } \\
(2004) \\
\text { (Informed } \\
\text { Consent, } \\
\text { Defined). }\end{array}$ & $\begin{array}{l}\text { Eccleston v. } \\
\text { Chait, } \\
492 \text { N.W.2d } \\
860 \\
\text { (Neb. 1992). }\end{array}$ & $\begin{array}{l}\text { Hamilton v. Bares, } \\
678 \text { N.W.2d } 74 \\
(\text { Neb. 2004). }\end{array}$ & \\
\hline
\end{tabular}




\begin{tabular}{|c|c|c|c|c|c|}
\hline State & Classification & $\begin{array}{l}\text { Statutory } \\
\text { Authority }\end{array}$ & Key Case & $\begin{array}{l}\text { Other Pertinent/ } \\
\text { Recent Case Law }\end{array}$ & Explanatory Notes \\
\hline 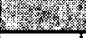 & 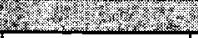 & 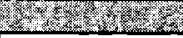 & 200 ror soath & War & 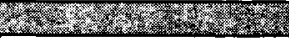 \\
\hline NV & $\begin{array}{l}\text { Physician- } \\
\text { Based }\end{array}$ & \begin{tabular}{|l|} 
NEv. REv. \\
STAT. \\
\$41A.110 \\
(2005) \\
(Consent of \\
Patient: \\
When \\
Conclusively \\
Established); \\
NEv. REv. \\
STAT. \\
\$449.710 \\
(2005) \\
(Specific \\
Rights: \\
Information \\
Concerning \\
Facility; \\
Treatment; \\
Billing; \\
Visitation). \\
\end{tabular} & $\begin{array}{l}\text { Smith v. Cotter, } \\
810 \text { P.2d 1204 } \\
\text { (Nev. 1991). }\end{array}$ & $\begin{array}{l}\text { Bronneke v. } \\
\text { Rutherford, } \\
89 \text { P.3d 40 } \\
\text { (Nev. 2004). }\end{array}$ & \\
\hline \begin{tabular}{|l|}
$\mathrm{NH}$ \\
\end{tabular} & $\begin{array}{l}\text { Physician- } \\
\text { Based }\end{array}$ & $\begin{array}{l}\text { N.H. REV. } \\
\text { STAT. ANN. } \\
\text { \$508:13 } \\
\text { (2006) } \\
\text { (Professional } \\
\text { Malpractice; } \\
\text { Evidence). } \\
\end{array}$ & $\begin{array}{l}\text { Smith v. Cote, } \\
513 \text { A.2d 341 } \\
\text { (N.H. 1986). }\end{array}$ & None & . \\
\hline NJ & $\begin{array}{l}\text { Patient- } \\
\text { Based }\end{array}$ & None & $\begin{array}{l}\text { Largey v. } \\
\text { Rothman, } \\
\text { 540 A.2d 504 } \\
\text { (N.J. 1988). } \\
\end{array}$ & $\begin{array}{l}\text { Howard v. } \\
\text { UMDNJ, } \\
\text { 800 A.2d 73 } \\
\text { (N.J. 2002). } \\
\end{array}$ & \\
\hline NM & Hybrid & None & $\begin{array}{l}\text { Gerety v. } \\
\text { Demers, } \\
589 \text { P.2d } 180 \\
\text { (N.M. 1978). }\end{array}$ & $\begin{array}{l}\text { Henning v. } \\
\text { Parsons, } \\
\text { 623 P.2d 574 } \\
\text { (N.M. Ct. App. } \\
\text { 1980). }\end{array}$ & $\begin{array}{l}\text { The New Mexico } \\
\text { standard is unique in } \\
\text { that it does not base } \\
\text { the standard of } \\
\text { disclosure on what a } \\
\text { reasonable physician } \\
\text { would reveal or what } \\
\text { a reasonable patient } \\
\text { would want, but on } \\
\text { what a reasonable } \\
\text { person with the } \\
\text { physician's medical } \\
\text { knowledge probably } \\
\text { would reveal. The } \\
\text { Gerety decision is } \\
\text { largely based on } \\
\text { Canterbury, but did } \\
\text { not follow it as far as } \\
\text { to adopt the full } \\
\text { patient-based } \\
\text { standard. }\end{array}$ \\
\hline
\end{tabular}




\begin{tabular}{|c|c|c|c|c|c|}
\hline State & Classification & $\begin{array}{l}\text { Statutory } \\
\text { Authority }\end{array}$ & Key Case & \begin{tabular}{|l|} 
Other Pertinent/ \\
Recent Case Law
\end{tabular} & Explanatory Notes \\
\hline 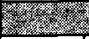 & $210 \% 2012$ & 0.460 .62 & \multicolumn{2}{|c|}{ 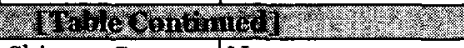 } & 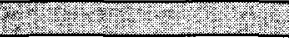 \\
\hline NY & $\begin{array}{l}\text { Physician- } \\
\text { Based }\end{array}$ & $\begin{array}{l}\text { N.Y. PUB. } \\
\text { HEALTH } \\
\text { LAW } \\
\text { \$2805-d } \\
\text { (McKinney } \\
\text { 2005) } \\
\text { (Limitation } \\
\text { of Medical, } \\
\text { Dental or } \\
\text { Podiatric } \\
\text { Malpractice } \\
\text { Action Based } \\
\text { on Lack of } \\
\text { Informed } \\
\text { Consent). } \\
\end{array}$ & $\begin{array}{l}\text { Shinn v. St. } \\
\text { James Mercy } \\
\text { Hosp., } \\
\text { 675 F. Supp. } 94 \\
\text { (W.D.N.Y. } \\
\text { 1987). }\end{array}$ & None & \\
\hline NC & $\begin{array}{l}\text { Physician- } \\
\text { Based }\end{array}$ & $\begin{array}{l}\text { N.C. GEN. } \\
\text { STAT. ANN. } \\
\text { \$90-21.13 } \\
\text { (West 2005) } \\
\text { (Informed } \\
\text { Consent to } \\
\text { Health Care } \\
\text { Treatment or } \\
\text { Procedure). }\end{array}$ & $\begin{array}{l}\text { Foard v. } \\
\text { Jarman, } \\
\text { 387 S.E.2d } 162 \\
\text { (N.C. 1990). }\end{array}$ & $\begin{array}{l}\text { Osburn v. Danek } \\
\text { Med., Inc., } \\
520 \text { S.E.2d } 88 \\
\text { (N.C. Ct. App. } \\
\text { 1999). }\end{array}$ & \\
\hline ND & $\begin{array}{l}\text { Patient- } \\
\text { Based }\end{array}$ & None & $\begin{array}{l}\text { Jaskoviak v. } \\
\text { Gruver, } \\
2002 \text { ND 1, } 638 \\
\text { N.W.2d 1. } \\
\end{array}$ & \begin{tabular}{|l|} 
Flatt v Kantak, \\
2004 ND 173, 687 \\
N.W.2d 208.
\end{tabular} & \\
\hline $\mathrm{OH}$ & $\begin{array}{l}\text { Patient- } \\
\text { Based }\end{array}$ & None & $\begin{array}{l}\text { Nickell v. } \\
\text { Gonzalez, } \\
477 \text { N.E.2d } 1145 \\
\text { (Ohio 1985). }\end{array}$ & $\begin{array}{l}\text { Maglosky v. Kest, } \\
\text { No. 85382, 2005 } \\
\text { WL 2386605 } \\
\text { (Ohio Ct. App. } \\
\text { Sept. 29, 2005). }\end{array}$ & \\
\hline OK & $\begin{array}{l}\text { Patient- } \\
\text { Based }\end{array}$ & None & $\begin{array}{l}\text { Scott v. } \\
\text { Bradford, } \\
\text { 606 P.2d 554 } \\
\text { (Okla. 1980). } \\
\end{array}$ & $\begin{array}{l}\text { Spencer v. Seikel, } \\
742 \text { P.2d 1126 } \\
\text { (Okla. 1987). }\end{array}$ & \\
\hline OR & $\begin{array}{l}\text { Patient- } \\
\text { Based }\end{array}$ & $\begin{array}{l}\text { OR. REV. } \\
\text { STAT. } \\
\$ 677.097 \\
\text { (2006) } \\
\text { (Obtaining } \\
\text { Informed } \\
\text { Consent of } \\
\text { Patient). }\end{array}$ & None & \begin{tabular}{|l|} 
Macy v. \\
Blatchford, \\
8 P.3d 204 \\
(Or. 2000); \\
Arena v. Gingrich, \\
748 P.2d 547 \\
(Or. 1988). \\
\end{tabular} & $\begin{array}{l}\text { In general, Oregon } \\
\text { courts are concerned } \\
\text { with providing a } \\
\text { patient material } \\
\text { information to make a } \\
\text { decision, but limit a } \\
\text { physician's duty to } \\
\text { disclose to the } \\
\text { amount of } \\
\text { information a } \\
\text { reasonable physician } \\
\text { would provide in } \\
\text { cases where the } \\
\text { physician thinks that } \\
\text { the information may } \\
\text { be detrimental to the } \\
\text { patient. }\end{array}$ \\
\hline
\end{tabular}




\begin{tabular}{|c|c|c|c|c|c|}
\hline State & Classification & $\begin{array}{l}\text { Statutory } \\
\text { Authority }\end{array}$ & Key Case & $\begin{array}{l}\text { Other Pertinent/ } \\
\text { Recent Case Law }\end{array}$ & Explanatory Notes \\
\hline . & $\sqrt{10+2}$ & 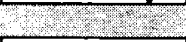 & \multicolumn{2}{|c|}{ Thable continued } & 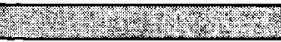 \\
\hline PA & $\begin{array}{l}\text { Patient- } \\
\text { Based }\end{array}$ & \begin{tabular}{|l|} 
40 PA. Cons. \\
STAT. \\
$\$ 1303.504$ \\
$(2006)$ \\
(Informed \\
Consent).
\end{tabular} & $\begin{array}{l}\text { Cooper v. } \\
\text { Roberts, } \\
286 \text { A.2d } 647 \\
\text { (Pa. Super. Ct. } \\
\text { 1971). }\end{array}$ & $\begin{array}{l}\text { Stover v. Ass'n of } \\
\text { Thoracic \& } \\
\text { Cardiovascular } \\
\text { Surgeons, } \\
635 \text { A.2d 1047 } \\
\text { (Pa. Super. Ct. } \\
\text { 1993). }\end{array}$ & $\begin{array}{l}\text { Pennsylvania has } \\
\text { recently codified its } \\
\text { common law doctrine } \\
\text { of informed consent. } \\
\text { While the relevant } \\
\text { statute has not been } \\
\text { thoroughly examined } \\
\text { by Pennsylvania } \\
\text { courts, it appears to } \\
\text { retain the patient- } \\
\text { based standard of } \\
\text { informed consent in } \\
\text { those specific } \\
\text { circumstances where } \\
\text { informed consent is } \\
\text { required. }\end{array}$ \\
\hline RI & $\begin{array}{l}\text { Patient- } \\
\text { Based }\end{array}$ & None & $\begin{array}{l}\text { Wilkinson v. } \\
\text { Vesey, } \\
\text { 295 A.2d } 676 \\
\text { (R.I. 1972). } \\
\end{array}$ & $\begin{array}{l}\text { Miller v. Rhode } \\
\text { Island Hosp., } \\
625 \text { A.2d } 778 \\
\text { (R.I. 1993). } \\
\end{array}$ & \\
\hline $\mathrm{SC}$ & $\begin{array}{l}\text { Physician- } \\
\text { Based }\end{array}$ & None & $\begin{array}{l}\text { Hook v. } \\
\text { Rothstein, } \\
316 \text { S.E.2d } 690 \\
\text { (S.C. Ct. App. } \\
\text { 1984). } \\
\end{array}$ & $\begin{array}{l}\text { Stallings v. Ratliff, } \\
\text { 356 S.E.2d 414 } \\
\text { (S.C. Ct. App. } \\
\text { 1987). }\end{array}$ & \\
\hline SD & $\begin{array}{c}\text { Patient- } \\
\text { Based }\end{array}$ & None & \begin{tabular}{|l|} 
Wheeldon v. \\
Madison, \\
374 N.W. 2d \\
367 (S.D. 1985). \\
\end{tabular} & $\begin{array}{l}\text { Savold v. Johnson, } \\
443 \text { N.W.2d } 656 \\
\text { (S.D. 1990). }\end{array}$ & \\
\hline $\mathrm{TN}$ & $\begin{array}{l}\text { Physician- } \\
\text { Based }\end{array}$ & $\begin{array}{l}\text { TENN. CODE } \\
\text { ANN. } \\
\$ 29-26-118 \\
\text { (2000) } \\
\text { (Consent; } \\
\text { Adequacy). } \\
\end{array}$ & \begin{tabular}{|l} 
Cardwell v. \\
Bechtol, \\
724 S.W.2d 739 \\
(Tenn. 1987).
\end{tabular} & $\begin{array}{l}\text { Ashe v. Radiation } \\
\text { Oncology Assocs., } \\
9 \text { S.W.3d } 119 \\
\text { (Tenn. 1999). }\end{array}$ & \\
\hline $\mathrm{TX}$ & $\begin{array}{c}\text { Patient- } \\
\text { Based }\end{array}$ & \begin{tabular}{|l|} 
TEX. Crv. \\
Prac. \& \\
REM. \\
$\$ 74.101$ \\
(2005) \\
(Theory of \\
Recovery). \\
\end{tabular} & $\begin{array}{l}\text { Peterson v. } \\
\text { Shields, } \\
652 \text { S.W.2d. } 929 \\
\text { (Tex. 1983). }\end{array}$ & $\begin{array}{l}\text { Greene v. Thiet, } \\
846 \text { S.W.2d } 26 \\
\text { (Tex. App. 1992); } \\
\text { Gibson v. } \\
\text { Methodist Hosp., } \\
\text { 822 S.W.2d 95 } \\
\text { (Tex. App. 1991). }\end{array}$ & \\
\hline UT & $\begin{array}{c}\text { Patient- } \\
\text { Based }\end{array}$ & $\begin{array}{l}\text { UTAH CODE } \\
\text { ANN. } \\
\text { \$78-14-5 } \\
\text { (2006) } \\
\text { (Failure to } \\
\text { Obtain } \\
\text { Informed } \\
\text { Consent - } \\
\text { Proof } \\
\text { Required of } \\
\text { Patient - } \\
\text { Defenses - } \\
\text { Consent to } \\
\text { Health } \\
\text { Care). } \\
\end{array}$ & None & $\begin{array}{l}\text { Reiser v. Lohner, } \\
641 \text { P.2d } 93 \\
\text { (Utah 1982). }\end{array}$ & \\
\hline
\end{tabular}




\begin{tabular}{|c|c|c|c|c|c|}
\hline State & Classification & $\begin{array}{l}\text { Statutory } \\
\text { Authority }\end{array}$ & Key Case & $\begin{array}{l}\text { Other Pertinent/ } \\
\text { Recent Case Law }\end{array}$ & Explanatory Notes \\
\hline \multicolumn{6}{|c|}{ [Table Contimued] } \\
\hline VT & $\begin{array}{c}\text { Physician- } \\
\text { Based }\end{array}$ & $\begin{array}{l}\text { VT. STAT. } \\
\text { ANN. tit. 12, } \\
\text { \$1909 } \\
\text { (2005) } \\
\text { (Limitation } \\
\text { of Medical } \\
\text { Malpractice } \\
\text { Action Based } \\
\text { on Lack of } \\
\text { Informed } \\
\text { Consent). } \\
\end{array}$ & $\begin{array}{l}\text { Perkins v. } \\
\text { Windsor Hosp. } \\
\text { Corp., } \\
\text { 455 A.2d } 810 \\
\text { (Vt. 1982). }\end{array}$ & $\begin{array}{l}\text { Mello v. Cohen, } \\
724 \text { A. } 2 \text { d } 471 \\
\text { (Vt. 1998). }\end{array}$ & \\
\hline VA & $\begin{array}{c}\text { Physician- } \\
\text { Based }\end{array}$ & $\begin{array}{l}\text { VA. CoDE } \\
\text { ANN. } \\
\$ 8.01-581.20 \\
(2006) \\
\text { (Standard of } \\
\text { Care in } \\
\text { Proceeding } \\
\text { Before } \\
\text { Malpractice } \\
\text { Review } \\
\text { Panel... .). } \\
\end{array}$ & $\begin{array}{l}\text { Rizzo v. Schiller, } \\
445 \text { S.E.2d } 153 \\
\text { (Va. 1994). }\end{array}$ & $\begin{array}{l}\text { Tashman v. Gibbs, } \\
\text { 556 S.E.2d } 772 \\
\text { (Va. 2002). }\end{array}$ & \\
\hline WA & $\begin{array}{c}\text { Patient- } \\
\text { Based }\end{array}$ & $\begin{array}{l}\text { WASH. REV. } \\
\text { CoDE } \\
\$ 7.70 .050 \\
\text { (2006) } \\
\text { (Failure to } \\
\text { Secure } \\
\text { Informed } \\
\text { Consent - } \\
\text { Necessary } \\
\text { Elements of } \\
\text { Proof - } \\
\text { Emergency } \\
\text { Situations). }\end{array}$ & $\begin{array}{l}\text { Backlund v. } \\
\text { University of } \\
\text { Washington, } \\
975 \text { P.2d 950 } \\
\text { (Wash. 1999). }\end{array}$ & $\begin{array}{l}\text { Brown v. Dahl, } \\
\text { 705 P.2d } 781 \\
\text { (Wash. Ct. App. } \\
\text { 1985). }\end{array}$ & \\
\hline WV & $\begin{array}{c}\text { Patient- } \\
\text { Based }\end{array}$ & None & $\begin{array}{l}\text { Adams v. El- } \\
\text { Bash, } \\
\text { 338 S.E.2d } 381 \\
\text { (W. Va. 1985). }\end{array}$ & None & \\
\hline WI & $\begin{array}{c}\text { Patient- } \\
\text { Based }\end{array}$ & $\begin{array}{l}\text { WIS. STAT. } \\
\text { ANN. } \\
\$ 448.30 \\
\text { (West 2006) } \\
\text { (Information } \\
\text { on Alternate } \\
\text { Modes of } \\
\text { Treatment). }\end{array}$ & $\begin{array}{l}\text { Scaria v. St. Paul } \\
\text { Fire \& Marine } \\
\text { Ins. Co., } \\
\text { 227 N.W.2d 647 } \\
\text { (Wis. 1975). }\end{array}$ & $\begin{array}{l}\text { Hannemann v. } \\
\text { Boyson, } \\
\text { 2005 WI 94, } 282 \\
\text { Wis. 2d 714, 698 } \\
\text { N.W.2d 714 (Wis. } \\
\text { 2005). }\end{array}$ & \\
\hline WY & $\begin{array}{c}\text { Physician- } \\
\text { Based }\end{array}$ & None & $\begin{array}{l}\text { Roybal v. Bell, } \\
778 \text { P.2d 108 } \\
\text { (Wyo. 1989). }\end{array}$ & $\begin{array}{l}\text { Havens v, } \\
\text { Hoffman, } \\
902 \text { P.2d } 219 \\
\text { (Wyo. 1995). }\end{array}$ & \\
\hline
\end{tabular}


HeinOnline -- 32 Am. J.L. \& Med. 5022006 